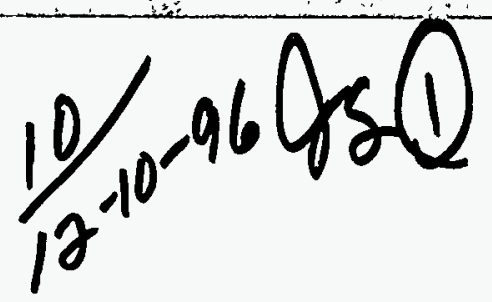

ERNEST GRLANDQ LAWRENLE

BERKELEY NATIDNAL LABDRATDRY

\title{
Preliminary Studies of Water Seepage Through Rough-Walled Fractures
}

\section{J.T. Geller, G. Su, and K. Pruess}

Earth Sciences Division

July 1996

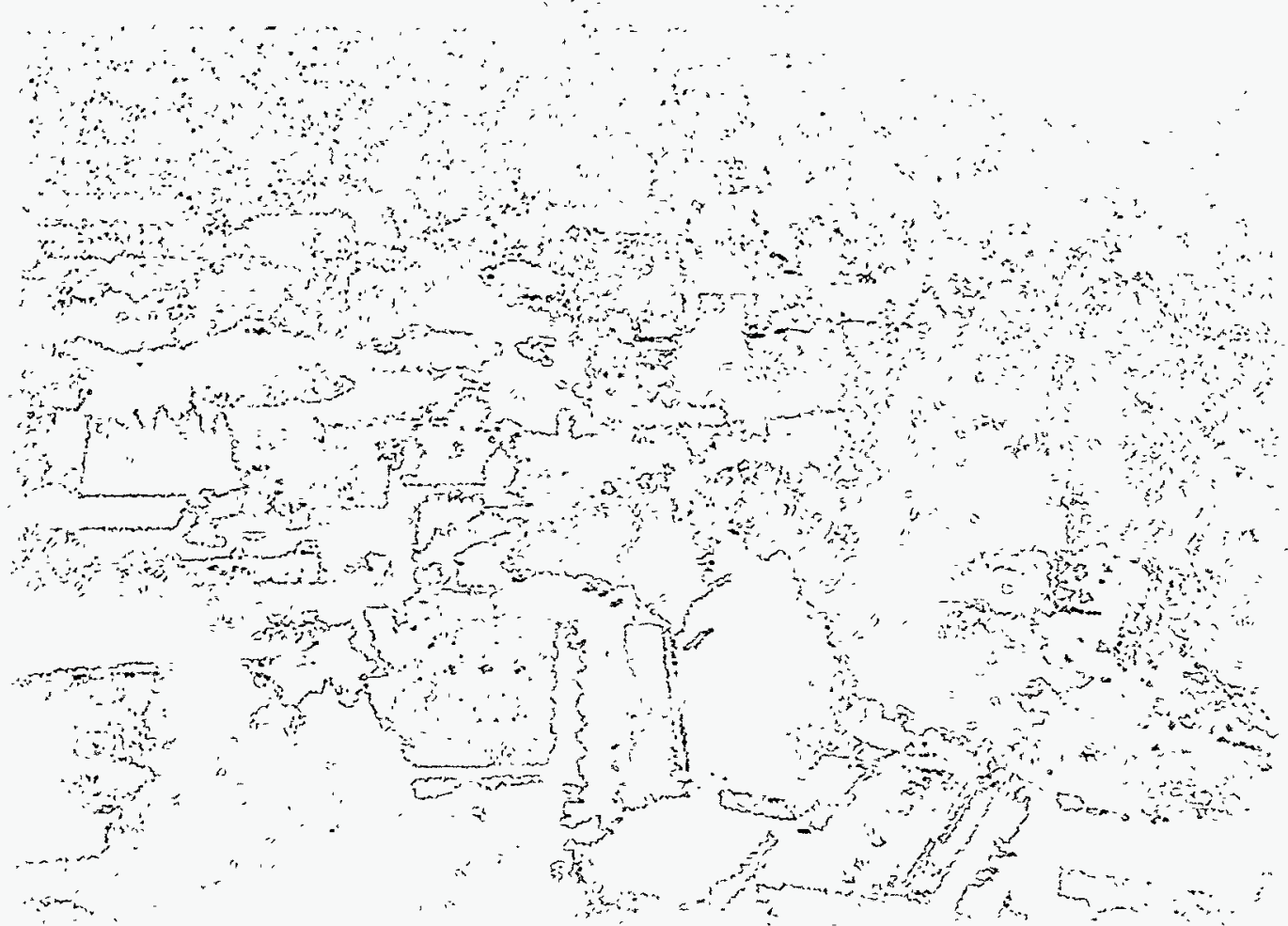




\section{DISCLAIMER}

This document was prepared as an account of work sponsored by the United States Government. While this document is believed to contain correct information, neither the United States Government nor any agency thereof, nor The Regents of the University of California, nor any of their employees, makes any warranty, express or implied. or assumes any legal responsibility for the accuracy, completeness, or usefulness of any information, apparatus, product, or process disclosed, or represents that its use would not infringe privately owned rights. Reference herein to any specific commercial product, process. or service by its trade name, trademark, manufacturer, or otherwise. does not necessarily constitute or imply its endorsement, recommendation, or favoring by the United States Government or any agency thereof. or The Regents of the University of California. The views and opinions of authors expressed herein do not necessarily state or reflect those of the United States Government or any agency thereof, or The Regents of the University of California.

Available to DOE and DOE Contractors

from the Office of Scientific and Technical Information

P.O. Box 62, Oak Ridge, TN 37831

Prices available from (615) 576-8401

Available to the public from the

National Technical Information Service

U.S. Department of Commerce

5285 Port Royal Road, Springfield, VA 22161

Ernest Orlando Lawrence Berkeley National Laboratory is an equal opportunity employer. 
LBNL - 38810

$\mathrm{UC}-403$

\title{
Preliminary Studies of Water Seepage Through Rough-Walled Fractures
}

\author{
Jil T. Geller ${ }^{1}$, Grace Su$^{1,2}$ and Karsten Pruess ${ }^{1}$
}

1. Earth Sciences Division, Lawrence Berkeley National Laboratory at Berkeley

2. Department of Civil Engineering, University of California at Berkeley

July 1996

This work was supported by the Director, Office of Energy Research, Office of Health and Environmental Sciences, Biological and Environmental Research Program, of the U.S. Department of Energy under Contract No. DE-AC03-76SF00098.

DISTRIBUTION OF THIS DOCURAENT IS UNLIMITED 


\section{DISCLAIMER}

Portions of this document may be illegible in electronic image products. Images are produced from the best available original document. 


\section{Table of Contents}

Abstract.................................................................... ii

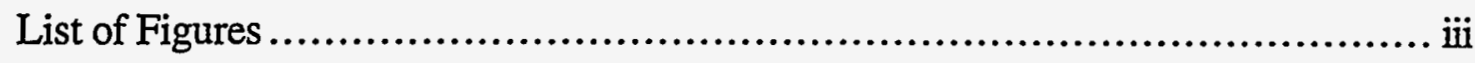

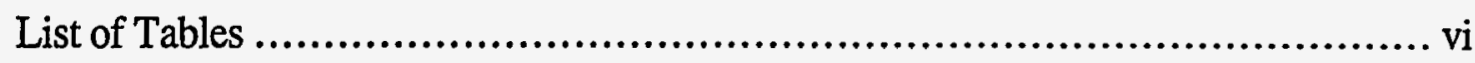

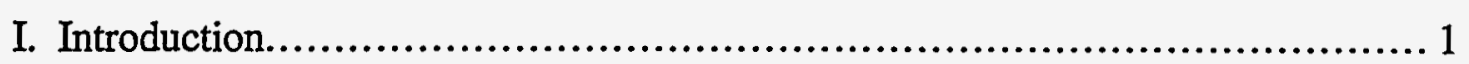

II. Background............................................................... 3

III. Physical Experiments....................................................6 6

Fracture Replica Experiments........................................... 7

Parallel Plate Experiments................................................ 18

IV. Summary and Conclusions ................................................ 20

Acknowledgment......................................................... 22

References.................................................................... 22

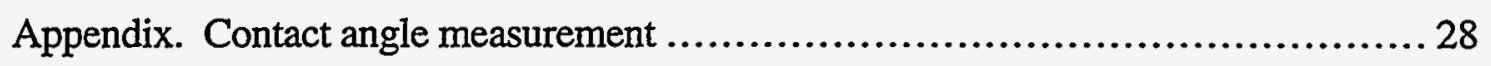

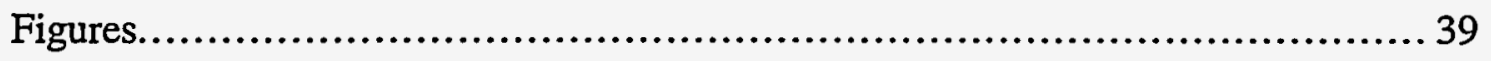




\section{ABSTRACT}

For groundwater aquifers in fractured rock, fractures play a significant role in the transport of water and contaminants through the unsaturated zone to the groundwater table. Fractures can provide preferential flow paths for infiltrating liquids that dramatically accelerate contaminant transport compared to predictions based upon spatially uniform infiltration. The actual liquid distribution during infiltration determines the contact area between the flowing water and rock, and liquid residence time, which in turn affects the potential for rock-water and rock-solute interaction, as well as mass transfer between liquid and gas phases. This report summarizes flow-visualization experiments of water percolation through transparent replicas of a natural rock fracture. We have focused on phenomenological and exploratory experiments that can lead to a conceptual model which incorporates the important physical mechanisms that control flow. Experiments are conducted for inlet conditions of constant, negative water pressures, over a range of angles of fracture inclinations, both sub-horizontal and sub-vertical. We observe highly localized and extremely non-uniform flow paths in the plane of the fracture and particularly, pervasive unsteadiness, or intermittency, of flow, as portions of the flow channels undergo

cycles of draining and filling, and small connecting threads snap and reform. This unsteady behavior occurs even in the presence of constant pressure boundary conditions. Flow intermittency will tend to diminish matrix-fracture interactions, with serious implications for solute transport. Fracture loading has a significant effect on the location of flow channels. In sub-horizontal angles, the variation of fracture inclination from $20^{\circ}$ to $40^{\circ}$ has relatively subtle effects on flow behavior. Some liquid-filled regions drain as the angle approaches $40^{\circ}$, and the frequency of thread snapping and reformation appears to increase. More quantitative information is derived from experiments in sub-vertical angles, where flow rates are measured as a function of the fracture inlet pressure and the frequency of thread-snapping and formation is recorded. Intermittent flow behavior is investigated in complementary parallel-plate experiments, where sequences of medium to large to small apertures are shown to cause the formation of liquid threads that undergo cycles of snapping and reforming. The results of these studies provide direction for simulating water percolation through fractured rock as well as the basis for developing more quantitative methods to be used in future experimental work. 


\section{List of Figures}

Figure 1. Schematic representation of flow-visualization experiments in fracture replicas.

Figure 2. Full view of liquid distribution in Series $1 \mathrm{~A}, \theta=20^{\circ}, \mathrm{P}_{\mathrm{w}}=-1.8 \mathrm{~cm}$.

Figure 3. Liquid distribution during percolation, Series $1 \mathrm{~A}, \theta=20^{\circ}, \mathrm{P}_{\mathrm{w}}=-1.8 \mathrm{~cm}$. Arrows indicate location of thread-snapping. Circles are for comparison with Figure 4(a).

Figure 4. Liquid distribution during percolation, Series $1 \mathrm{~A}, \theta=35^{\circ}, \mathrm{P}_{\mathrm{w}}=-1.8 \mathrm{~cm}$. Circles indicate liquid-filled regions that have drained relative to Figure 3. (c)-(d) changing liquid distribution over time-scale of seconds.

Figure 5. Liquid distribution during percolation, Series $1 \mathrm{~A}, \theta=40^{\circ}, \mathrm{P}_{\mathrm{w}}=-1.8 \mathrm{~cm}$. Circle indicates liquid-filled region that has drained relative to Figure 4. (a)-(c) changing liquid distribution over a time-scale of seconds. (d) liquid distribution two minutes later.

Figure 6. Miscible displacement during percolation, Series $1 \mathrm{~B}, \theta=19^{\circ}, \mathrm{P}_{\mathrm{w}}=-3.0 \mathrm{~cm}$. (a) distribution of clear water (the bright regions are occupied by water) (b) dyed water displacement of clear water (steady-state distribution) (c)-(f) clear water displacing dyed water.

Figure 7. Thread snapping and reformation during Series $1 \mathrm{~B}, \theta=19^{\circ}, \mathrm{P}_{\mathrm{w}}=-3.0 \mathrm{~cm}$. Enlargement of lower right-hand section of Figure 6. (a)-(d) are taken within seconds of one another.

Figure 8. Liquid distribution during percolation, Series $2 \mathrm{~A}, \theta=30^{\circ}, \mathrm{P}_{\mathrm{w}}=-1.5 \mathrm{~cm}$. (a) steady distribution of clear water (the bright regions are occupied by water) (b)-(c) dyed water.

Figure 9. Liquid distribution during percolation, Series $2 \mathrm{~A}, \theta=30^{\circ}, \mathrm{P}_{\mathrm{w}}=-1.0 \mathrm{~cm}$. The orientation of the fracture cast is rotated $180^{\circ}$ from the Series 1 experiment. (a) immediately following re-connection of capillary siphon after no-flow period of several hours. (b) 82 minutes later; note the decrease in the number of flowing channels compared to (a).

Figure 10. Liquid distribution during percolation, Series $2 \mathrm{~B}, \theta=30^{\circ}, \mathrm{P}_{\mathrm{w}}=-2.3 \mathrm{~cm}$. The orientation of the fracture cast is rotated $180^{\circ}$ from the Series $2 \mathrm{~A}$ experiments. (a) full-view 
of fracture, box indicates area enlarged in (b)-(f). (b)-(f) sequence of thread-snapping and reformation in lower left-hand channel, over time-scale of seconds.

Figure 11. Schematic of inlet ceramic plate used in Series 2C. (a) cross-section in plane of fracture (b) top view along fracture inlet edge.

Figure 12. Mariotte bottle for constant head with gravitational flow used in Series 2C.

Figure 13. Liquid distribution during percolation, Series $2 \mathrm{C}, \theta=70^{\circ}, \mathrm{P}_{\mathrm{w}}=-3.5 \mathrm{~cm}$. The fracture orientation is the same as in series $2 \mathrm{~B}$. Liquid channels appear disconnected, but water is flowing through the right channel as indicated by the change in distribution with time. Photographs are within seconds of one another. (b)-(d) are enlargements of boxed area in (a).

Figure 14. Flow behavior as a function of inlet pressure head $\left(\mathrm{P}_{\mathrm{w}}\right)$ for Series $2 \mathrm{C}, \theta=70^{\circ}$. (a) flowrate into fracture (b) location of thread snapping in right channel (c) location of thread snapping in left channel.

Figure 15. Frequency of thread snapping for negative inlet pressure heads, Series $2 \mathrm{C}, \theta=$ $70^{\circ}$. (a) $P_{w}=-3.5 \mathrm{~cm}$ (b) $P_{w}=-2.5 \mathrm{~cm}$ (c) $P_{w}=-1.5 \mathrm{~cm}$ (d) $P_{w}=-0.5 \mathrm{~cm}$.

Figure 16. Frequency of thread snapping for positive inlet pressure heads in Series $2 \mathrm{C}, \theta$ $=70^{\circ}$. (a) $P_{w}=0 \mathrm{~cm}$ (b) $P_{w}=0.5 \mathrm{~cm}$ (c) $P_{w}=1.0 \mathrm{~cm}$ (d) $P_{w}=2.0 \mathrm{~cm}$.

Figure 17. Snap-off rates and liquid volume/snap-off in Series $2 \mathrm{C}$ experiments. (a) Total snap-off rate (b) Liquid volume/snap-off.

Figure 18. Schematic of parallel plate flow cells. (a) Aperture sequence hypothesized as giving rise to flow intermittency. (b) Cross-sections of lucite and glass plate cells used in Series 3 experiments.

Figure 19. Sequence of thread formation and snapping in lucite parallel plate flow cell, progressing from (a) through (h), $\theta=30^{\circ}, \mathrm{P}_{\mathrm{w}}=-1.2 \mathrm{~cm}$.

Figure 20. Stable thread formation in glass parallel plate flow cell (a) $\theta=30^{\circ}, \mathrm{P}_{\mathrm{w}}=-1.0$ cm (b) $\theta=34^{\circ}, \mathrm{P}_{\mathrm{w}}=-0.75 \mathrm{~cm}$.

Figure 21. Sequence of thread formation and snapping in glass parallel plate flow cell, with filter paper in bottom section, $\theta=48^{\circ}, \mathrm{P}_{\mathrm{w}}=-1.2 \mathrm{~cm}$. (a)-(d) Thread snaps near bottom 
section. (e)-(h) Thread snaps near top section, leaving residual drop of liquid near bottom section. Frames were photographed within seconds of one another.

Figure 22. Frequency of thread snapping in Series $3 C$ (parallel glass plates), $P_{w}=-1.8 \mathrm{~cm}$. (a) $\theta=74^{\circ}$ (b) $\theta=70^{\circ} \mathrm{cm}$.

Figure A1. Profiles of water drops on various solid surfaces (a) 30:10 epoxy (b) 100:30 epoxy (c) polished granite (d) window-pane glass (e) granite fracture surface (f) 100:30 epoxy cast of granite fracture surface.

Figure A2. Plate arrangement for capillary rise experiments.

Figure A3. Capillary rise as a function of inverse plate separation $(1 / b)$, with water. (a) glass plates (b) Polished epoxy $30: 10$, shim spacing $=10 \mathrm{~cm}$ (c) Rigorously cleaned glass plates (d) Cast epoxy 100:30, shim spacing $=6 \mathrm{~cm}$ (e) Polished epoxy, 100:30, shim spacing $9.8 \mathrm{~cm}$ (f) Roughened epoxy (g) Smooth granite, shim spacing $=6.5 \mathrm{~cm}$.

Figure A4. Capillary rise as a function of inverse plate separation $(1 / b)$, with $0.4 \%$ liquitint. (a) Polished epoxy 100:30 (b) Smooth granite (c) Cast epoxy (d) Sanded granite. 
List of Tables

Table 1. Percolation experiment conditions

Table 2. Intermittent flow behavior for Series $2 \mathrm{C}$ experiments

Table A1. Surface tension of several liquids measured by the Wilhemy plate method.

Table A2. Summary of calculated contact angles from receding meniscus measurements

Table A3. Comparison of calculated contact angle measurements from receding and advancing menisci 


\section{INTRODUCTION}

For groundwater aquifers in fractured rock, fractures play a significant role in the transport of water and contaminants through the unsaturated zone to the groundwater table. Fractures can provide preferential flow paths for infiltrating liquids that dramatically accelerate contaminant transport compared to predictions based upon spatially uniform infiltration. The actual liquid distribution during infiltration determines the contact area between the flowing water and rock, and liquid residence time, which in turn affects the potential for rock-water and rock-solute interaction, as well as mass transfer between liquid and gas phases.

A serious concern regarding the suitability of Yucca Mountain for nuclear waste isolation is the potential for rapid transport of dissolved radionuclides along localized preferential flow paths in fractures. Hydrogeologic and geochemical studies at Rainier Mesa, a stratigraphic analog to Yucca Mountain, provide strong evidence for fast water flow through unsaturated fractured rock (Wang et al. 1993), where transient and spatially infrequent seeps through faults, joints and fractures intersecting horizontal tunnels and drill holes have been documented. An analysis of the seeps indicates they are chemically distinct from matrix water and their isotopic ratios indicate recent meteoric origin. The most likely mechanism of such water occurring at depth is fast path flow through the fractures. The analysis of bomb-pulse ${ }^{36} \mathrm{Cl}$ in Yucca Mountain boreholes provides possible evidence for fast path flow of water through fractures in welded tuff, although sample contamination has not been ruled out as a cause of elevated ${ }^{36} \mathrm{Cl}$ concentrations (Fabryka-Martin et al., 1993). A draft report by Fabryka-Martin et al. (1996) describes the presence of bomb-pulse ${ }^{36} \mathrm{Cl}$ in the ESF tunnel. A simulation of two-dimensional water flow through Yucca Mountain to explain measured ${ }^{36} \mathrm{Cl}$ and ${ }^{14} \mathrm{C}$ profiles indicates that fracture and lateral flow are both important flow paths, that water mixing from different flow paths with different travel times should be significant and that this mixing will lead to discrepancies between travel times predicted by ${ }^{36} \mathrm{Cl}$ and ${ }^{14} \mathrm{C}$ (Liu et al., 1995). In another example of fast path flow through fractures in arid regions, Nativ et al. (1995) analyzed recharge water through fractured chalk in the Negev Desert, Israel, to support fast path flow as a mechanism for the occurrence of industrial pollutants in the regional groundwater aquifer. 
These observations cannot be reconciled with conceptual models of uniform infiltration or models that postulate strong capillary imbibition effects from the rock matrix that draw flowing water from the fracture. Alternative concepts for performance assessment at Yucca Mountain have been proposed such as the "weeps model" (Gauthier, 1994), which assumes infiltrating water flows through fractures with minimal matrix/fracture interaction. This model does not incorporate the physics of unsaturated flow through fractures, but rather computes flow as gravity-driven through parallel plates and accounts for non-laminar flow. Interestingly, Gauthier (1994) found that flow-pattern perturbations, caused by either climate change or repository heat generation, greatly increase the number of waste-storage containers that would be contacted by weeps.

The issue of preferential flow through fractures is important in the exploitation of geothermal reservoirs, which are typically highly fractured. Observed short-circuiting of injected spent geothermal brines to production wells presumably occurs along fractures and drastically reduces the producible energy from a given reservoir compared to the total reservoir volume (Horne, 1982). Measured tracer velocities from 0.1 to $100 \mathrm{~m} \mathrm{~h}^{-1}$ over distances of several hundred meters, which are several orders of magnitude greater than average linear velocities in a porous-medium-type reservoir, provide evidence for preferential pathways in geothermal fields (Pruess and Bodvarsson, 1984). Predicting the performance of a geothermal field requires an understanding of heat and mass transport in these fast-paths.

In this report we summarize preliminary laboratory studies of water percolation through fractures. We have focused on phenomenological and exploratory experiments to directly observe the physical mechanisms that control flow. The results of these studies can provide direction for simulating water percolation and provide the basis for developing more quantitative methods to be used in future experimental work. In the next section, we briefly review the general theory of multi-phase flow in porous media, and then discuss some considerations for the case of water seepage. This discussion is followed by a description and evaluation of the laboratory experiments we have conducted. 


\section{BACKGROUND}

The simultaneous flow of more than one fluid phase through porous media occurs in many contexts, including petroleum, natural gas and geothermal reservoirs, groundwater aquifers contaminated by organic solvents and fuels, as well as in the unsaturated zone above the water table. On the macroscopic scale, multiphase flow is commonly described by extending Darcy's Law as follows:

$$
\tilde{F}_{\beta}=-k \frac{k_{r, \beta}}{\sim \mu_{\beta}} \rho_{\beta}\left(\nabla P_{\beta}-\rho_{\beta} \tilde{g}\right)
$$

(Scheidegger, 1974; Peaceman, 1977) where the tilde indicates a vector quantity, $F_{\beta}$ is the mass flux of phase $\beta, k$ is the inherent permeability of the medium (a tensor), $k_{r, \beta}$ is the relative permeability factor, $\mu_{\beta}$ is the viscosity, $\rho_{\beta}$ is the fluid density, $P_{\beta}$ is the fluid pressure and $g$ is the acceleration of gravity.

The complementary mass balance equation for phase $\beta$ is:

$$
n \frac{\partial \rho_{\beta} S_{\beta}}{\partial t}=-\nabla \cdot \tilde{F}_{\beta}
$$

where $n$ is the porosity, or volume of voids per volume of porous media, and $S_{\beta}$ is the saturation of phase $\beta$, or fraction of void space occupied by phase $\beta$.

The pressure difference across the interface of the fluid phases is the capillary pressure. For an interface spanning an opening between parallel plates of width $b$, the capillary pressure, $P_{c}$, derived from the Young-LaPlace equation, is:

$P_{c}=P_{n, w}-P_{w}=\frac{2 \gamma \cos \theta}{b}$

where $P_{w}$ and $P_{n, w}$ are the equilibrium fluid pressures in the wetting and non-wetting phases, respectively, $\gamma$ is the interfacial tension between the fluids, and $\theta$ is the contact angle between the fluid-fluid interface and the solid phase. A fluid wets the solid phase, relative to the non-wetting fluid, when the contact angle measured through the wetting phase is less than $90^{\circ}$.

These effective continuum flow equations have been applied to fractures, based upon the conceptual model that considers a fracture as a two-dimensional heterogeneous porous medium, with the heterogeneities represented by variable apertures in the fracture 
plane (Tsang and Tsang, 1989; Pruess and Tsang, 1990; Cox, et al., 1995). Local permeability is directly proportional to the square of the aperture, or:

$k=\frac{b^{2}}{12}$

derived for laminar flow between parallel plates (Marsily, 1986).

The migration of liquids through the unsaturated zone proceeds under the combined action of gravity, capillary and pressure forces, where the advancing liquid displaces air. It is commonly assumed that the air provides negligible resistance to flowing water, owing to its much lower viscosity compared to that of water, and is of constant pressure. The Richards equation for the flow of water in unsaturated conditions is based upon this assumption, and the assumption of constant liquid density, which leads to the following simplified form of Equations (1) and (2):

$$
\frac{\partial\left(n S_{w}\right)}{\partial t}=\nabla \cdot\left[\frac{k k_{r, w}}{\mu_{w}}\left(\nabla P_{w}-\rho_{w} \tilde{g}\right)\right]
$$

The pressure of the wetting phase is equal to the pressure of a reference phase, here taken to be gas, $P_{g}$, minus the capillary pressure, as follows:

$$
P_{w}=P_{g}-P_{c}
$$

The $z$ flux component through a fracture inclined at angle $\phi$ from the horizontal, for $z$ downward and parallel to the fracture inclination, is:

$$
F_{w, z}=-k_{z} \frac{k_{r, w}}{\mu_{w}} \rho_{w}\left(\frac{\partial P_{w}}{\partial z}-\rho_{w} g \sin \phi\right)
$$

Correspondingly, the horizontal flux component, in direction $x$ transverse to the direction of flow, is:

$$
F_{w, x}=-k_{x} \frac{k_{r, w}}{\mu_{w}} \rho_{w} \frac{\partial P_{w}}{\partial x}
$$

where $k_{z}$ and $k_{x}$ are the media permeabilities in the $z$ and $x$ directions, respectively.

Without external pressure forces, the horizontal flux component is driven by pressure gradients due to ponding and by capillary forces, while the $z$ flux component is driven by capillary and gravity forces. The extent of horizontal spreading caused by capillary forces will be determined by the aperture, $b$, and the angle of fracture inclination, 
$\phi$. Equations (3) and (4) indicate the relationship between the aperture and capillary pressure and the permeability of the medium. Larger values of $b$ result in higher permeability, increasing the $x$ and $z$ flux components, but decreasing the capillary-pressure driving force. Smaller angles of inclination will decrease gravity-driven vertical water flux relative to capillary forces, thereby increasing lateral spreading.

Models derived from macro-scale continuum concepts average properties over a control volume and require a certain temporal stability. The ability of these models to describe liquid seepage in fractures must be tested against experimental observations, to see whether the averaging overlooks phenomena that may be controlling factors in transport predictions.

Preferential flow refers to the focusing of flow into narrow channels, or fingers. Field evidence and theoretical work has shown that flow in fractures is not an area-filling phenomenon, but proceeds non-uniformly along localized preferential paths. Tsang et al. (1991) used a variable-aperture channel model, which assumes that flow in fractured rock is dominated by a few variable-aperture channels, to interpret data from a field tracer test in fractured granite in the Stripa Mine, Sweden (e.g. Abelin et al., 1987). In two-phase flow through homogeneous media, fingering can develop as a result of microscopic instabilities at the macroscopically-planar gas-liquid interface, where gravity forces overcome stabilizing capillary forces. Chuoke (1959) derived equations that determine the critical wavelength of a spatial perturbation beyond which a finger can grow, as a function of infiltration velocity, relative fluid densities and viscosities, and surface tension. Larger viscosity differences and higher velocities lead to smaller finger spacings, while larger interfacial tensions lead to wider finger spacings (Kueper and Frind, 1988). In porous media, or fractures, where the scale of heterogeneities is on the order of the macroscopically planar interfaces, fingering will develop in the most permeable regions which are more open and therefore have the lowest breakthrough pressures to the advancing front. Glass et al. (1989 a, b; 1991) examined the theoretical and experimental relationships between finger width, propagation velocity and flowrates of water in initially dry homogeneous porous media. Their results showed the dramatic effect of subtle heterogeneities in nominally-homogeneous media that caused fingers to meander and merge. Once fingers form, they propagate according to macroscopic flow potentials and dominant fingers grow at the expense of smaller fingers, unless horizontally spreading water behind the advancing the finger finds a flow path of lower resistance. In fractures, the variability of aperture sizes and presence of asperity 
contacts cause flow-focusing, ponding and bypassing (Pruess and Antunez, 1995). The heterogeneity in surface wettability may also affect liquid distribution in fractures.

Another aspect of unsaturated flow affecting solute transport is its oscillatory nature. Laboratory experiments have demonstrated the occurrence of oscillation phenomena under two-phase flow conditions in fractures (Persoff et al., 1995) and in gravity-driven drainage in coarse porous media (Prazak et al, 1992). Thunvik and Braester (1990) performed numerical simulation experiments to show that gas breakthrough in a discrete network of water-saturated fractures was controlled by gas pressure build-up in the high permeability fractures, and as a consequence, the use of average permeabilities led to errors in the prediction of breakthrough times. Flow oscillations under two-phase flow conditions have also been observed in field experiments by NAGRA at the Wellenberg site in central Switzerland (Vinard and McCord, 1991) and in the Stripa Validated Drift Experiment in Sweden (Long et al., 1992; Olsson, 1992).

\section{PHYSICAL EXPERIMENTS}

The objectives of the physical experiments are to:

- develop techniques for qualitative and quantitative laboratory-scale measurement of liquid seepage behavior in fractures

- observe seepage behavior in flow cells that incorporate natural fracture topography and identify important phenomena

- test mechanistic hypotheses to explain seepage behavior in cells having idealized geometry

Water-infiltration visualization experiments for ponded inlet conditions and near-vertical media inclination have indicated gravity dominated infiltration and pervasive fingering (e.g. Nicholl et al, 1994). Our experiments are designed to observe water flow behavior for inlet conditions of constant, negative water pressure, i.e., without external pressure forces, in order to eliminate flow instabilities arising from the inlet conditions. To accomplish this, we introduce water to the flow cell by means of a capillary siphon that draws water from a reservoir of constant water-level below the elevation of the flow cell inlet, shown in Figure 1. Changing the angle of flow-cell inclination allows us to vary the relative strength of 
capillary vs. gravity forces. Capillary forces induce spreading independent of flow direction and dampen flow instabilities, while gravity forces promote flow instabilities, increasing at higher angles.

\section{Fracture Replica Experiments}

Flow visualization experiments were performed in $21.5 \mathrm{~cm} \times 33 \mathrm{~cm}$ sized transparent replicas of a natural granite fracture obtained from the Stripa Mine, Sweden. The transparent replica is an epoxy cast (Eccobond 27, W. R. Grace Co., Canton, MA) made from a silicone mold (Rhodorsil RTV 1556, Rhone-Poulec, Inc., Monmouth Junction, NJ ) of the fracture surface. Both the silicone mold and epoxy cast are cured at room temperature. Details of the casting procedure, originally developed by Gentier (1986), are described in Su (1995) and Persoff and Pruess (1995a). The fracture replica is placed over a light table and observations were photographed with a $35 \mathrm{~mm}$ SLR camera (Nikon, model N8008) or video camera (JVC KY-F55BU with lens JVC TY-10x6 MDPU) to obtain better resolution of time-dependent behavior. The video recorder (Sony SVHS no. SVO-5800) has time coding, which provides a temporal resolution of 1/30 s. Digital images are acquired from the video tape after the experiment with a frame grabber (Truevision, Targa 16/32 $+\mathrm{F}$ with Diaquest software controller) and measurements on the images are made with Adobe Photoshop $₫ 3.0$ for Windows.

The advantages of using epoxy casts are that they allow the direct observation of liquid flow behavior and provide an accurate reproduction of the fracture surface topography, as was demonstrated in a comparison of profilometry measurements with a $10 \mu \mathrm{m}$ resolution of a rock and its epoxy cast (Persoff and Pruess, 1993). The epoxy replicas differ from natural rock fractures in several respects. The stress-state and mating of the fracture replica halves is different from the in-situ rock conditions, which may affect the aperture and asperity contact distributions. Note that this problem also exists for laboratory testing of actual rock fractures where the stress state has changed from in-situ conditions. Persoff and Pruess (1995b) compared fluid flow behavior between a fractured rock sample and its epoxy replica and noted larger absolute permeabilities in the replica relative to the rock. The casts do provide the general geometric features of the fracture surface, and results must be interpreted based upon the laboratory-measured aperture distributions.

The difference in surface chemistry of the epoxy compared to the natural rock and the 
impermeability of the epoxy cast affect the wettability of the surfaces to water. The replica may not reproduce small-scale surface roughness that is not measured by the profilometer due to limitations of resolution. To compare wetting behavior, we derived contact angles from capillary rise measurements of water on epoxy, glass and rock, with air as the second fluid phase. These measurements are described in the Appendix. The contact angle of water on epoxy ranges from $57^{\circ}$ to $65^{\circ}$, which falls in the range of intermediate or neutral wettability, as defined by Dullien (1988) for fluids with contact angles between $50^{\circ}$ and $90^{\circ}$. Most common aquifer minerals, such as quartz, carbonates and sulfates, are strongly water-wet, however natural hydrophobic organic materials on the mineral surface, such as humic acids, as well as anthropogenic organic compounds, may change the wettability of the surface (Bradford and Leij, 1995a), creating conditions of neutral wettability. We observed that water wetted a smooth granite surface relative to air with a contact angle closer to that of water on the smooth epoxy surface, than water on glass, which is commonly used as an analog for natural rock surfaces (e.g. Nicholl et al., 1994). A water drop on the fracture surface of the same rock spread spontaneously, illustrating the important role that near-surface porosity in natural rock may have on wetting behavior. Although the porosity of granite is very small (less than $1 \%$ ), weathering near the fracture surface and fracture coating materials may cause porosity near the fracture surface to be larger than in the bulk rock.

For conditions of neutral wettability, capillary forces and trapping of the non-wetting phase are reduced compared to the strongly water-wet systems. In an analysis of relative permeability measurements in porous media as a function of contact angle, neutrally wet systems exhibit less phase interference such that relative permeability is higher at a given saturation, compared to strongly water-wet systems (Dullien, 1988) (although the sum of the relative permeabilities are still much less than one). Dullien (1988) also noted that spontaneous imbibition did not occur for contact angles between $49^{\circ}$ to $90^{\circ}$. Persoff and Pruess (1995b) compared nitrogen-water relative permeability as a function of capillary pressure in rock fractures and their epoxy casts. The difference in the relative permeability curves between the rock fracture and its epoxy cast was attributed to the different surface properties of the rock and epoxy, and some of the data indicated that, to a first order, the relative permeability could be scaled to $1 / \cos \theta$. 
Several series of flow-visualization experiments were performed as described in the following paragraphs, and listed in Table 1. Prior to each experiment, the replica was washed in hot water with Liquinox ${ }^{\circledR}$, rinsed with deionized water, then rinsed with methanol.

Series 1A: The fracture replica was a cast made from Eccobond 27 parts A \& B, mixed to a ratio of 100:30 (part A: part B), according to the manufacturer's specification; the cast thickness varied from approximately $0.3 \mathrm{~cm}$ to $0.7 \mathrm{~cm}$. The replica was mounted over a halogen light box and subjected to a gas confining pressure of $35 \mathrm{kPa}$. Gas confinement was achieved by pressurizing the space between confining plates and the outside surfaces of the replica. The fracture replica, confining plates and rubber gasket between the outside surface of the replica and confining plates were held together with aluminum flanges.

Deionized water with $0.2 \%$ by volume blue dye (Liquitint Patent Blue, Milliken Chemical, Inman, SC) was supplied uniformly to the fracture inlet with a piece of acrylic felt to create a capillary siphon (Figure 1). The other three sides of the fracture were open to atmosphere. The water level of the inlet constant-head reservoir was $1.8 \mathrm{~cm}$ below the fracture inlet. Filter paper was attached to the downstream end to wick away water and minimize capillary barrier effects at the outlet. Flow was observed and photographed at increasing angles of inclination, beginning at $20^{\circ}$ from the horizontal to $40^{\circ}$. The angle was set by raising the lab-jacks, shown in Figure 1, without disassembling the fracture or interrupting the flow.

Although great care was taken to maintain uniform and steady boundary conditions at the fracture inlet, water flow generally proceeded in an extremely unsteady manner along highly non-uniform preferential flow paths. Figure 2 is a photograph of flow through the fracture, inclined at $20^{\circ}$ from the horizontal. Flow is restricted to a single channel that extends the length of the fracture, with some horizontal spreading near the outlet end. The channel includes relatively wide regions, extending $10 \mathrm{~mm}$ or more, of mostly stagnant water. These are connected by narrow passages or "threads", some of which are so thin that it is difficult to actually see the connections between the larger water-filled regions. All of the flow passes through these threads which go through cycles of breaking and reforming. These cycles occur sporadically, typically following a longer period of no observable changes in liquid distribution. 
Table 1. Seepage experiment conditions

\begin{tabular}{|c|c|c|c|c|c|}
\hline Series & Flow cell & Loading & $\begin{array}{l}\text { Inlet } \\
\text { conditions/ } \\
\mathrm{P}_{\mathrm{vg}}(\mathrm{cm})^{(4)} \\
\end{array}$ & $\theta$ & Comments \\
\hline $1 \mathrm{~A}$ & $\begin{array}{l}\text { replica, } 100: 30 \\
\text { mixture, } 1 / 4-1 / 2 " \\
\text { thick }\end{array}$ & (1) & $\begin{array}{l}(5) / \\
-1.8\end{array}$ & $\begin{array}{l}20^{\circ}- \\
40^{\circ}\end{array}$ & infiltration of dyed water \\
\hline $1 B$ & $-"-$ & (2) & $\begin{array}{l}(5) / \\
-3.0 \mathrm{~cm}\end{array}$ & $19^{\circ}$ & miscible displacement \\
\hline $2 A^{(8)}$ & $\begin{array}{l}\text { replica, 30:10 } \\
\text { mixture, 1" thick }\end{array}$ & (2) & $\begin{array}{l}(6) / \\
-1.5 \\
\end{array}$ & $30^{\circ}$ & sequential infiltration events \\
\hline $2 \mathrm{~B}$ & -"- & (2) & $\begin{array}{l}(6) / \\
-2.3 \\
\end{array}$ & $30^{\circ}$ & infiltration of dyed water \\
\hline $2 \mathrm{C}$ & -"- & (1) & $\begin{array}{l}(7) / \\
-3.5 \text { to }+2.0 \\
\end{array}$ & $70^{\circ}$ & $\begin{array}{l}\text { infiltration of dyed water; } \\
\text { flowrate measurements } \\
\text { recording of time-dependent } \\
\text { behavior }\end{array}$ \\
\hline $3 \mathrm{~A}$ & $\begin{array}{l}\text { lucite parallel plate } \\
\text { aperture sequence }\end{array}$ & (3) & $\begin{array}{l}(5) / \\
-1.2 \\
\end{array}$ & $30^{\circ}$ & infiltration of dyed water \\
\hline $3 \mathrm{~B}$ & $\begin{array}{l}\text { glass parallel plate } \\
\text { aperture sequence }\end{array}$ & (2) & $\begin{array}{l}(6) / \\
-1.0,-0.75 \\
\end{array}$ & $30^{\circ}, 34^{\circ}$ & $\begin{array}{l}\text { no filter paper in bottom } \\
\text { section }\end{array}$ \\
\hline $3 \mathrm{C}$ & -"- & (2) & $\begin{array}{l}(6) / \\
-1.2\end{array}$ & $\begin{array}{l}48^{\circ}, 70^{\circ} \\
74^{\circ}\end{array}$ & filter paper in bottom section \\
\hline
\end{tabular}

Notes:

(1) $35 \mathrm{kPa}$ nitrogen confining pressure. (2) compressed between 1/2" lucite plates. (3) compressed with C-clamps. (4) $P_{w}$ is the fracture inlet pressure head, measured as the distance between the elevation of the water level in the inlet reservoir relative to the fracture inlet edge. (5) Felt siphon across full length of inlet (6) Felt siphon across middle third of inlet (7) Ceramic end-cap across middle third of inlet (8) Fracture inlet was rotated $180^{\circ}$ relative to orientation in Series $1,2 \mathrm{~B}$ and $2 \mathrm{C}$.

It is difficult to confirm whether a blue-colored area is fully water saturated without careful measurements of light attenuation. However, in our subsequent discussion, we assume that blue areas are water-saturated and that the variation in the intensity of the blue color reflects a change in aperture. Increased light attenuation is expected through larger apertures, producing a more intense, or darker blue, and a lighter blue in the small apertures. The exception to this are the very pale blue areas adjacent to areas of dark blue, which indicate the presence of a water film on the replica surface.

Figure 3 shows the midsection of the fracture following changes in liquid distribution. The clock time is noted below each photograph. Light blue regions indicate the presence of a water film. A comparison of Figures 3(a) through (d) shows that the liquid threads reform, thicken and thin along the water films, as indicated by the numbered arrows. Some of the threads are horizontal, or even suggest an upward flow direction, as indicated 
by Arrow 1. Figure 4 shows similar liquid distribution and flow behavior at an angle of $35^{\circ}$. The regions indicated by the circles have drained somewhat compared to the $20^{\circ}$ angle. Figures 4(c) and (d) were photographed within seconds of one another, to capture a transient event of liquid filling a region. Figure 5 shows a sequence of photographs where $\phi$ was increased to $40^{\circ}$. The first three frames are photographed within seconds of one another to capture an intermittent event of water draining from the lower third of the channel; the last frame is taken two minutes later where the channel is at its most-drained state and a connecting thread indicated by the arrow has snapped. At $\phi=40^{\circ}$, more drainage of the encircled area has occurred compared to the lower angles. Generally, more frequent thread-snapping and draining was observed at the higher angles, however the flow paths and locations of thread-snapping did not change as the fracture inclination was increased.

Series 1B: The same fracture replica and inlet arrangement used in Series 1A was used to conduct miscible displacement experiments, shown in Figure 6. The fracture replica was reassembled and compressed by two $1 / 2$ " thick lucite plates, instead of confining gas pressure. The assembly was mounted over a fluorescent lamp light table. The first liquid introduced to the fracture was clear, deionized water (Figure 6(a)). After the clear water broke through the outlet end, dyed water $\left(0.8 \%\right.$ Liquitint $^{\oplus}$ in deionized water) was introduced into the fracture (Figure 6(b)), followed by another flush of clear water (Figures $6(c)-(f))$. The inlet water was changed by replacing the water in the inlet reservoir and saturating the felt strip with the new liquid. In each step, the displacing liquid was introduced until no further changes in dye distribution were observed. The location of water channels in Series 1B occurs farther to the sides of the replica compared to Series 1A. This difference is attributed to the different fracture loading of the two experiments; the gas compression in Series 1A apparently caused the central region of the fracture to be tighter compared to Series 1B.

Several important observations can be made from the miscible displacement experiments. Figure 6(b) shows one finger of clear water slightly left of the middle of the fracture replica while the rest of the wetted area is occupied by dyed water. This clearwater region formed during infiltration into the initially dry fracture, and was subsequently bypassed by the active flow paths of the water. Figures 6(c) and 6(d) show lighter regions that indicate a path of faster flow within the established flow channels after introducing 
clear water to displace the dyed water. Even the smallest threads show a gradient of dye concentration transverse to the direction of flow. The lighter regions broaden with time, showing that advective, dispersive and diffusive solute transport are all important during infiltration. Most of the dyed water was displaced after four hours of flow.

As in the Series 1A experiments, unsteady flow behavior was observed in Series 1B. Figure 7 shows a sequence of four photographs taken while intermittent flow occurred near the bottom of the right channel shown in Figure 6. After the thread had snapped and drained into the ponded region of water directly below the thread, a new finger immediately began to form and fill the region of the channel that had drained. The cycle of thread snapping and reforming was on the order of several seconds, and then the flow appeared steady again. The location of the intermittent flow occurred in the same portion of the flow channel each time.

Series 2A: A second cast of the Stripa fracture was made, which was significantly thicker than the cast used in Series 1 (approximately $2 \mathrm{~cm}$ thick), and consequently much more rigid. The cast was prepared with a 30:10 mixture of part A to part B of the epoxy resin instead of the manufacturer-recommended ratio of 100:30. This resulted in an excess of part $B$ that did not bind to part A and appears to have affected the surface properties of the cast, as the following discussion will show. The fracture cast orientation was rotated $180^{\circ}$ from Series 1. The fracture was compressed between two lucite plates, as in Series 1B. The felt siphon only contacted the center $1 / 3$ of the fracture top, compared to the full width of the fracture in Series 1 . The light table was modified so that its angle was adjustable and the fracture replica was set parallel to the table, eliminating the need for the lab-jacks to set the angle of the fracture.

In this first experiment (2A), the fracture was inclined $30^{\circ}$ and the water level of the inlet reservoir was $1.5 \mathrm{~cm}$ below the fracture inlet. The fracture surfaces were not washed before assembly. Clear water was initially introduced to the fracture, shown in Figure 8(a) where a channel at the top of the fracture is followed by a spread-out region. The clear water in the inlet reservoir was replaced with dyed water, which immediately formed a channel and broke through the fracture, and later diffused out into the partially saturated region adjacent to the main channel. This can be seen in Figure 8(b), which was taken 7 minutes after the dyed water was introduced and in Figure 8(c), taken within seconds of 8(b). Midway down the fracture, Figure 8(c) shows the formation of a second channel 
parallel to an existing channel in Figure 8(b). The water channels more towards the fracture center compared to Series $1 \mathrm{~B}$, probably due to the thicker cast which allowed more even fracture compression. The 30:10 epoxy mixture apparently allows more surface sorption of water with the excess part $B$, which created a brighter region adjacent to the flow channels of partial water saturation which does not appear to flow. The dyed water diffused only a short distance across this low saturation region. Flow continued overnight until the inlet reservoir was depleted of water. The following morning, the flow of water was re-initiated under the same conditions. Overnight, water migrated transverse to the direction of flow, seen by the extended light region in Figure 9(a), which was taken immediately after water flow was initiated. The higher dye concentration at the edges of the halo may have resulted from evaporation. Many new flow channels can be seen in this image, however several hours later, in Figure 9(b), only several flow paths remain active.

Series 2B: The fracture replica used in Series 2A was washed, reassembled and rotated $180^{\circ}$, such that the flow direction was the reverse of the direction in Series $2 \mathrm{~A}$ (i.e. the same orientation as in Series $1 \mathrm{~A}$ and $1 \mathrm{~B})$. The felt capillary siphon contacted only the middle third of the fracture inlet. Figure 10(a) shows the liquid distribution, for the same fracture inclination as in Series $2 \mathrm{~A}$, with the water elevation $2.3 \mathrm{~cm}$ below the fracture inlet. Although the flow distribution at the top and bottom of the fracture in Series $2 B$ is similar to the bottom and top of Series $2 \mathrm{~A}$, respectively, the number of channels and their locations differ somewhat, illustrating the sensitivity of channeling to the sequence of apertures encountered. The washing appears to have conditioned the replica surface, eliminating the extensive water sorption that occurred in Series $2 \mathrm{~A}$. The lighter regions alongside the flowing channels indicate that the finger-width during penetration of the initially dry fracture was wider and subsequently drained to the flowing channel. The lower left-hand channel in Figure 10(a) has a "thumb" of residual water indicating an initial penetration that was subsequently bypassed. Figures $10(b)$-(f) focus on the location of thread snap-off and reformation occurring in the lower left-hand channel seen in Figure 10(a). This channel is much less tortuous than the flow channeling observed in Series 1A (Figures 2 through 5), and thread snap-off and reformation occur only in this one location (as opposed to multiple locations in Series 1A). When the thread breaks, the upper meniscus retreats somewhat, and then thickens and advances. The lower meniscus of the broken thread is pulled 
downward, ahead of the upper meniscus and the thread reconnects and thins near the bottom of the image in Figure 10(f).

Series 2C: In these experiments, a ceramic end-cap designed for two-phase flow experiments (Persoff and Pruess, 1995a), patented by Persoff et al. (1995) was placed in the center third of the fracture inlet to deliver water to the fracture edge. The advantage of using the porous ceramic is that it provides better control of the inlet boundary conditions than the capillary siphon, while allowing ambient air to freely flow in and out of the fracture edge through grooves milled into sides and bottom of the end-cap. Figure 11 shows the details of the $7.62 \times 1.9 \times .95 \mathrm{~cm}$ end-cap, machined from ceramic having a 50 $\mathrm{kPa}$ bar entry pressure (Soil Moisture Corporation, Santa Barbara, $\mathrm{CA}$ ), such that it remains saturated for capillary pressures below that value. A stainless steel tube intersects a tunnel drilled lengthwise through the end-cap to accept water. The tunnel distributes the water uniformly and close to the grooves on the bottom of the plate which contact the fracture edge. A second tube intersects the tunnel to extract the air initially present in the tunnel by means of a syringe. Dyed water ( $0.2 \%$ Liquitint in deionized water by volume) was supplied with a constant head Mariotte bottle, shown in Figure 12, allowing the inlet pressure to be varied by adjusting the height of the Mariotte bottle. Flow rates to the inlet end-cap were measured using a variable area flow-meter (Gilmont, shielded flow-meter, micro, Cole Parmer, IL).

The fracture replica was the same as used in Series $2 \mathrm{~A}$ and $2 \mathrm{~B}$ with the same light table arrangement, inclined at an angle of $70^{\circ}$. The fracture was subjected to a confining gas pressure of $35 \mathrm{kPa}$, as in Series 1A. Filter paper was placed at the outlet of the fracture to allow for better drainage of the water and the sides of the fracture were sealed with gummed tape. The ceramic plate was saturated with water, placed into the opening in the fracture edge, and then the inlet water pressure was set to $-3.5 \mathrm{~cm}$ relative to the plate bottom. The water pressure head at the inlet was increased from $-3.5 \mathrm{~cm}$ to $-1.5 \mathrm{~cm}$ in increments of $1 \mathrm{~cm}$ each day. The pressure was then increased from $-1.5 \mathrm{~cm}$ to $2 \mathrm{~cm}$ in increments of $0.5 \mathrm{~cm}$ each day. The resulting fingering patterns were videotaped for 45 minutes at each pressure head.

Water quickly entered the fracture after the saturated ceramic plate was placed at the inlet. A channel on the left formed after a few minutes, and another channel on the right completely formed after approximately half an hour, shown in Figure 13. A relatively 
broad, water-filled region formed above the right channel and below the inlet plate, but no such region formed above the left channel. The apertures in the region above the right channel are probably smaller than those found above the left channel. After flow had equilibrated at the initial inlet pressure head of $-3.5 \mathrm{~cm}$ (approximately 24 hours) water only continued to flow through the right channel. The lack of flow in the left channel was deduced from the fact that the filter paper below the exit point of the left channel was dry. Residual water from the initial invasion was held by capillary forces along what had been the left channel. The fact that no changes were observed in the residual water distribution also indicated that this channel was not flowing.

The water proceeded intermittently through the right channel at a pressure head of $-3.5 \mathrm{~cm}$. Figure 13 shows four sequential photographs of the intermittent flow at this head. Typically, a finger advanced through the right channel (Figure 13 (b)) which snapped after the finger merged into a small pond of water held by capillary forces several centimeters down-gradient (Figure 13 (c)). Once the finger snapped, a slug of water quickly flowed down the rest of the right channel (Figure 13 (d)). The average flow rate measured at the inlet at this pressure was $1.3 \mathrm{~mL} \mathrm{hr}^{-1}$. The flow rates fluctuated as the water progressed through the flow channels. Since an analog flow-meter was used, the flow rates could not be recorded continuously during the experiment. Three to eight values of flow rates were measured at each pressure head. The flow rate generally increased after the thread snapped and then decreased to a nearly constant flow rate as the channel reformed. The average and standard deviation of the noted flow rates at each pressure head are shown in Table 2. The magnitude of the flow rate deviations do not indicate a dependence upon pressure or flow rate.

The flow rate to the inlet of the fracture increased slightly at an inlet pressure head of $-2.5 \mathrm{~cm}$. Under these conditions, water began flowing through both the left and right channels in an unsteady manner and the water entered the right channel at a faster rate than the left channel. This was evident from observations of the rate of finger growth after the thread had snapped in each channel. When the inlet pressure head was changed to $-1 \mathrm{~cm}$ several days later, water began flowing through the left channel at a faster rate than the right channel. The rate of flow through the left channel continued to be greater than the right channel as the pressure at the inlet was increased. The water continued to flow intermittently through both channels until the inlet pressure head was increased to $2 \mathrm{~cm}$. At 
this head, only the right channel exhibited intermittent behavior, and the left channel appeared to remain steady.

Figures 14 through 16 summarize the observations of flow behavior as a function of inlet pressure head. Figure 14 (a) is a plot of the flow rate as a function of the inlet pressure head. The actual pressure at the fracture inlet is somewhat lower than the difference in elevations between fracture inlet and Mariotte bottle due to head loss through the ceramic end-cap. The flow rate increases non-linearly as the pressure increases, which is characteristic of two-phase flow. Future experiments will be conducted to see if this behavior is an artifact of the ceramic end-cap, or if it reflects the behavior of the fracture. One explanation for the increase in flow rate is that at lower pressures, water only flows through the teeth of the endcaps and the grooves are occupied by air. At higher pressures, water may fill the grooves in the ceramic endcap, which would provide a greater crosssection of flow for the water and allow higher flow rates.

Figures 14 (b) and (c) show the location where the finger first snapped in the right and left channels, respectively, relative to the fracture inlet. In the right channel, the location is nearly constant at all the pressure heads. In the left channel, the location of the snapping is constant for the lowest three inlet pressures, then moves away from the fracture inlet at positive pressures; this distance appears to increase with pressure head. The change in snapping location in the left channel corresponds to the increase in flow rates inFigure 14(a). The presence of the capillary-controlled region above the right hand channel and its absence above the left hand channel may be responsible for the different behavior of the 2 channels. The location of the thread snapping at a given pressure during the 45 minutes for which the experiments were recorded was constant, with the exception of $P_{w}=0 \mathrm{~cm}$. The left channel broke $1.9 \mathrm{~cm}$ rather than $6.6 \mathrm{~cm}$ from the inlet boundary three times during this time interval. This other snapping location occurred sporadically during the 45 minute interval. The first of these events occurred about 13 minutes into this 45 minute interval, the second around 2 minutes after the first event, and the last about 6 minutes after the second event.

The time interval between intermittent flow events was noted from inspection of the video recordings over a 45 minute period at each pressure head to determine whether or not this behavior was periodic. Figures 15 and 16 plot the accumulated number of snapping events versus time, for negative and positive pressure heads, respectively. In most cases, 
the number of snap-off events grows linearly with time, indicating periodic behavior. The slopes of these lines provide a quantitative measure of the frequency of flow intermittency, which are tabulated in Table 2. It is interesting to note that the frequency of snapping events increased and then decreased considerably in the left channel as the pressure was increased. The total snap-off rate, or the sum of snap-off rates in the left and right channels, is low at the negative pressure heads, increasing as the pressure head approaches zero. At pressure heads greater than zero, the total snap-off rate is higher than at the lowest two pressure heads $(-3.5$ and $-2.5 \mathrm{~cm})$ but there is no evident correlation with flow rate or pressure head.

Table 2. Intermittent flow behavior for Series $2 \mathrm{C}$ experiments

\begin{tabular}{|c|c|c|c|c|c|c|}
\hline$\overline{\mathrm{P}_{\mathrm{w}}}$ & Average & Standard & \multicolumn{3}{|c|}{ Snap-off rate (events/min) } & Liquid \\
\hline (cm) & $\left(m L h r^{-1}\right)$ & $\left(\mathrm{mL} \mathrm{hr} \mathrm{r}^{-1}\right)$ & left channel & right channel & total & $(\mathrm{mL})$ \\
\hline-3.5 & 1.331 & 0.451 & no snapping & 0.134 & 0.134 & 0.166 \\
\hline-2.5 & 1.445 & 0.086 & 0.081 & 0.079 & 0.160 & 0.151 \\
\hline-1.5 & 2.117 & 0.107 & 0.126 & 0.178 & 0.304 & 0.116 \\
\hline-1.0 & 2.381 & 0.145 & 0.155 & 0.094 & 0.249 & 0.159 \\
\hline-0.5 & 4.043 & 0.306 & 0.063 & 0.332 & 0.395 & 0.171 \\
\hline 0.0 & 4.589 & 0.274 & $\begin{array}{l}0.374^{(1)} \\
0.133^{(2)}\end{array}$ & 0.043 & 0.550 & 0.139 \\
\hline 0.5 & 5.749 & 0.194 & 0.234 & 0.058 & 0.292 & 0.328 \\
\hline 1.0 & 6.075 & 0.184 & 0.215 & 0.045 & 0.260 & 0.389 \\
\hline 2.0 & $\begin{array}{c}\text { not } \\
\text { measured }\end{array}$ & $\begin{array}{c}\text { not } \\
\text { measured }\end{array}$ & no snapping & 0.392 & 0.392 & -- \\
\hline
\end{tabular}

(1) snap-off occurred $6.6 \mathrm{~cm}$ from fracture inlet

(2) snap-off occurred $1.9 \mathrm{~cm}$ from fracture inlet

Alternatively, the volume of liquid metered through the fracture between snap-off events appears to exhibit more stable behavior as a function of flow rate. This value is estimated from the average flow rate divided by the total snap-off rate, shown in Table 2 . The volume of liquid per snap-off is fairly constant at pressure heads less than and equal to zero and then increases at pressure heads greater than zero. This trend is clearly seen in Figure 17, which plots the total snap-off rate and liquid volume/snap-off as a function of flow rate. The different behavior at the higher flow rates suggests that a change in flow regime occurs as inlet pressure heads move from negative to positive. The change in location of thread snapping in the left channel at higher flow rates is also consistent with a 
change in flow regime. As mentioned earlier, future experiments will determine whether the ceramic endcap causes the change in behavior at higher flow rates.

\section{Parallel Plate Experiments}

Series 3 experiments were conducted to examine in more detail the cyclic formation and snapping of the thin threads observed in the fracture replica experiments. This behavior is hypothesized to evolve from a sequence of aperture sizes that progress from medium to large to small in the direction of flow, shown in Figure 18(a). Water flowing through the medium aperture section advances under gravity and encounters a capillary barrier at the interface of the medium and large aperture sections, allowing the formation of the thread through the large aperture section. When the thread reaches the small aperture, it experiences a strong capillary force that pulls the thread through at a rate faster than the . supply of water through the top section, causing the thread to break. The flow capacity, or permeability, of the small aperture section must be sufficient to pull the liquid away. This aperture sequence has been qualitatively observed in the fracture replica experiments, where broader regions of water, indicating smaller apertures, occur above and below the location of thin thread formation and snapping in a relatively larger aperture segment.

Lucite and glass parallel plate cells of medium-large-small aperture sequences were assembled in an attempt to reproduce the thread formation and snapping observed in the fracture replicas. The cross-section of each cell is shown in Figure 18(b). The lucite cell consists of two plates, $3.81 \mathrm{~cm}$ wide $\mathrm{x} 15.24 \mathrm{~cm}$ long, milled to the dimensions shown in the figure, with $0.05 \mathrm{~mm}$ shims along the sides of the top section and filter paper on the bottom section. The plates are held together with clamps on the top and bottom sections. The glass cell has overall dimensions of $21.6 \mathrm{~cm}$ wide by $33 \mathrm{~cm}$ long. It is assembled by placing shims of the desired aperture between a continuous lower plate and three upper plates for each section, shown in Figure 19(b). A thin bead of silicone is applied along the outside edges between adjacent sections to hold the assembly together. Shims are then placed along the outside of the top and bottom sections for support against the confining 0.5 " lucite plates. Filter paper was placed in the small aperture section to provide strong capillary force with adequate capacity to pull the thread from the large aperture section.

Series 3A: Figures 19(a) through (h) show the advance of a finger in the lucite parallel plate cell, inclined at an angle of $30^{\circ}$, with the inlet water elevation $1.2 \mathrm{~cm}$ below the cell 
inlet, and the outlet filter paper immersed in a reservoir with a water level $2.3 \mathrm{~cm}$ below the cell outlet. The images are cropped to show the large aperture sections with a small strip of the medium and small aperture sections above and below. The medium aperture section is so thin that the dyed water that fills it appears transparent. Figure 19(a) was photographed immediately following snap-off of a finger in the large aperture section of the cell. In Figures 19(b) through (d), the finger advances along the same path as previous fingers. Once the finger meets the small aperture section, the top portion of the finger thins (Figures 19(e) through (g)) until it breaks at the thinnest point, leaving some residual water where it broke. This cycle occurred at regular intervals and the finger formed in the same location. Series 3B: Figures 20(a) and (b) show thin thread formation between glass plates, at $30^{\circ}$ and $34^{\circ}$ angles of inclination and inlet water levels $1 \mathrm{~cm}$ and $0.75 \mathrm{~cm}$ below the cell inlet, respectively. In these experiments, there was no filter paper in the lower section and the thread in the large aperture section did not break. One can see variations in liquid distribution between the experiments, due to the reassembly of the glass plates, however the general features were similar, where the liquid accumulated in the top section, formed a thin stable thread in the middle section, and generally filled the lower section. The thread is much thinner than in the finger observed in the lucite cell, in part due to the larger dimensions of the glass cell, as well as the stronger wettability of glass by water, compared to lucite.

Series $3 \mathrm{C}$ : Figure 21 shows sequences of thread formation and breaking in the glass parallel plate cell with filter paper in the lower section. Series $3 \mathrm{C}$ was conducted at angles of inclination of $48^{\circ}, 70^{\circ}$ and $74^{\circ}$, and an inlet water level $1.2 \mathrm{~cm}$ below the cell inlet. In Figure 21 (b), the thread snaps off immediately above the bottom section. The advancing front of the thread widens while its "tail" remains thin (Figure 21(c)), until it reaches the bottom section. In Figure 21(e), the thread has just snapped near the top section of the cell. A residual drop of liquid is left near the bottom section, and a film of liquid remains where the thread was. In Figures $21(\mathrm{f})$ and $(\mathrm{g})$, the advancing front of the thread thickens and lengthens until it meets the bottom section. The frequency and location of thread snapping appeared to be random, albeit recurring, based upon observations over one hour, as compared to the regular and repeatable behavior observed in the smaller lucite cell. The behavior of this thread appears similar to that observed in the Series $2 B$ experiment (Figure 10). 
The same parallel plate sequence was used at a higher angles of inclination, $74^{\circ}$ and $70^{\circ}$, with an inlet elevation of $-1.2 \mathrm{~cm}$ and the frequency of thread-snaps was measured. The plots are shown in Figure 22, where the linearity of the cumulative number of snap-off events with time suggests that this behavior is periodic. The snap-off rates were 0.29 and 0.36 snaps/min, which are comparable to the snapping rates measured in the fracture replica experiment at 70 degrees indicated in Table 2 . The liquid volume/snap-off cannot be calculated because the liquid flow rates were not measured in the Series 3 experiments.

\section{SUMMARY AND CONCLUSIONS}

Laboratory experiments demonstrate the occurrence of highly localized and extremely non-uniform flow paths for unsaturated conditions in variable-aperture fractures. In comparison to conditions of spatially uniform flow, this behavior could drastically accelerate groundwater travel in unsaturated fractured-porous media, and strongly diminish the area available for matrix-fracture interaction. Additionally, mass transfer between the liquid and gas phases may be greatly enhanced due to the relatively large specific surface area between the phases for threads and fingers, compared to uniform infiltration. We also observe pervasive unsteadiness, or intermittency, of flow, as portions of the flow channels undergo cycles of draining and filling, and small connecting threads snap and reform. This unsteady behavior occurs even in the presence of constant pressure boundary conditions. Flow intermittency will tend to diminish matrix-fracture interactions even further, with serious implications for solute transport. Sequences of medium to coarse to fine apertures were shown to cause the formation of liquid threads that undergo cycles of snapping and reforming in glass plates. The variation of fracture inclination without interrupting flow from $20^{\circ}$ to $40^{\circ}$ had relatively subtle effects on flow behavior. Some liquid-filled regions drained at the higher angles, and the frequency of thread snapping and reformation appeared to increase. More obvious changes in flow behavior may occur at steeper angles. Fracture loading had a significant effect on the location of flow channels.

The erratic nature of the thread snap-off and reformation observed in the low angle experiments suggests that its frequency reflects the interplay of concurrent processes, each having different time constants. For the large specific surface area between the liquid and 
gas phases along the thread, evaporation may be significant. Surface tension changes may be important for liquids with solutes having surfactant properties. The role of these parameters will be tested in parallel plate cells by changing the liquid vapor pressure by subjecting the cell to different temperatures, and using different liquids with different surface tensions and vapor pressure. Longer time records are needed to determine whether this process can be characterized as chaotic. This will require means of detecting the occurrence of snap-off other than direct observation. The feasibility of using optical or pressure sensors for detecting snap-off will be evaluated.

Preliminary experiments to obtain more quantitative information on flow behavior utilize patented ceramic endcaps to control inlet boundary conditions. The experiments are recorded with high resolution, time-coded video image acquisition to achieve a temporal resolution of the liquid distribution of $1 / 30 \mathrm{~s}$, to allow a study of the time scales of intermittent flow behavior. There was no obvious relationship between snap-off rates and flow rate, however the volume of liquid "metered" through the fracture between snap-off events was constant at low flow rates and increased at higher flow rates. Further efforts include characterizing snap-off behavior as a functionof angle of inclination, and measuring the aperture distribution of the fracture from light attenuation measurements (Persoff et al., 1993; Nicholl and Glass, 1994) using a high-resolution digital camera.

Infiltration experiments should be conducted on a variety of fracture samples to assess how different fracture aperture distributions affect flow behavior. Existing samples can be rotated $90^{\circ}$ and $180^{\circ}$ so that the flowing water samples different sequences of apertures. A series of experiments to compare the behavior of flow through the replicas with flow through the natural rock fracture should be conducted, following Persoff and Pruess (1995b), who also mated a replica with the natural rock to maintain the ability to observe flow, while incorporating the surface properties and porosity of the natural rock. Both halves of the natural rock should be used for the same boundary conditions as the tests with the replicas; differences in flow and pressure responses can be used to evaluate the effects of the rock matrix and surface chemistry on infiltration. Different liquids should be used to investigate the role of viscosity, density, surface tension and contact angle on infiltration behavior. Further instrumentation may facilitate the comparison of flow behavior between the rock and replica, such as tensiometers to measure pressure fluctuations in the fracture plane in relationship to intermittent flow behavior. 


\section{ACKNOWLEDGMENT}

This work was supported by the Director, Office of Energy Research, Office of Health and Environmental Sciences, Biological and Environmental Research Program, of the U.S. Department of Energy under Contract No. DE-AC03-76SF00098. Thanks are due to Christine Doughty and Joseph Wang for their review of the manuscript and suggestions of improvements. Surface tension measurements were made in the Chemical Engineering Department at the University of California, Berkeley, with the assistance of Keith Karraker. We thank Jiamin Wan for her direction in performing the contact angle measurements with the captive drop method.

\section{REFERENCES}

Adamson, A. W., Physical Chemistry of Surfaces, 4th edition, John Wiley \& Sons, Inc., New York, 664 pp., 1982.

Abelin, H., L. Birgersson, J. Gidlund, L. Moreno, I. Neretnieks, H. Wíden, and J. Agren, 3D migration experiment - report 3: Performed experiments, results and evaluation, Stripa Project Technical Report 87-21, Swedish Nuclear Fuel and Waste Management Company (SKB), Stockholm, Nov. 1987.

Bradford, S. A. and F. J. Leij, Fractional wettability effects on two-and threefluid capillary pressure-saturation relations, Journal of Contaminant Hydrology, 20, 89-109, 1995a.

Bradford, S. A. and F. J. Leij, Wettability effects on scaling two- and threefluid capillary pressure-saturation relations, Environmental Science and Technology, Vol. 29, 1446-1455, $1995 \mathrm{~b}$.

Chuoke, R. L., and P. van Meurs, The instability of slow, immiscible, viscous liquidliquid displacements in permeable media, Petroleum Transactions, ATME, Vol. 216, pp. 188-194, 1959. 
Cox, B. L., S. Finsterle and J. S. Y. Wang, Experimental and numerical aqueous flow through a partially saturated fracture, in Proceedings, Sixth Annual International High-Level Radioactive Waste Management Conference, Las Vegas, NV, April 30May 5, 1995, pp. 20-22, American Nuclear Society, La Grange Park, IL, 1995.

Demond, A. H. and Lindner A. S., Estimation of interfacial tension between organic liquids and water, Environmental Science \& Technology, Vol. 27, No. 12, 23182331, 1993.

Dullien, F. A. L., Porous Media: Fluid Transport and Pore Structure, Academic Press, New York, 396 pp., 1979.

Dullien, F. A. L., Two-phase flow in porous media, Chem. Eng. Technol.,Vol. 11, 407424, 1988.

Fabryka-Martin, J. T., S. J. Wightman, W. J. Murphy, M. P. Wickham, M. W. Caffee, G. J. Nimz, J. R. Southon and P. Sharma, Distribution of chlorine-36 in the unsaturated zone at Yucca Mountain: an indicator of fast transport paths, in Conference Proceedings FOCUS '93: Site Characterization and Model Validation, September 26-29, 1993, Las Vegas, NV, pp. 58-68, American Nuclear Society, Inc., La Grange Park, II, 1993.

Fabryka-Martin, J. T., P. R. Dixon, S. Levy, B. Liu, H. J. Turin, and A. V. Wolfsberg, Summary Report of Chlorine-36 Studies: Systematic Sampling for Chlorine-36 in the Exploratory Studies Facility, Level 4 Milestone Report 3783AD, Los Alamos National Laboratory, March 29, 1996.

Gauthier, J. H., An Updated Fracture Flow Model for Total-System Performance Assessment of Yucca Mountain, in Proceedings. Fifth Annual International HighLevel Radioactive Waste Management Conference, Las Vegas, NV, Vol. 3, pp. 1663 - 1670, American Nuclear Society, La Grange Park, II, May, 1994.

Geller, J. T. and K. Pruess, On water infiltration in rough-walled fractures, in Proceedings. Sixth Annual International High-Level Radioactive Waste 
Management Conference, Las Vegas, NV, April 30- May 5, 1995, pp. 23-25, American Nuclear Society, La Grange Park, IL, 1995.

Gentier, S., Morphologie et comportement hydroméchanique d'une fracture naturelle dans un granite sous constrainte normale, $\mathrm{Ph} . \mathrm{D}$. Thesis, Univ. D' Orléans, France, 1986.

Glass, R. J., J.-Y. Parlange, and T. S. Steenhuis, Immiscible displacement in porous media: Stability analysis of three-dimensional, axisymmetric disturbances with application to gravity-driven wetting front instability, Water Resources Research, Vol. 27, No. 8, pp. 1947-1956; August 1991.

Glass, R. J., J-Y. Parlange, and T. S. Steenhuis, Wetting front instability 1 . Theoretical discussion and dimensional analysis, Water Resources Research, Vol. 25, No. 6, pp. 1187-1194, June 1989.

Glass, R. J., J-Y. Parlange, and T. S. Steenhuis, Wetting front instability 2. Experimental determination of relationships between system parameters and twodimensional unstable flow field behavior in initially dry porous media, Water Resources Research, Vol. 25, No. 6, pp. 1195-1207, June 1989.

Horne, R. N., Geothermal reinjection experience in Japan, Journal of Petroleum Technology, March, 1982, pp. 495-503, 1982.

Kueper, B. H. and E. O. Find, An overview of immiscible fingering in porous media, Journal of Contaminant Hydrology, vol. 2, 95-110, 1988.

Liu, B., J. Fabryka-Martin, A. Wolfsberg, B. Robinson and P. Sharma, Significance of apparent discrepancies in water ages derived from atmospheric radionuclides at Yucca Mountain, Nevada, submitted to Proceedings of 1995 American Institute of Hydrology Annual Meeting, May 14-18, 1995, Denver, CO, LA-UR-95-572, Los Alamos National Laboratory, final version February 23, 1995.

Marsily, G. de, Quantitative Hydrogeology, Academic Press, Orlando FL, 1986. 
Mei, M., R. S. Bowman, J. L. Wilson and N. R. Morrow, Wetting properties and stability of silane-treated glass exposed to water, air, and oil, Journal of Colloid and Interface Science, Vol. 157, 154-159 (1993)

Morrow, N. R., Capillary pressure correlations for uniformly wetted porous media, Journal of Canadian Petroleum Technology, Vol. 15, No. 4, pp. 49-69, 1976.

Morrow, N. R. and I. Chatzis, Measurement and correlation of conditions for entrapment and mobilization of residual oil, Report NMERDI 2-69-3309, New Mexico Energy Research and Development Institute, Santa Fe, New Mexico, 1982.

Nativ, R., E. Adar, O. Dahan and M. Geyh, Water recharge and solute transport through the vadose zone of fractured chalk under desert conditions, Water Resources Res., Vol. 31, No. 2, pp. 253-261, 1995.

Nicholl, M. J., R. J. Glass, and S. W. Wheatcraft, Gravity-driven infiltration instability in initially dry nonhorizontal fractures, Water Resour. Res., Vol. 30, No. 9, pp. 2533-2546, 1994.

Peaceman, D. W., Fundamentals of Numerical Reservoir Simulation, Elsevier Science, New York, 1977.

Persoff, P. and Pruess, K., Flow visualization and relative permeability measurements in rough-walled fractures, in Proceedings of the Fourth International High-Level Radioactive Waste Management Conference, Las Vegas, Nevada, April 26-30, 1993, vol. 2, pp. 2007-2019, American Society of Civil Engineers, New York, 1993.

Persoff, P. and K. Pruess, Two-phase flow visualization and relative permeability measurement in natural rough-walled rock fractures, Water Resour. Res., Vol. 31, No. 5, pp. 1173-1186, 1995a.

Persoff, P. and K. Pruess, Two-Phase Flow Experiments inNatural Rock Fractures from Yucca Mountain, LBL -37716, September, 1995b. 
Powers, S. E., W. H. Anckner and T. F. Seacord, The wettability of NAPL-contaminated sands, accepted for publication in the ASCE Journal of Environmental Engineering, 1996.

Prazak, J., M. Sir, F. Kubik, J. Tywoniak and C. Zarcone, Oscillation phenomena in gravity-driven drainage in coarse porous media, Water Resources Res., Vol. 28, No. 7, pp. 1849-1855, 1992.

Pruess, K. and Y. W. Tsang, On two-phase relative permeability and capillary pressure of rough-walled rock fractures, Water Resources Res., Vol. 26, 1915-1926, 1990.

Pruess, K. and G. S. Bodvarsson, Thermal effects of reinjection in geothermal reservoirs - with major vertical fractures, Joumal of Petroleum Technology, September 1984, pp. 1567-1578.

Scheidegger, A. E., The Physics of Flow Through Porous Media, 3rd ed., University of Toronto Press, Toronto, Ont., 1974.

$\mathrm{Su}, \mathrm{G}$., Water Infiltration and Intermittent Flow in Rough-Walled Fractures, Masters Thesis, Department of Civil Engineering, University of California, Berkeley, 1995.

Tsang, Y. W. and C. F. Tsang, Flow channeling in a single fracture as a two-dimensional strongly heterogeneous permeable medium, Water Resources Research, Vol. 25, No. 9, pp. 2076-2080, September, 1989.

Tsang, C. F., Y. W. Tsang, and F. V. Hale, Tracer transport in fractures: Analysis of field data based on a variable-aperture channel model, Water Resources Research, Vol. 27, No. 12, pp. 3095-3106, December, 1991.

Wan, J., Earth Sciences Division, Lawrence Berkeley Laboratory, personal communication. 
Wang, J. S. Y., N. G. W. Cook, H. A. Wollenberg, C. L. Carnahan, I. Javandel, and C. F. Tsang, Geohydrologic.Data and Models of Rainier Mesa and Their Implications to Yucca Mountain, in Proceedings. Fourth Annual International High-Level Radioactive Waste Management Conference, April, 1993, Las Vegas, NV, Vol. 1, pp. 675 - 681, American Nuclear Society, La Grange Park, IL, 1993.

Weser, C., Measurement of interfacial tension and surface tension - general review, GIT Fachzeitschrift für das Laboratorium, 24, 642-648; 734-742, G-I-T Verlag Ernst Giebeler, Darmstadt, 1980. 
APPENDIX. Contact angle measurement

The contact angle between a fluid-fluid interface and a solid indicates which fluid wets the solid. Water wets a solid when the contact angle measured through the water phase in a water-air-solid system is acute. Most common aquifer minerals, such as quartz, carbonates and sulfates are strongly water-wet, (Demond and Lindner, 1993) however natural hydrophobic organic materials on the mineral surface, such as humic acids, as well as anthropogenic organic compounds, may change the wettability of the surface (Bradford and Leij, 1995a). Many factors confound the application of laboratory measured contact angles on smooth mineral surfaces to multiphase flow. Long recognized in petroleum reservoirs, the condition of mixed wettability, where only a fraction of the total pore space is water wet, has only recently received attention within the context of groundwater aquifers (Bradford and Leij, 1995a). Powers et al. (1996) found that a wide range of wetting conditions results from the exposure of sands to complex organic liquid contaminant mixtures.

In homogeneous materials, contact angle hysteresis, manifested by the difference in receding and advancing contact angles, is affected by surface roughness and contamination (Dullien, 1979). Greater contact angle hysteresis has been observed on rough materials as compared to smooth materials (Morrow, 1976; Morrow and Chatzis, 1982). Contact angles derived from fits to capillary pressure-saturation curves for air and water in silica sand packs were $0^{\circ}$ for the receding angle and $32.7^{\circ}$ for the advancing angle (Bradford and Leij (1995b). Mei et al. (1993) reported a water-air advancing contact angle of $6.7^{\circ}$ and receding contact angle of $4.5^{\circ}$ on soda-lime glass. On rough surfaces, the local, microscopic contact angle differs from the macroscopically-measured contact angle. There is also a difference between the static and dynamic, or moving, contact angle on all solid surfaces. Finally, we have observed in our experiments with epoxy replicas and parallel plates of lucite and glass, that the flowing water conditions the surface and alters wetting behavior compared to the initially air-dry surface. The rough surface of the epoxy replicas promotes sticking of residual water behind the advancing flow that allows the reformation of thin threads that have snapped off at the same location. This was also observed in the . lucite and glass parallel plate cells with apparently smooth surfaces, where surface impurities and heterogeneities cause the sticking of residual water. 
We conducted a series of measurements to evaluate the wetting behavior of water on various solids in order to relate observations of infiltration behavior in epoxy replicas to the corresponding rock. Photographs of water drops on glass, smooth epoxy and granite, and a granite fracture surface and its epoxy cast were taken to visually compare the contact angles. A series of capillary rise experiments were conducted on glass, smooth and cast epoxy, and smooth granite to quantitatively measure the contact angle of water on these surfaces. A capillary rise experiment was also performed on an actual rough walled fracture and its epoxy replica.

The solid samples included

- $1 / 8$ " thick window-pane glass

- a natural fracture from granite rock (from the Stripa Mine, Sweden)

- an epoxy cast from the same natural fracture

- a smooth epoxy surface

- a smooth granite surface

- an epoxy cast from a smooth granite surface.

The epoxy cast from the smooth granite surface was made to compare the effect of the interaction of the epoxy with the mold and with the smooth epoxy surface. However, the cast from the smooth granite surface showed some roughness, perhaps due to micropores in the apparently smooth granite, and future tests should compare an epoxy cast on a completely non-porous surface, such as lucite. The smooth granite surface was prepared from a sample obtained from the Stripa Mine, but a different piece than the natural rock fracture sample. The surface was smoothed by grinding with water that contained a watersoluble coolant. The epoxy cast from the fracture was made with a 100:30 ratio of part $A$ to part B. Smooth epoxy surfaces were made from two mixtures of epoxy: one with a $100: 30$ ratio of part $A$ to part $B$, and the second to a 30:10 ratio of part $A$ to part $B$; each surface was cut and polished. To measure the effects of surface roughness, a sample of roughened epoxy was created by lightly sanding a smooth epoxy surface.

Cleaning methods: The glass, epoxy, and granite surfaces were washed in hot water with 'Liquinox ${ }^{\circledR}$, rinsed thoroughly with hot water, and rinsed again with deionized water. The surfaces were then cleaned with methanol and allowed to dry. To compare the effect of cleaning methods and calibrate our measurements to values reported in the literature, 
additional measurements were made on glass plates that were rigorously cleaned to remove inorganic and organic substances from the surfaces by soaking in a $10 \%$ nitric acid bath with distilled, deionized water for approximately 24 hours followed by drying at $300^{\circ} \mathrm{F}$ for approximately 30 minutes.

Visual Observations: Profiles of water drops on the horizontal solid samples were photographed to obtain a qualitative comparison of the contact angle of water on the various solids, shown in Figure A1. A $5 \mathrm{~mL}$ syringe was used to place approximately the same volume (one drop) of liquid on each sample. The drops on the smooth granite and smooth epoxy surfaces (both 30:10 and 100:30 mixtures) have similar heights and contact angles, all less than $90^{\circ}$. The 30:10 mixture appears to have a slightly larger contact angle compared to the 100:30 mixture and granite surface. The drop on the glass surface appears significantly flatter than the drops on the other smooth surfaces, with a much smaller contact angle. A comparison of a water drop on the natural fracture and epoxy cast of the fracture shows that the water drop on the natural fracture is flatter, indicating a smaller apparent contact angle for the rock, compared with the epoxy cast. It is commonly assumed that the contact angle for water on natural silica surfaces is zero and that glass is the best analog for these natural materials in terms of its wettability. These observations suggest that in addition to contact angle differences, small-scale roughness or near-surface porosity may strongly affect water-wetting. However, due to the qualitative nature of these observations, they can only be taken as indications of important phenomena worthy of more rigorous study.

Captive Drop Measurement: The contact angle of deionized and Millipore filtered water on a clean glass slide and on smooth epoxy was measured by the captive bubble method, described by Adamson (1982). In this method, a drop formed by manipulation of a micrometer syringe is made to contact the solid surface, such that the drop remains connected to the syringe needle. The contact angle is measured by means of a goniometer telemicroscope (microscope with a protractor). An average of three repeated measurements resulted in a contact angle of $70^{\circ}$ for water on epoxy at room temperature of $22.1^{\circ} \mathrm{C}$. In the case of water on the glass slide, the drop broke off from the syringe the instant it contacted the glass, preventing a static contact angle measurement with this technique. In these 
circumstances, it is common practice to report a contact angle of less than $10^{\circ}$ (J. Wan, personal communication).

\section{Capillary Rise Measurements with Smooth Plates:}

At equilibrium, the relationship between the height of the air-water meniscus, $h$, between two plates separated by distance $b$, is related to the contact angle, $\theta$, by the following equation:

$\rho g h=\frac{2 \sigma \cos \theta}{b}$

where $\sigma$ is the air-water surface tension, $\rho$ is the density of water, and $g$ is the acceleration of gravity. This equation can be rearranged to calculate the contact angle of water on the solid surface:

$$
\theta=\cos ^{-1}\left(\frac{\rho g h b}{2 \sigma}\right)
$$

For a series of measurements of capillary rise, $h$, at varying values of $b$, the contact angle can also be calculated from the slope of $h$ vs. $1 / b$ as determined from a least squares fit of the data to a straight line. From inspection of Equation (A1), the slope is equal to:

slope $=\frac{2 \sigma \cos \theta}{\rho g}$

The configuration for the capillary rise experiments is shown in Figure A2. Shims of thickness $b$ are inserted between the solid plates. Clamps placed on either side of the plates hold the shims in place. The plates are then placed vertically in a large container with a water depth of approximately $1 \mathrm{~cm}$. An advancing meniscus is measured by using initially dry plates and allowing equilibration overnight. A receding meniscus is achieved by assembling the plates horizontally in water to saturate them before standing them in the large water container. The height of the receding meniscus reaches equilibrium after approximately one hour. The elevation of the water level within the plates above the water level of the container, $h_{t}$, is measured visually on the outside of the plates with a scale having $1 \mathrm{~mm}$ divisions, where $h_{t}=h+\Delta h$ 
and $\Delta h$ is the distance between the bottom of the air-water meniscus and its contact point on the plate wall. For the granite plates, $h_{t}$ is measured by opening up the plates and measuring the length of the wetted surface.

For a cylindrical meniscus, $\Delta h$ is a function of the contact angle and plate separation, as follows:

$\Delta h=\frac{b}{2 \cos \theta}(1-\sin \theta)$

Substituting Equations (A1) and (A5) into Equation (A4) gives:

$\rho g h_{t}=\frac{2 \sigma \cos \theta}{b}+\frac{\rho g b}{2 \cos \theta}(1-\sin \theta)$

In Equation (A5), $\Delta h$ increases in direct proportion to $b$, because this equation is derived for a meniscus having a constant radius of curvature at every point of its crosssection (i.e. a cylindrical meniscus). Beyond a certain plate separation, this assumption is no longer valid, and an exact solution of the meniscus is required to compute $\Delta h$. Adamson (1982) gives the following equation for the rise of a meniscus, $\Delta h$, on a vertical plate that contacts a horizontal air-water interface:

$\Delta h=a(1-\sin \theta)^{1 / 2}$

where $a$ is the capillary constant, equal to $\sqrt{\sigma / \rho g}$. The value of $\Delta h$ reaches a maximum for $\theta=0$. For pure water, assuming a surface tension of $72 \mathrm{mN} / \mathrm{m}$ and zero contact angle, $\Delta h=2.7 \mathrm{~mm}$. This condition is equivalent to the case of infinite plate separation, which will be used in the calculation of the contact angle from capillary rise measurements presented later.

The surface tension of the liquids used in the capillary rise experiements, two Liquitint solutions ( $0.4 \%$ and $0.8 \%$ by volume), and deionized water, were measured with the Wilhemy plate method, (Weser, 1980). This method uses a balance and a rectangular platinum plate. The weight of the plate is measured by vertically suspending it off of the arm of the balance. A container containing the dyed water is then raised up to the bottom edge of the plate. The force which pulls the wetted plate into the liquid is equal to the 
change in weight relative to the weight of the plate alone, or $\Delta W$. The surface tension is calculated from the following equation:

$$
\sigma=\frac{\Delta W}{P}
$$

where $P$ is the wetted perimeter of the plate. After each measurement, the plate is dried over a flame from a Bunsen burner until it turns red-hot, to remove any residual water on the plate that might adversely affect the next measurement. Since the plates used in these measurements were slightly bent, the perimeter for these plates was determined by first placing the plate in clear, distilled water. The surface tension of this water was assumed to be $72 \mathrm{mN} \mathrm{m}^{-1}$, and the perimeter of the plate, $P$, was calculated from Equation (A8).

Four measurements were made with each liquid, at room temperature, tabulated in Table A1. The values reflect the surfactant properties of the Liquitint, reducing the surface tension of water by approximately $10 \%$. The surface tension is sensitive to the amount of Liquitint added.

Table A1. Surface tension of several liquids measured with the Wilhemy plate method

\begin{tabular}{lcc}
\hline Liquid & Surface Tension $\left(\mathrm{mN} \mathrm{m}^{-1}\right)$ & Standard Deviation $\left(\mathrm{mN} \mathrm{m}^{-1}\right)$ \\
\hline deionized water & 71.61 & 0.41 \\
0.4\% Liquitint in pure water* & 63.91 & 0.56 \\
0.8\% Liquitint in pure water* & 63.48 & 0.82 \\
0.4\% Liquitint in deionized water & 64.42 & 1.73 \\
0.8\% Liquitint in deionized water & 63.40 & 0.82 \\
\hline *deionized, micro-filtered water & & \\
\hline
\end{tabular}

The contact angle was calculated by implicitly solving Equation (A6) for the measured values $b$ and $h_{t}$, summarized in Table A2. Table A2 also includes the plate dimensions $H$ and $W I$. The measured surface tension values of 71.51 and $64.4 \mathrm{mN} \mathrm{m}^{-1}$ were used for the deionized water and Liquitint ${ }^{\oplus}$ solution, respectively. The contact angle was also derived from the slope of the linear regression of $h_{t}$ vs. $1 / b$, using Equation (A3) (see Figure A3). Equation (A7) is used to compute $\Delta h$ at $1 / b=0$, and is included in the regression. This was done iteratively by assuming a value of $\Delta h$ at $1 / b=0$, computing the 
contact angle from the linear regression and adjusting the assumed value until it agreed with the computed value.

For deionized water on the smooth granite, 100:30 polished epoxy, and cast epoxy, the calculated contact angle decreased as aperture increased. This was not the case for the glass, 30:10 polished epoxy and roughened epoxy. The contact angles derived from the slope of $h_{t}$ vs. $1 / b$ represent an average of the individually derived values. Figures A3 and A4 are plots of $h_{t}$ vs. $1 / b$ for the measurements with deionized water and $0.4 \%$ Liquitint respectively. On some of the surfaces, the lowest measured value of $h_{t}$ (at the smallest value of $1 / b$ ) falls noticeably above the regression line. Measurement errors and the effects of surface heterogeneities may be more significant as the capillary rise decreases. Larger samples should be obtained so that the capillary rise can be measured for smaller aperture values to increase the range and improve confidence in the correlation. The correction of $\Delta h$ in Equation (A6) turned out to be insignificant, changing the calculated contact angle by one hundredths of a degree. However, the calculated value of $\Delta h$ at infinite plate separation strongly affects the contact angle value derived from the slope of the regression line. The contact angles calculated from measurements of the advancing meniscus were higher than those of the receding meniscus, as compared in Table A3. The contact angle measured using a receding meniscus is more accurate than the angle measured using an advancing meniscus since the receding meniscus is less sensitive to surface impurities and heterogeneities. However, the lower contact angle for the acid-washed compared to the nominally-clean glass in Table A2, indicates the effect of surface impurities even for a receding meniscus. 
Table A2. Summary of Calculated Contact Angles from Receding Meniscus Measurements

$\begin{array}{lll}\text { Plate Dimensions } & \text { Deionized Water } & \text { Deionized water with } \\ & \left(\sigma=71.51 \mathrm{mN} \mathrm{m}^{-1}\right) & 0.4 \% \text { Liquitint }^{(}\end{array}$

\begin{tabular}{|c|c|c|c|c|c|c|c|c|}
\hline \multirow[b]{2}{*}{ Solid } & & & & & \multicolumn{4}{|c|}{$\left(\sigma=64.4 \mathrm{mN} \mathrm{m}^{-1}\right)$} \\
\hline & $\begin{array}{l}\text { W1 } \\
(\mathrm{cm})\end{array}$ & $\begin{array}{l}\mathrm{H} \\
(\mathrm{cm}) \\
\end{array}$ & $\begin{array}{l}b \\
(\mathrm{~mm}) \\
\end{array}$ & $\theta$ & $\begin{array}{r}\theta \text { fr } h_{t} \\
\text { vs. } 1 / b \\
\end{array}$ & $\begin{array}{l}b \\
(\mathrm{~mm}) \\
\end{array}$ & $\theta$ & $\begin{array}{c}\theta \text { fr } h \\
\text { vs. } 1 / b \\
\end{array}$ \\
\hline \multirow[t]{3}{*}{ Glass } & 7.8 & 21.5 & 0.1 & 26.36 & 27.14 & \multirow{3}{*}{\multicolumn{2}{|c|}{ not measured }} & \\
\hline & & & 0.2 & 7.47 & & & & \\
\hline & & & 0.25 & 34.30 & - & & & \\
\hline \multirow{3}{*}{$\begin{array}{l}\text { Acid washed } \\
\text { glass }^{(1)}\end{array}$} & 7.8 & 21.5 & 0.1 & 15.33 & 17.72 & 0.1 & 14.76 & 16.03 \\
\hline & & & 0.25 & 11.30 & & 0.2 & 8.57 & \\
\hline & & & 0.35 & 15.86 & & 0.25 & 35.16 & \\
\hline \multirow{3}{*}{$\begin{array}{l}\text { Smooth } \\
\text { granite }\end{array}$} & 6.5 & 2.8 & 0.2 & 59.35 & 60.27 & 0.2 & 57.81 & 57.56 \\
\hline & & $6^{(2)}$ & 0.25 & 58.91 & & 0.25 & 52.52 & \\
\hline & & & 0.35 & 53.00 & & 0.35 & 48.34 & \\
\hline \multirow{3}{*}{$\begin{array}{l}\text { Sanded } \\
\text { granite }\end{array}$} & 6.5 & 2.8 & \multirow{3}{*}{\multicolumn{2}{|c|}{ not measured }} & & 0.2 & 52.50 & 54.50 \\
\hline & & $6^{(2)}$ & & & & 0.25 & 55.22 & \\
\hline & & & & & & 0.35 & 54.20 & \\
\hline
\end{tabular}

\begin{tabular}{|c|c|c|c|c|c|c|c|c|}
\hline & 10.0 & 5.5 & 0.2 & 54.64 & 56.64 & \multicolumn{2}{|c|}{ not measured } & \\
\hline$(30: 10)$ & & & 0.35 & 54.71 & & & & \\
\hline Polished & 9.8 & 5.5 & 0.2 & 64.72 & 65.45 & 0.2 & 54.66 & 56.07 \\
\hline epoxy & & & 0.25 & 64.51 & & 0.25 & 55.22 & \\
\hline$(100: 30)$ & & & 0.35 & 61.22 & & 0.35 & 50.35 & \\
\hline \multirow{3}{*}{$\begin{array}{l}\text { Cast epoxy } \\
(100: 30)\end{array}$} & 6.0 & 2.8 & 0.2 & 61.17 & 61.54 & 0.2 & 46.74 & 47.54 \\
\hline & & $6^{(2)}$ & 0.25 & 58.91 & & 0.25 & 43.73 & \\
\hline & & & 0.35 & 53.00 & & & & \\
\hline \multirow{3}{*}{$\begin{array}{l}\text { Roughened } \\
\text { epoxy } \\
(100: 30)\end{array}$} & 10 & 5.5 & 0.2 & 62.96 & 62.64 & \multirow{3}{*}{\multicolumn{2}{|c|}{ not measured }} & \\
\hline & & & 0.25 & 58.91 & & & & \\
\hline & & & 0.35 & 61.22 & & & & \\
\hline
\end{tabular}


The capillary rise measurements from the experiment using the rigorously-cleaned glass (acid wash and baking) resulted in a contact angle of $17.7^{\circ}$. Deviation from the theoretical value of $<10^{\circ}$ may have resulted from the error in the measurements of $h_{t}$ and $b$, heterogeneities on the glass plate surface and error in the value of the surface tension.

The contact angle of deionized water on the 30:10 polished epoxy is about nine degrees less than on the 100:30 epoxy, most likely due to the excess part $B$ in the 30:10 mixture. The contact angle of deionized water on the smooth granite, $60.3^{\circ}$, is much closer to the values measured for 100:30 polished and cast epoxy ( $65.4^{\circ}$ and $61.5^{\circ}$, respectively), than to the value for glass. The slightly roughened epoxy has a contact angle of $62.6^{\circ}$. Surface roughness in the cast epoxy and roughened epoxy resulted in lower contact angles compared to the polished epoxy; one would expect the replica to exhibit contact angles closer to the cast epoxy than the polished epoxy.

The presence of Liquitint in the water had a smaller effect on the contact angle on glass and granite, compared to its effect on the contact angle on epoxy. The addition of $0.4 \%$ Liquitint to deionized water resulted in almost a ten degree decrease in contact angle on polished 100:30 epoxy, and a slightly greater decrease in contact angle on the cast epoxy. These results indicate that Liquitint has a stronger affinity for the epoxy than for the granite.

To test for the presence of contamination on the smooth granite surface affecting the contact angle, capillary rise was also measured on the smooth granite after light sanding of the surface with fine sand paper. The contact angle of water with Liquitint on the sanded granite is only three degrees lower than on the smooth granite.

The contact angle of water on epoxy was also measured by capillary rise in an epoxy block with circular holes of $0.86 \mathrm{~mm}, 1.47 \mathrm{~mm}, 1.98 \mathrm{~mm}, 5.05 \mathrm{~mm}$ and $10.1 \mathrm{~mm}$ diameter. The initially dry block was placed in a shallow water bath and allowed to equilibrate overnight. The resulting contact angle was $64.4^{\circ}$, which is very close to the value measured from the receding meniscus on the polished 100:30 epoxy of $65.4^{\circ}$, but lower than the value of $72.2^{\circ}$ measured for the advancing meniscus on the polished 100:30 epoxy (Table A4). The holes in the epoxy block were not rolled and polished, therefore there was some surface roughness that caused the water to rise higher and produce the lower contact angle. 


\begin{tabular}{|c|c|c|}
\hline & Receding & Advancing \\
\hline Solid & $\theta$ fr $h_{t}$ vs. $1 / b$ & $\theta$ fr $h_{t}$ vs. $1 / b$ \\
\hline glass & 27.14 & 50.49 \\
\hline $\begin{array}{l}\text { polished epoxy } \\
(100: 30)\end{array}$ & 65.45 & 72.21 \\
\hline $\begin{array}{l}\text { cast epoxy } \\
(100: 30)\end{array}$ & 61.54 & 61.38 \\
\hline granite & 60.27 & 69.29 \\
\hline
\end{tabular}

The capillary rise of a rough-walled rock fracture and its epoxy replica was also measured. The rock and epoxy replica were cut to squares of $7.5 \mathrm{~cm}$ sides. The total thickness of the rock and replica were the same. The initially dry rock and replica were placed side by side between two lucite blocks. The lucite, rock, and replica were sandwiched together using two large clamps, and placed in a shallow water bath (less than $1 \mathrm{~cm}$ deep), as in Figure A1, and allowed to equilibrate overnight. The spacing between the two lucite blocks on all sides was the same to the $0.05 \mathrm{~mm}$ precision of the caliper. The capillary rise of the advancing meniscus on the rough walled rock was measured to be around 2-2.5 cm, except for a portion on the right hand side of the fracture where the water rose to the top of the rock. The water also rose about $2-2.5 \mathrm{~cm}$ in the middle portion of the epoxy replica, and the water rose about $5 \mathrm{~cm}$ on the left hand edge and $3.5 \mathrm{~cm}$ on the right hand edge. The capillary rise was also measured using the granite rock as one half of the fracture and its epoxy mate as the other half. The capillary rise was measured to be about $1.5 \mathrm{~cm}$, which is slightly lower than what was measured using the two halves of the fracture made out of the same material. 


\section{Summary and Conclusions}

Water-air-solid contact angles derived from capillary rise measurements of a receding meniscus on smooth granite, 100:30 epoxy, 30:10 epoxy and glass surfaces, all cleaned by the same procedure, were $60^{\circ}, 65^{\circ}, 57^{\circ}$ and $27^{\circ}$, respectively. The contact angle on acid-washed glass by the same method was $18^{\circ}$. Lightly sanding the surface of the epoxy caused a $2^{\circ}$ reduction in contact angle compared to the smooth epoxy. In all samples, the contact angle derived from the capillary rise of an advancing meniscus was higher than for a receding meniscus. The addition of $0.4 \%$ Liquitint $^{\circledR}$ reduced the surface tension of the deionized water to $64.4 \mathrm{mN} \mathrm{m}^{-1}$ and caused a decrease in the contact angle on the glass and granite by approximately $1^{\circ}$ to $2^{\circ}$ and by $9^{\circ}$ to $14^{\circ}$ on the epoxy. Sanding the smooth granite surface to remove any surface contamination caused a $3^{\circ}$ reduction in contact angle. The capillary rise of an advancing meniscus in a natural granite fracture, as compared with its epoxy replica, was the same in the middle of the sample and higher in the rock along the edges.

The relatively large contact angles measured on the smooth granite surface is surprising in light of the conventional assumption of zero contact angle for silica mineral surfaces, however intermediate or neutral wettability can occur on silica mineral surfaces following exposure to contaminants. Photographs of water drop profiles on smooth solid surfaces agreed qualitatively with the capillary rise data, indicating that the contact angle of water on our smooth granite sample is closer to the contact angle on epoxy rather than glass. However, the profile of a water drop on the granite fracture was significantly flatter than the water drop profile on its epoxy replica, perhaps due to imbibition driven by smallscale roughness and near-surface porosity. These results indicate that in using epoxy replicas to simulate water percolation in natural rock fractures, the system represented is one of neutral wettability and that the impermeable nature of the replica may have a significant effect on infiltration behavior. 


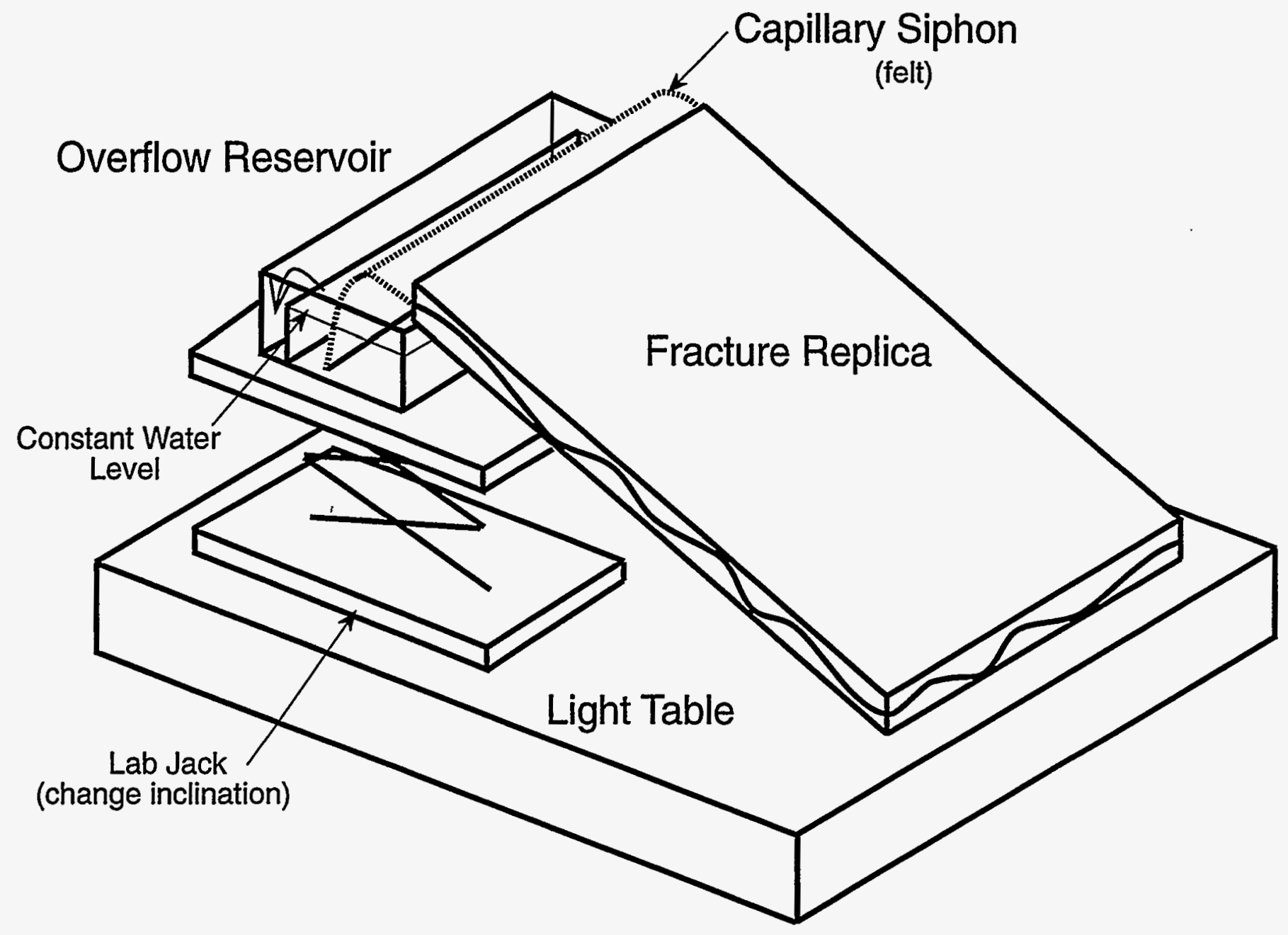

Figure 1. Schematic representation of flow-visualization experiments in fracture replicas 


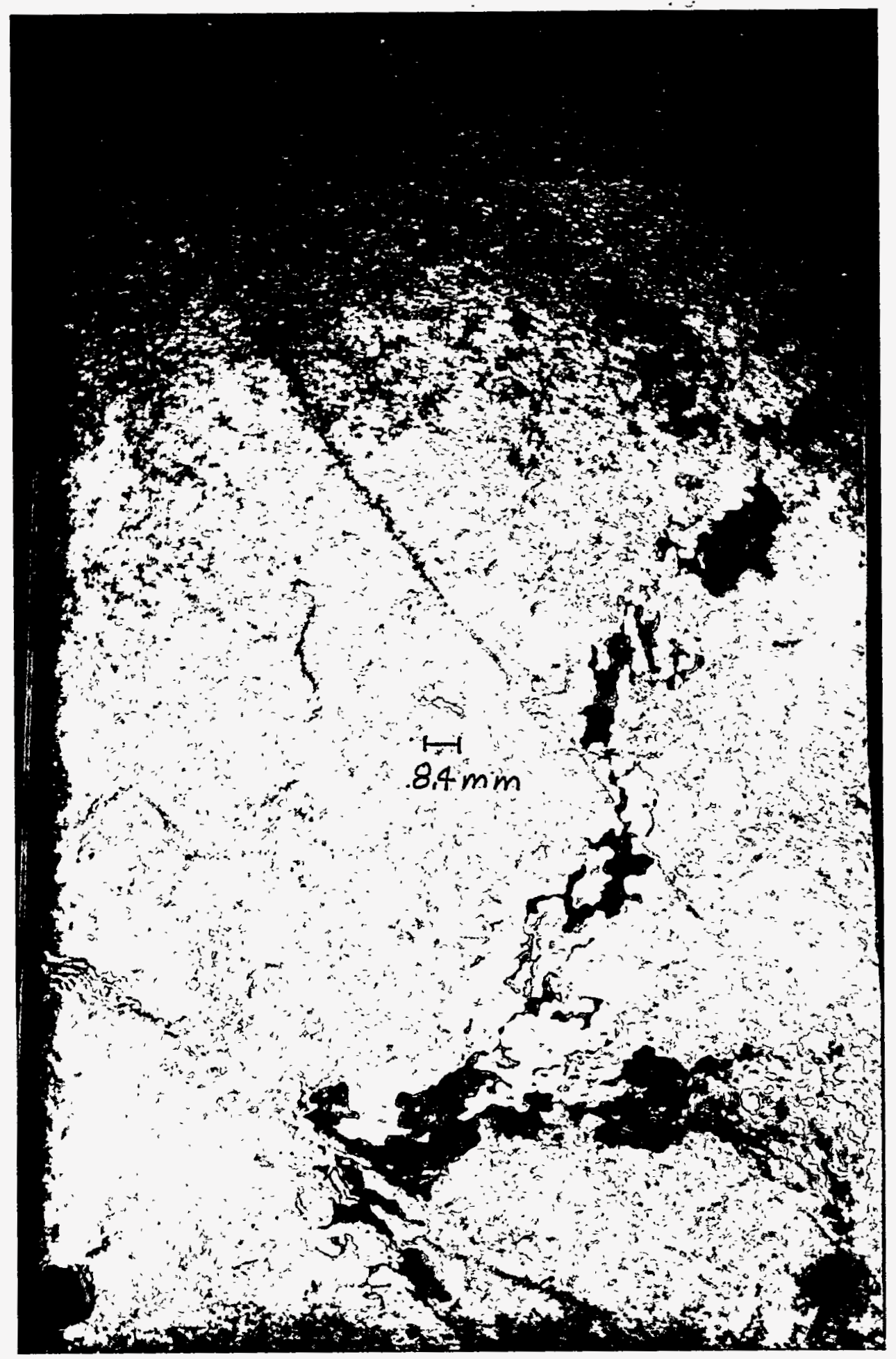

Figure 2. Full view of liquid distribution in series $1 \mathrm{~A}, \theta=20^{\circ}, \mathrm{P}_{\mathrm{w}}=-1.8 \mathrm{~cm}$ XBD 9604-01588.BIM 


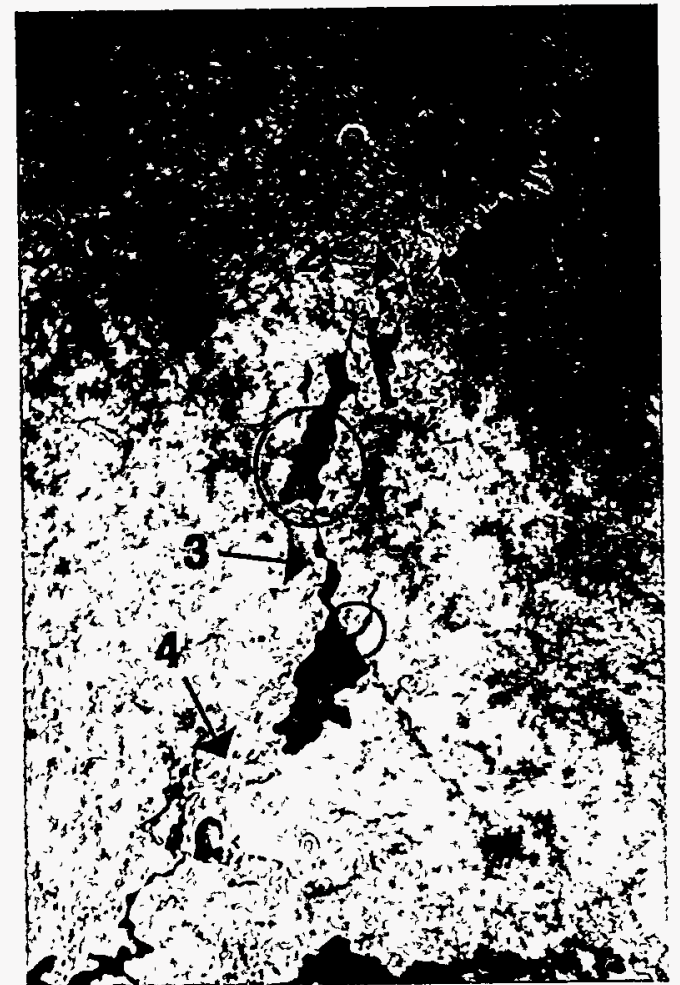

(a) $t=15: 00$

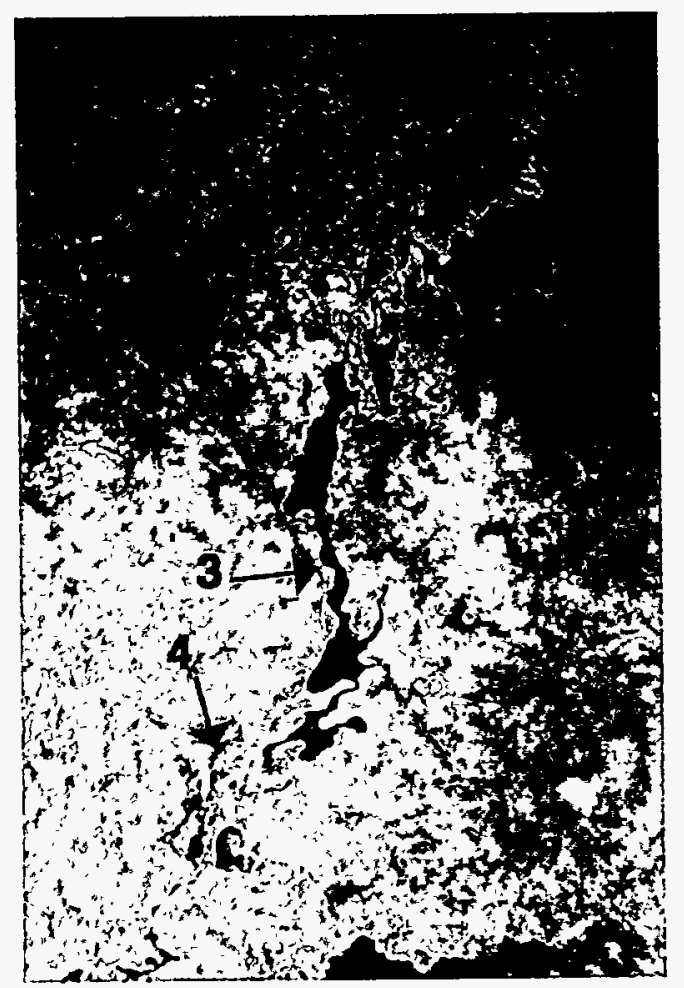

(c) $t=15: 32$

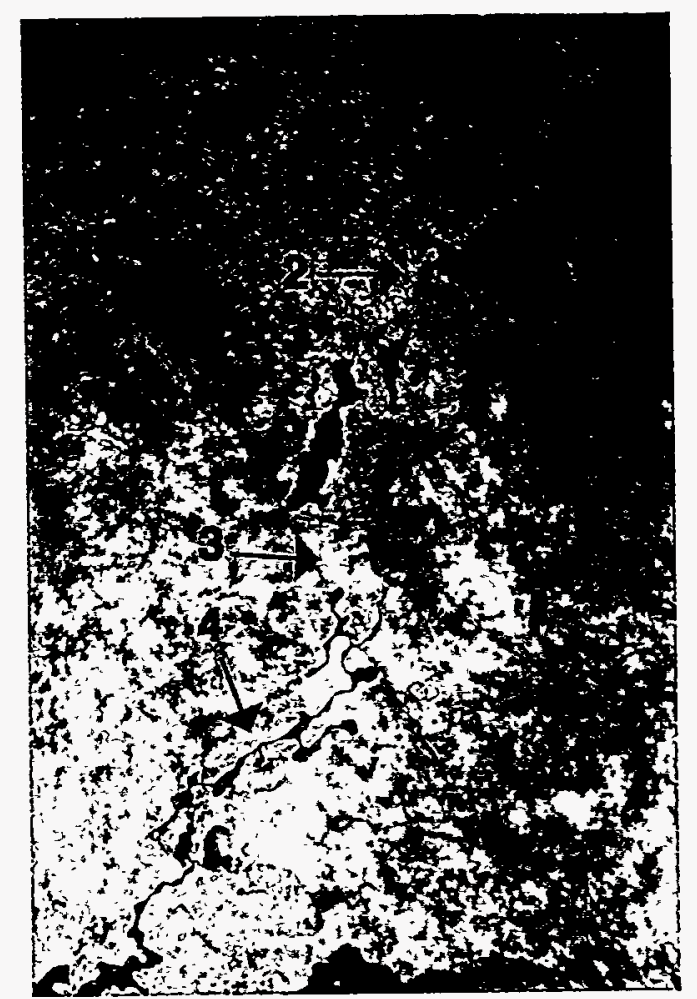

(b) $t=15: 20$

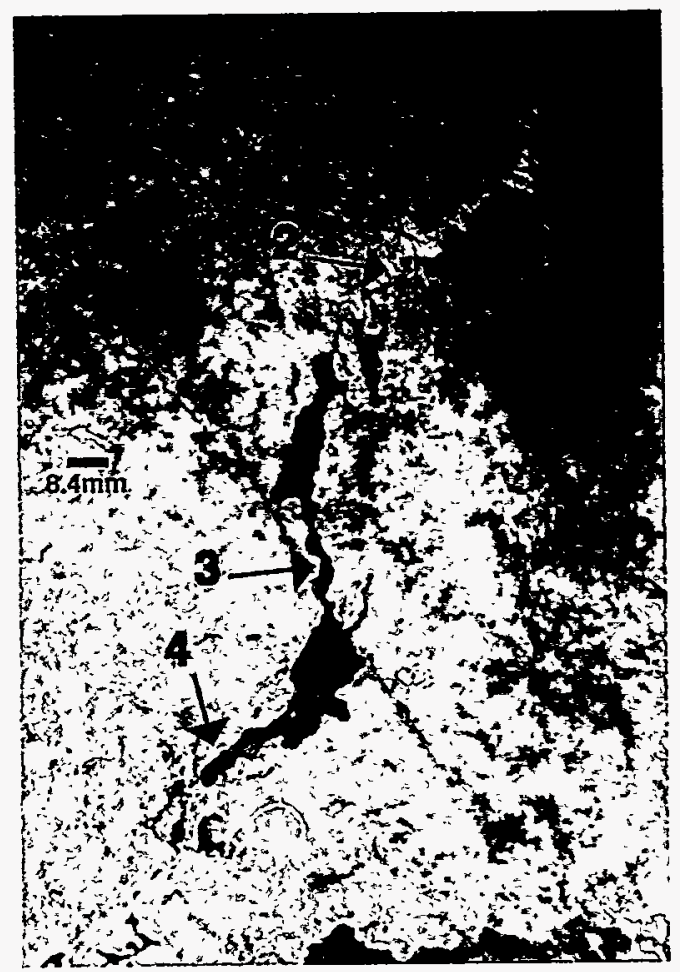

(d) $\mathrm{t}=15: 44$

Figure 3. Liquid distribution during percolation, Series $1 \mathrm{~A}, \theta=20^{\circ}, \mathrm{P}_{\mathrm{w}}=-1.8 \mathrm{~cm}$. Arrows indicate location of thread-snapping. Circles are for comparison with Figure 4(a). 


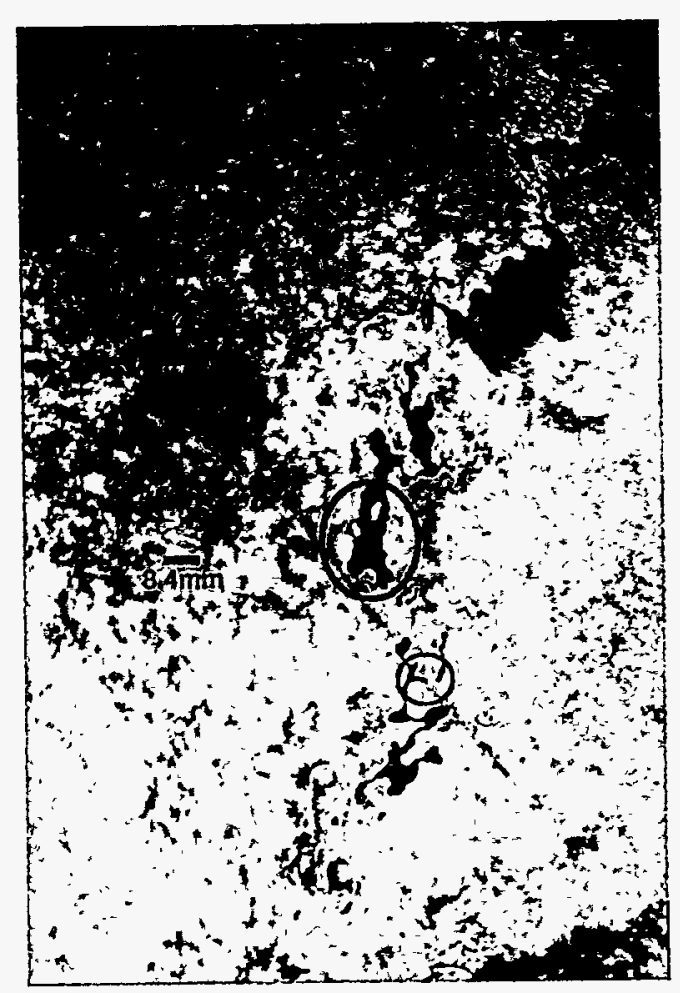

(a) $t=14: 32$

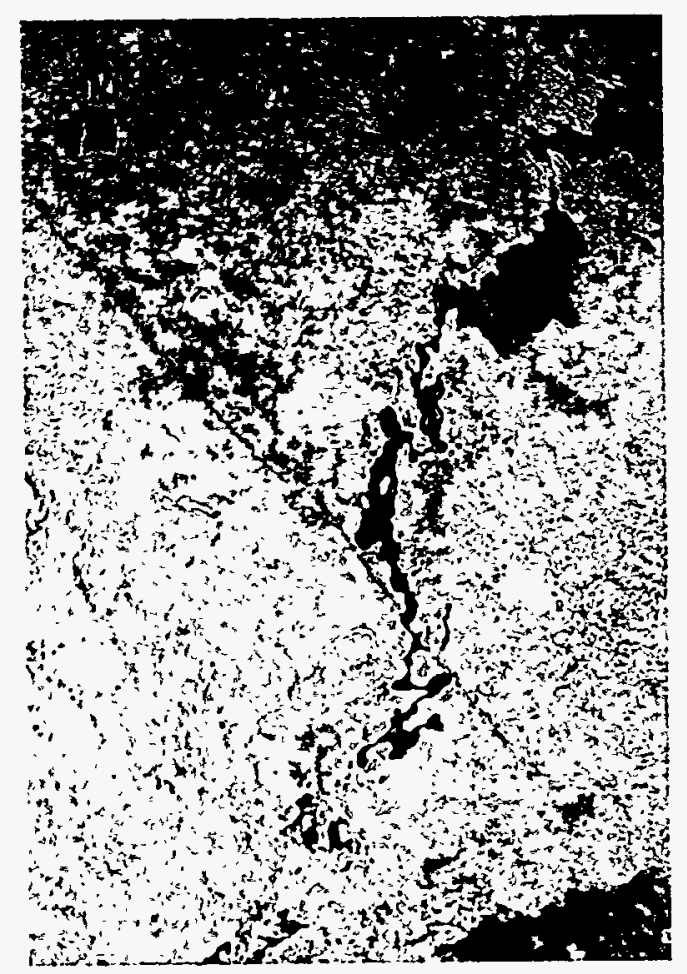

(c) $t=14: 46-1$

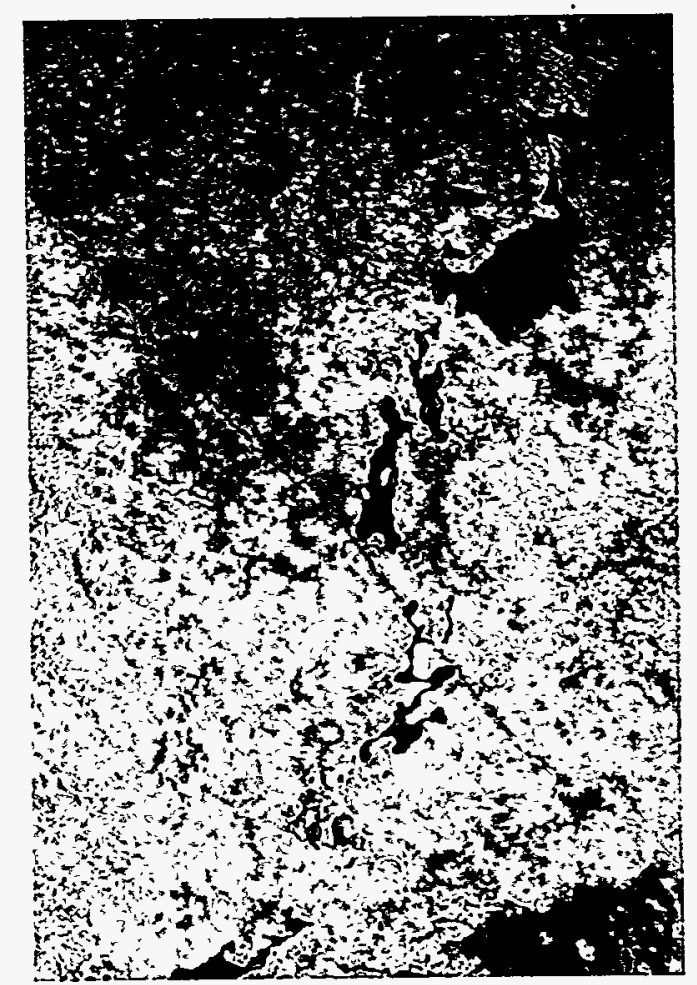

(b) $t=14: 39$

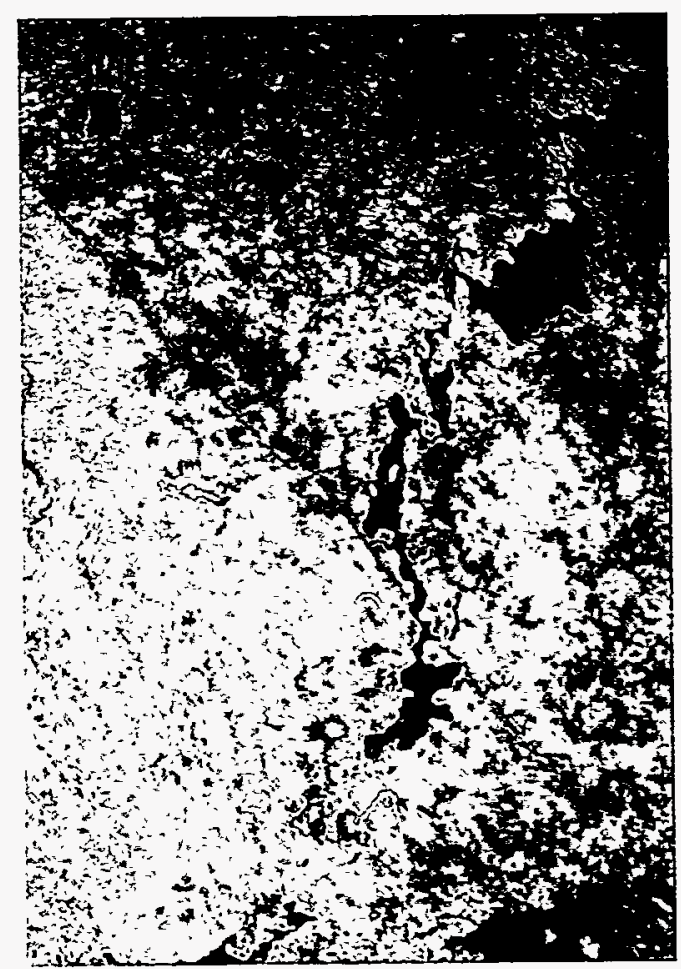

(d) $t=14: 46-2$

Figure 4. Liquid distribution during percolation, Series $1 \mathrm{~A}, \theta=35^{\circ}, \mathrm{P}_{w}=-1.8 \mathrm{~cm}$. Circles indicate liquid-filled regions that have drained relative to Figure 3. (c)-(d) changing liquid distribution over time-scale of seconds. 


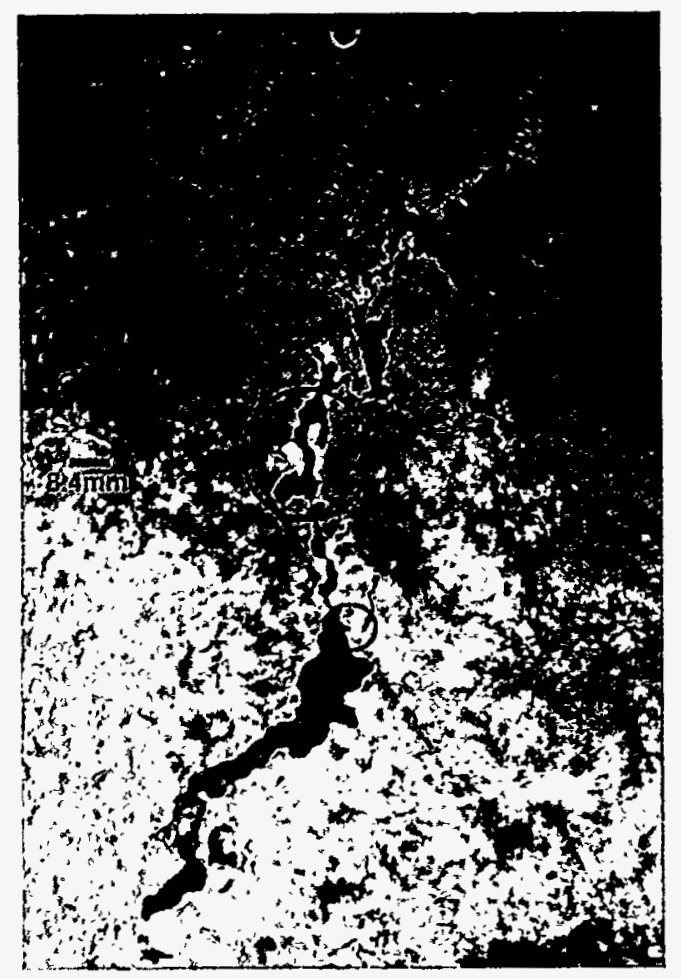

(a) $t=14: 50-1$

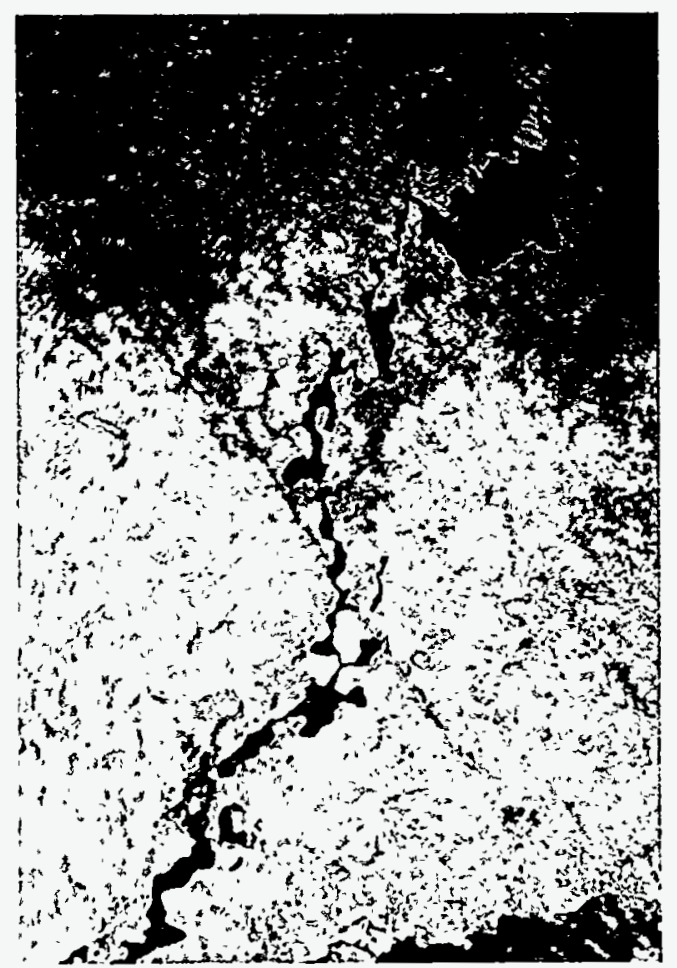

(c) $\mathrm{t}=14: 50-3$

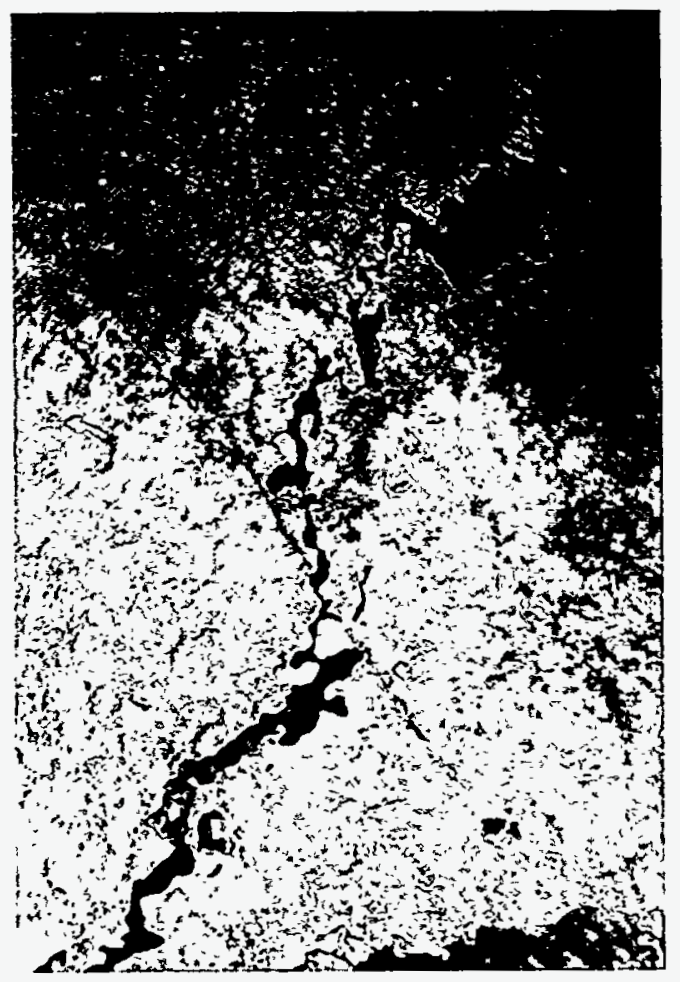

(b) $t=14: 50-2$

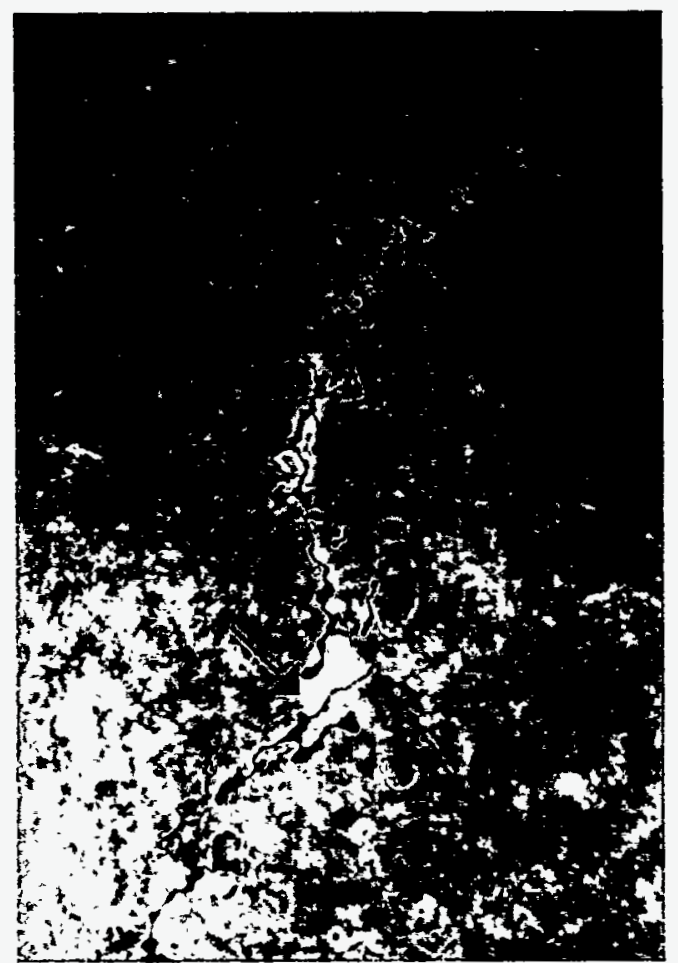

(d) $t=14: 52$

Figure 5. Liquid distribution during percolation, series $1 \mathrm{~A}, \theta=40^{\circ}, \mathrm{P}_{\mathrm{w}}=-1.8 \mathrm{~cm}$. Circle indicates liquid-filled region that has drained relative to Figure 4. (a)-(c) changing liquid distribution over a time-scale of seconds. (d) liquid distribution two minutes later. 

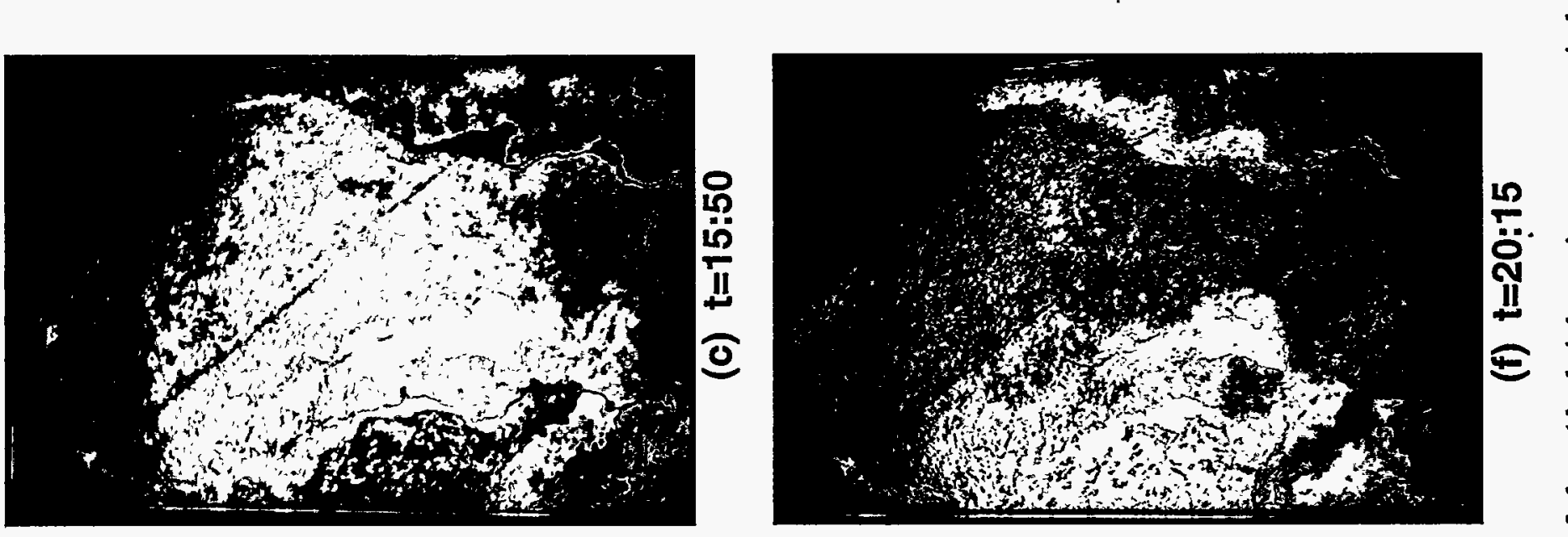

.
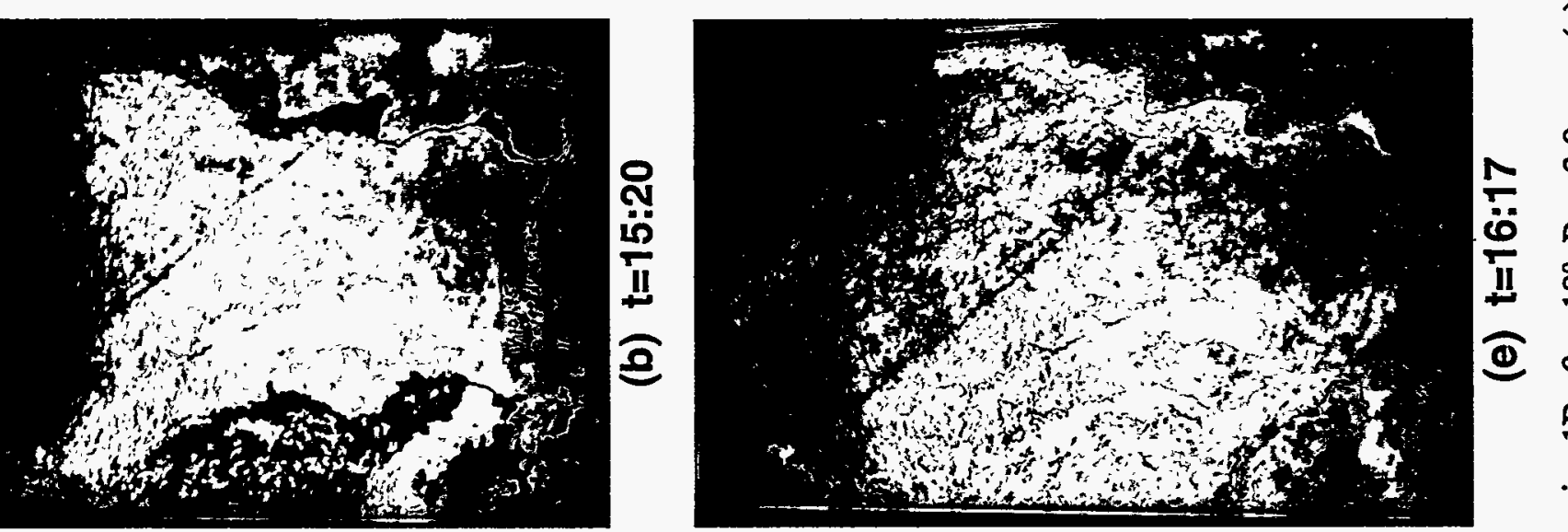


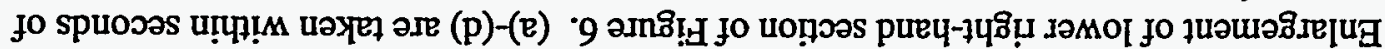

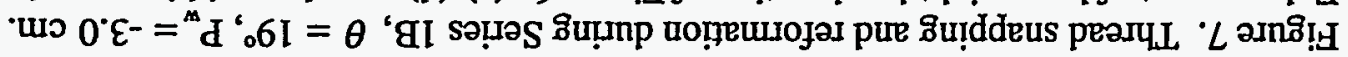

$7-00: \varepsilon 1=1(p)$

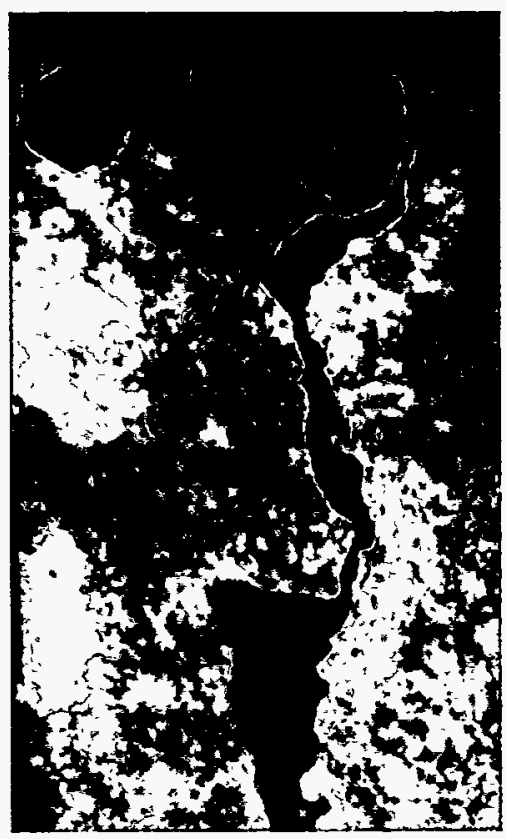

$Z-00: \varepsilon L=l(q)$

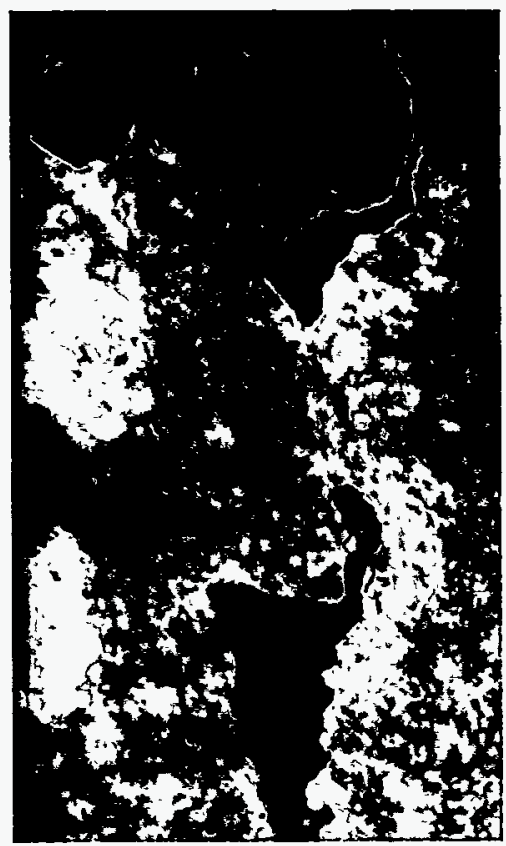

$\varepsilon-00: \varepsilon L=l(0)$

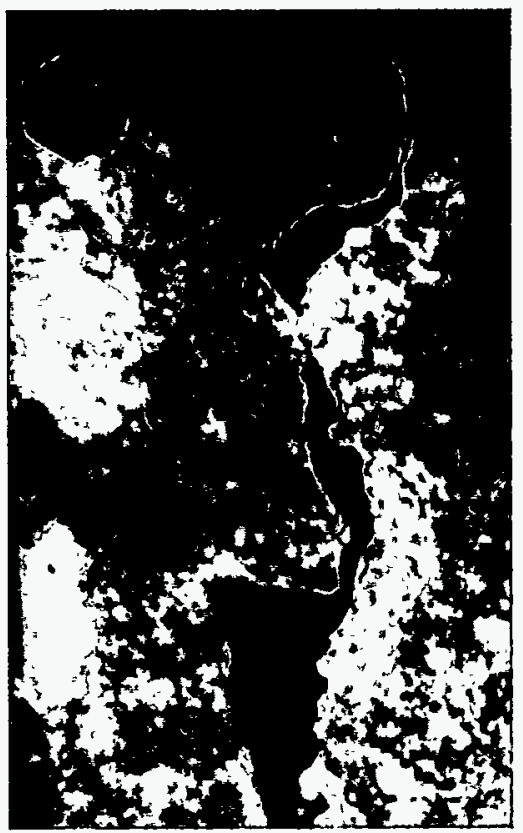

$L-00: \varepsilon l=l(e)$

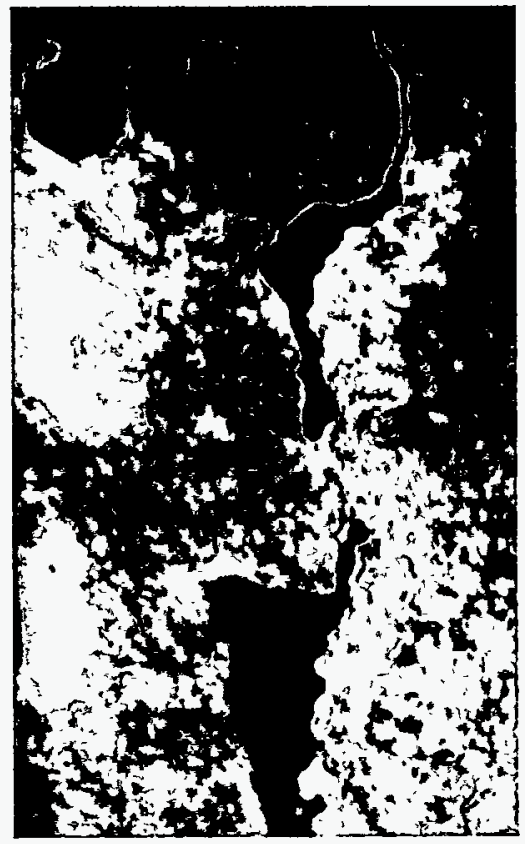




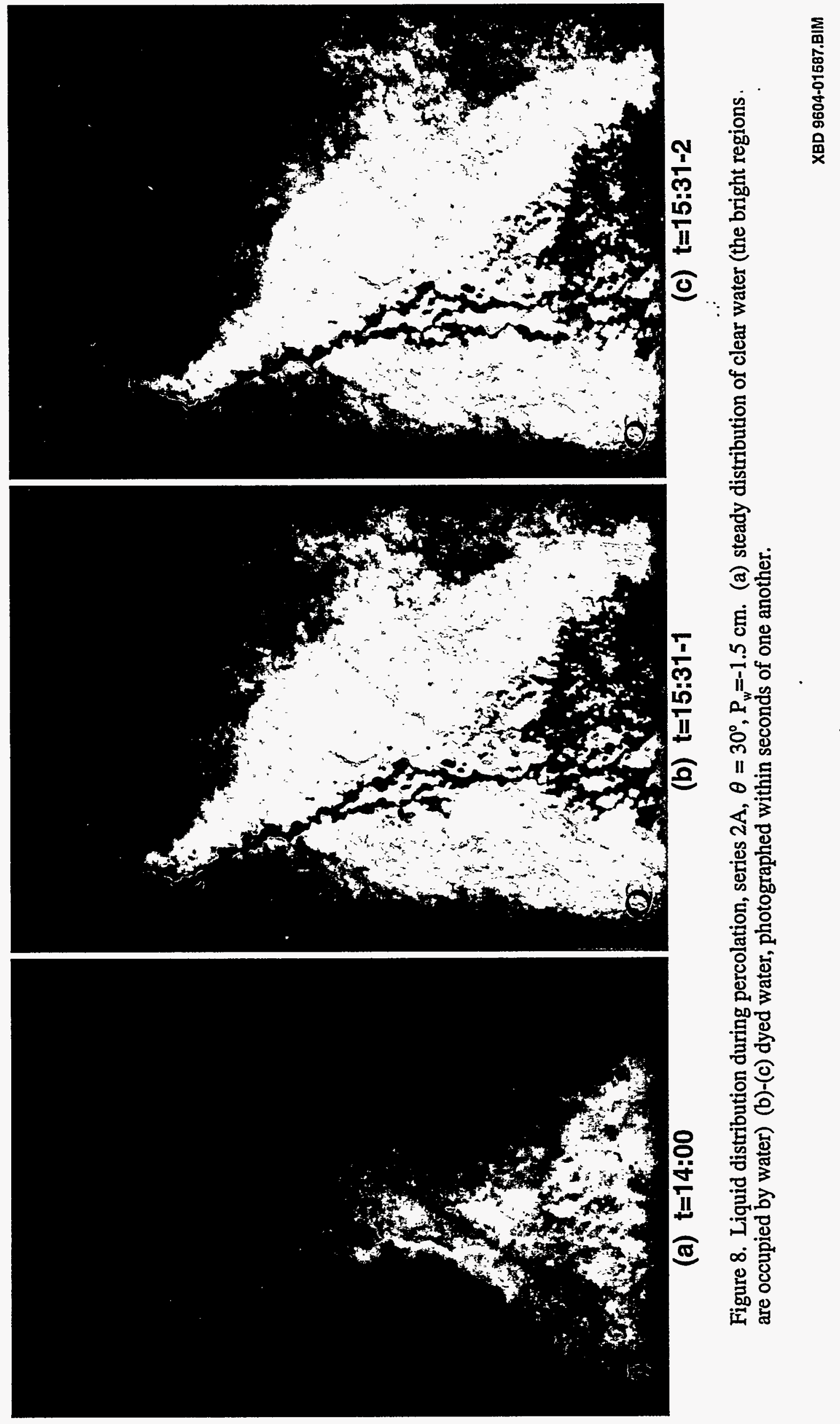


(B) 01

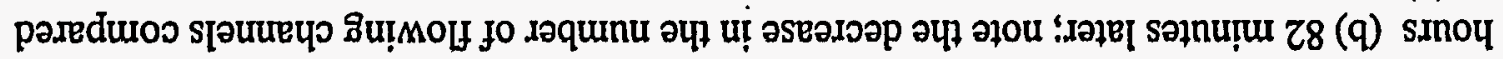

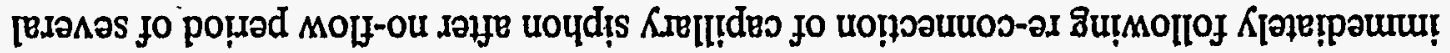

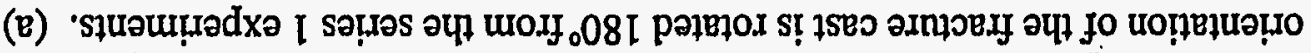

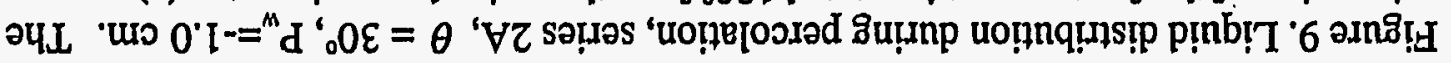

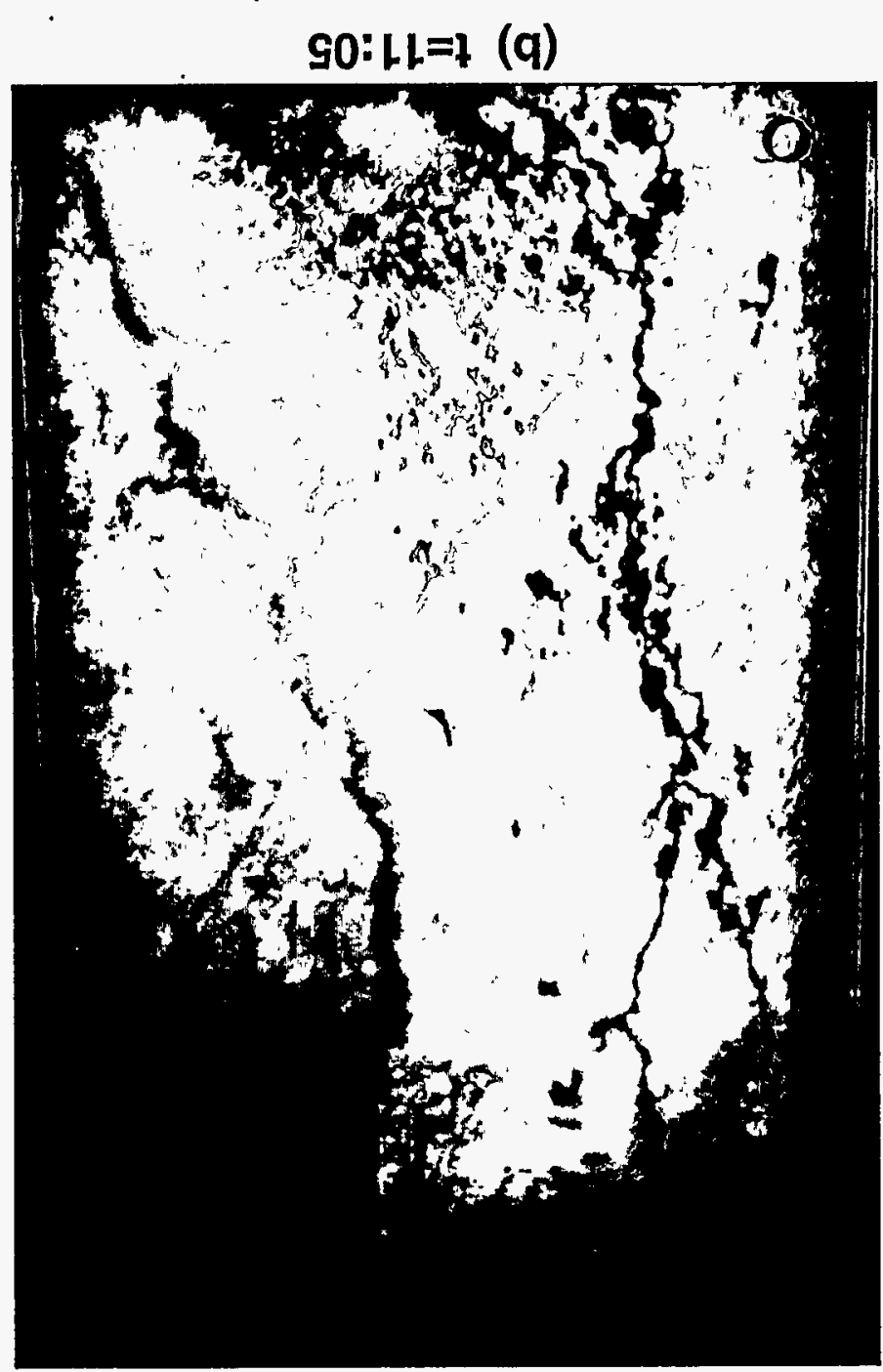

$\varepsilon t: 6=l(\varepsilon)$

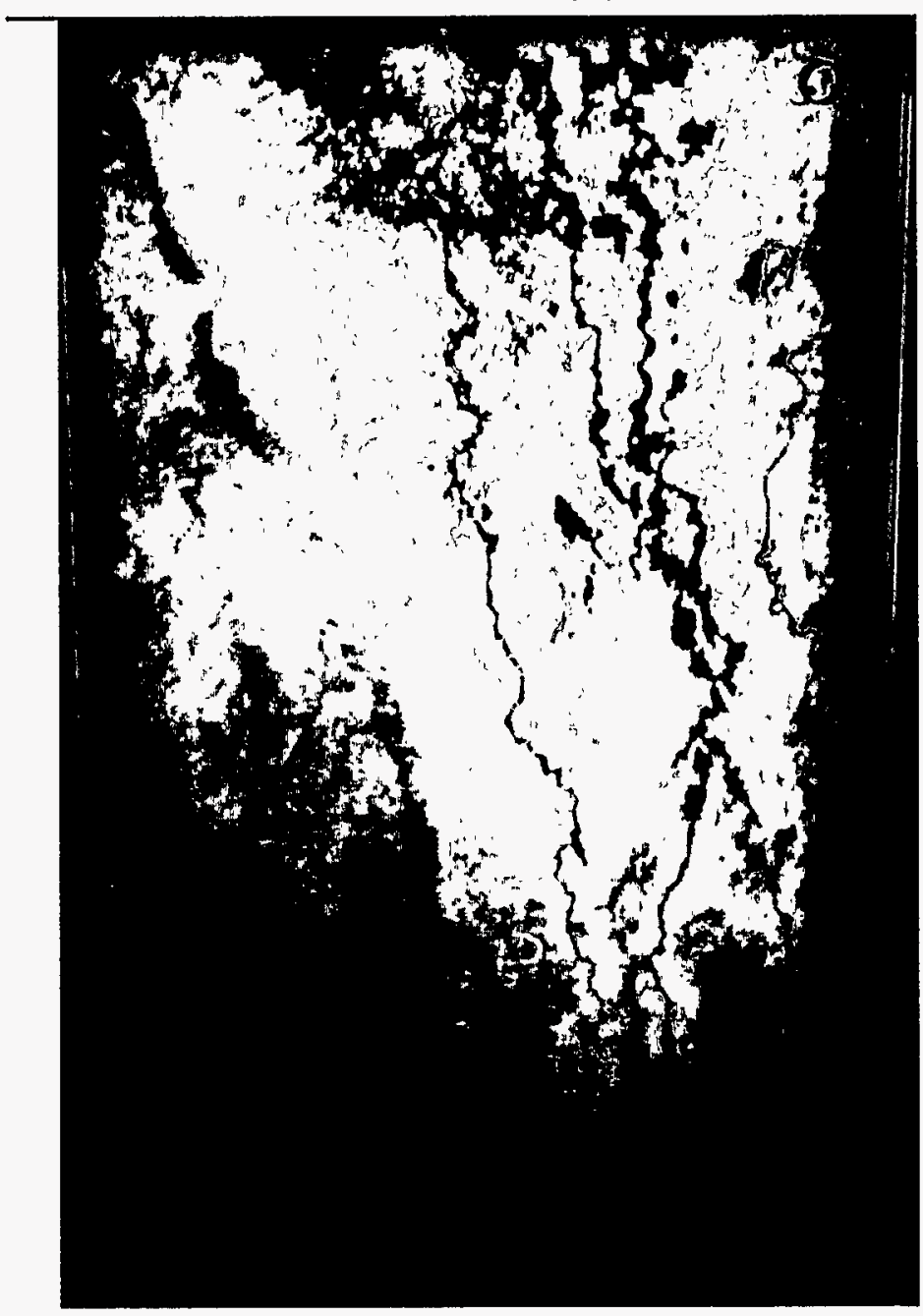




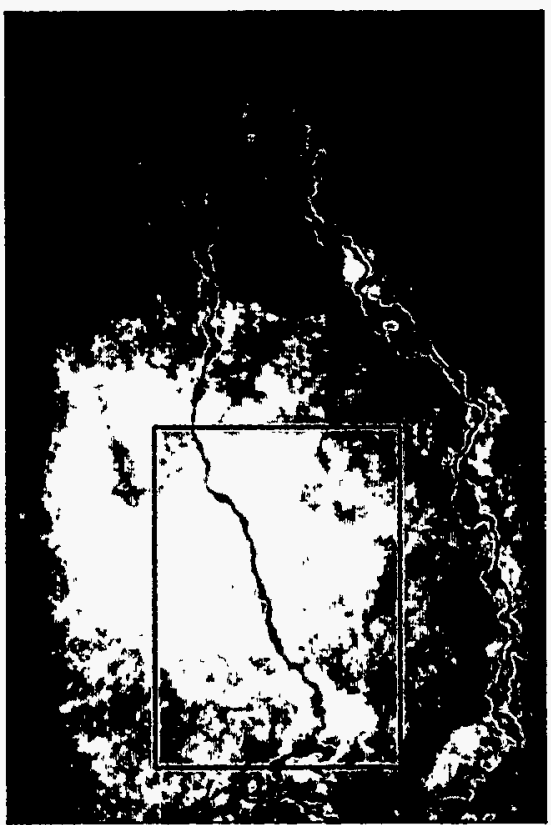

(a) $\mathrm{t}=17: 40$

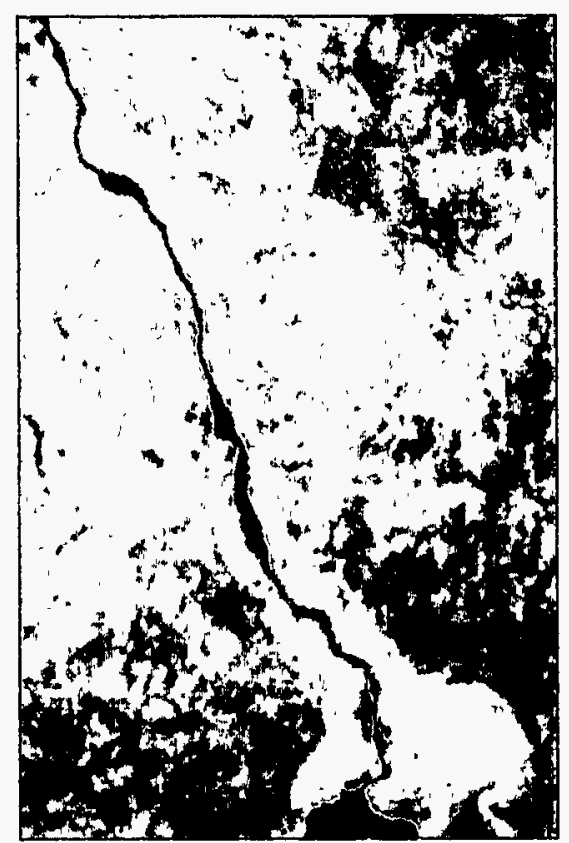

(d) $\mathrm{t}=17: 45-3$

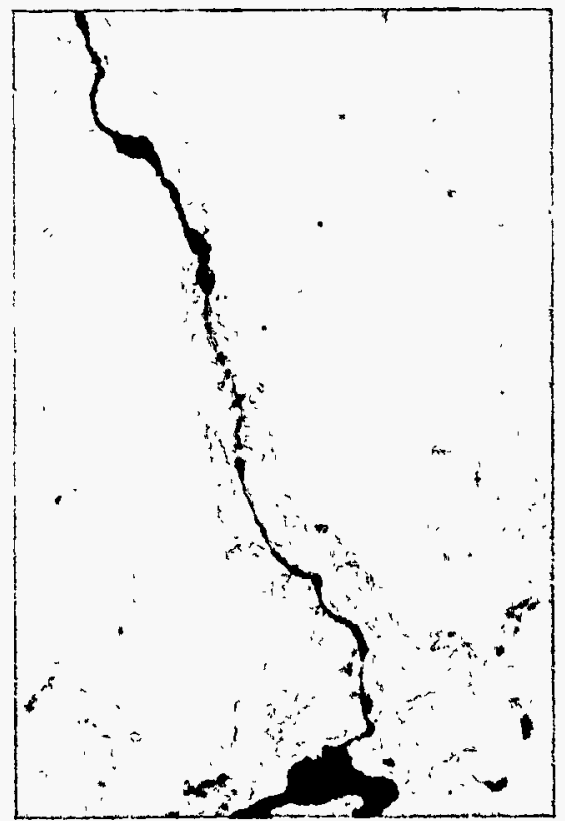

(b) $\mathrm{t}=17: 45-1$

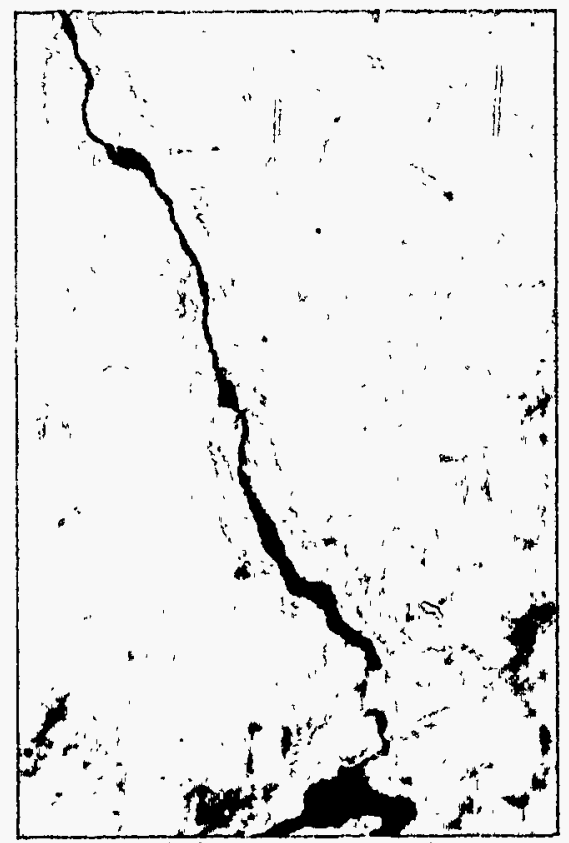

(e) $t=17: 45-4$

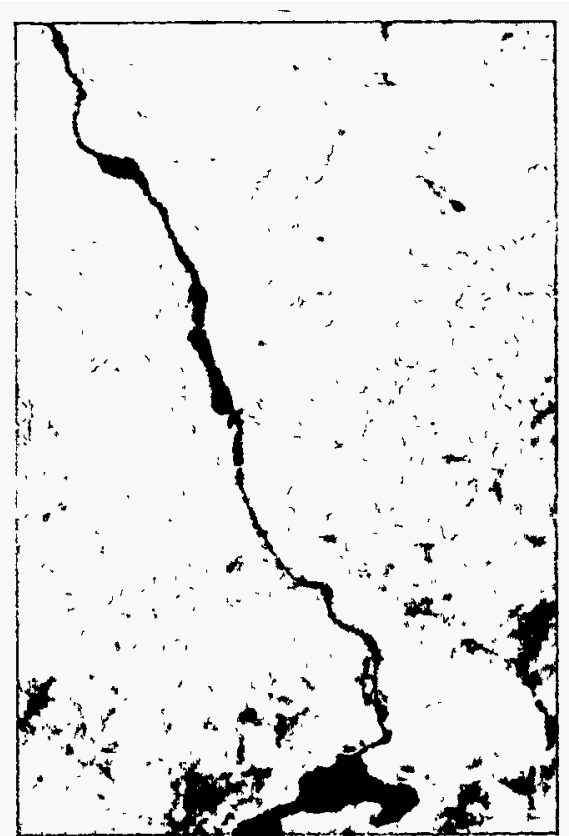

(c) $\mathrm{t}=17: 45-2$

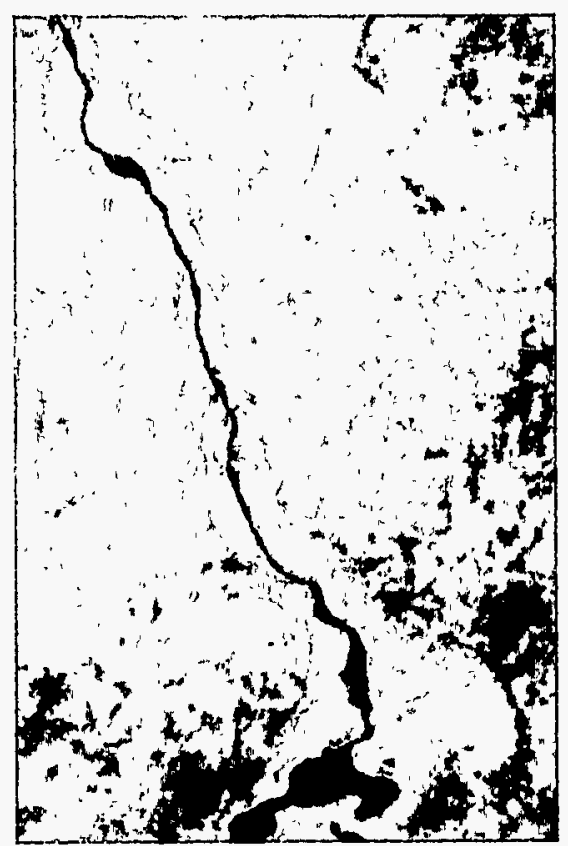

(f) $t=17: 45-5$

Figure 10. Liquid distribution during percolation, Series $2 \mathrm{~B}, \theta=30^{\circ}, \mathrm{P}_{\mathrm{w}}=-2.3 \mathrm{~cm}$. The orientation of the fracture cast is rotated $180^{\circ}$ from the Series $2 A$ experiments. (a) full-view of fracture, box indicates area enlarged in (b)-(f). (b)-(f) sequence of thread-snapping and reformation in lower left-hand channel, over time-scale of seconds. 


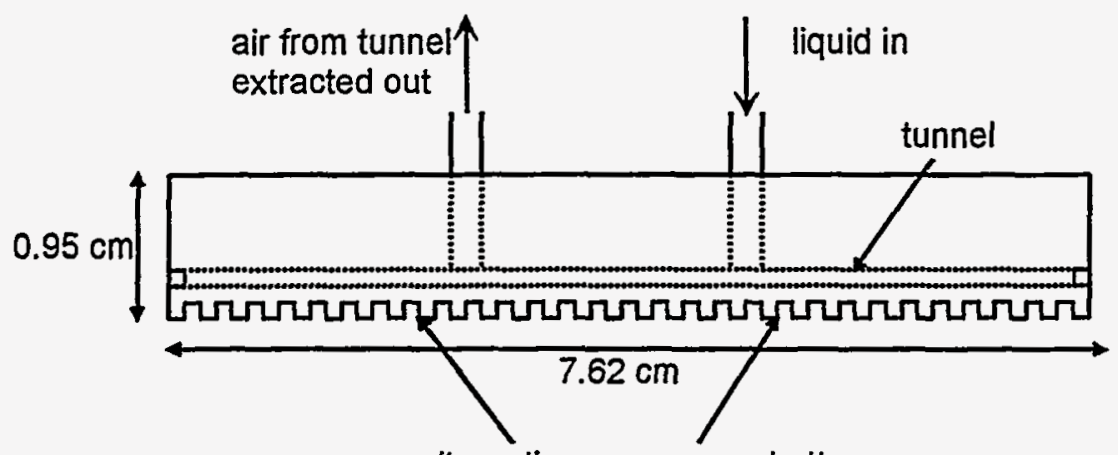

alternating grooves on bottom

for air entry into and out of fracture

(a) front view of ceramic porous plate

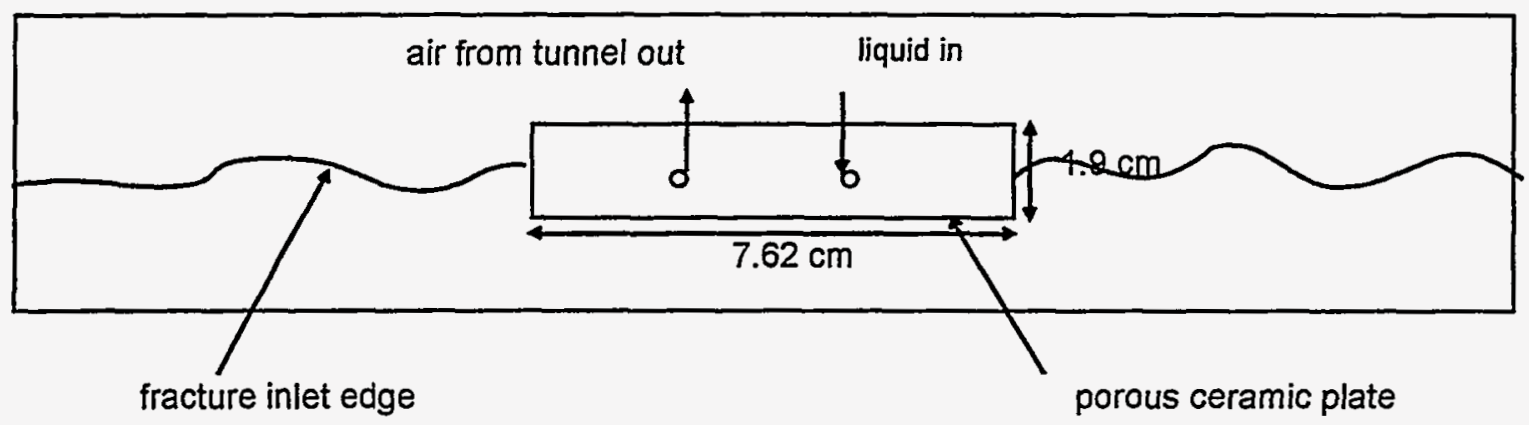

(b) inlet ceramic plate placed in opening along fracture edge

Flgure 11: Schematic of inlet ceramic plate 


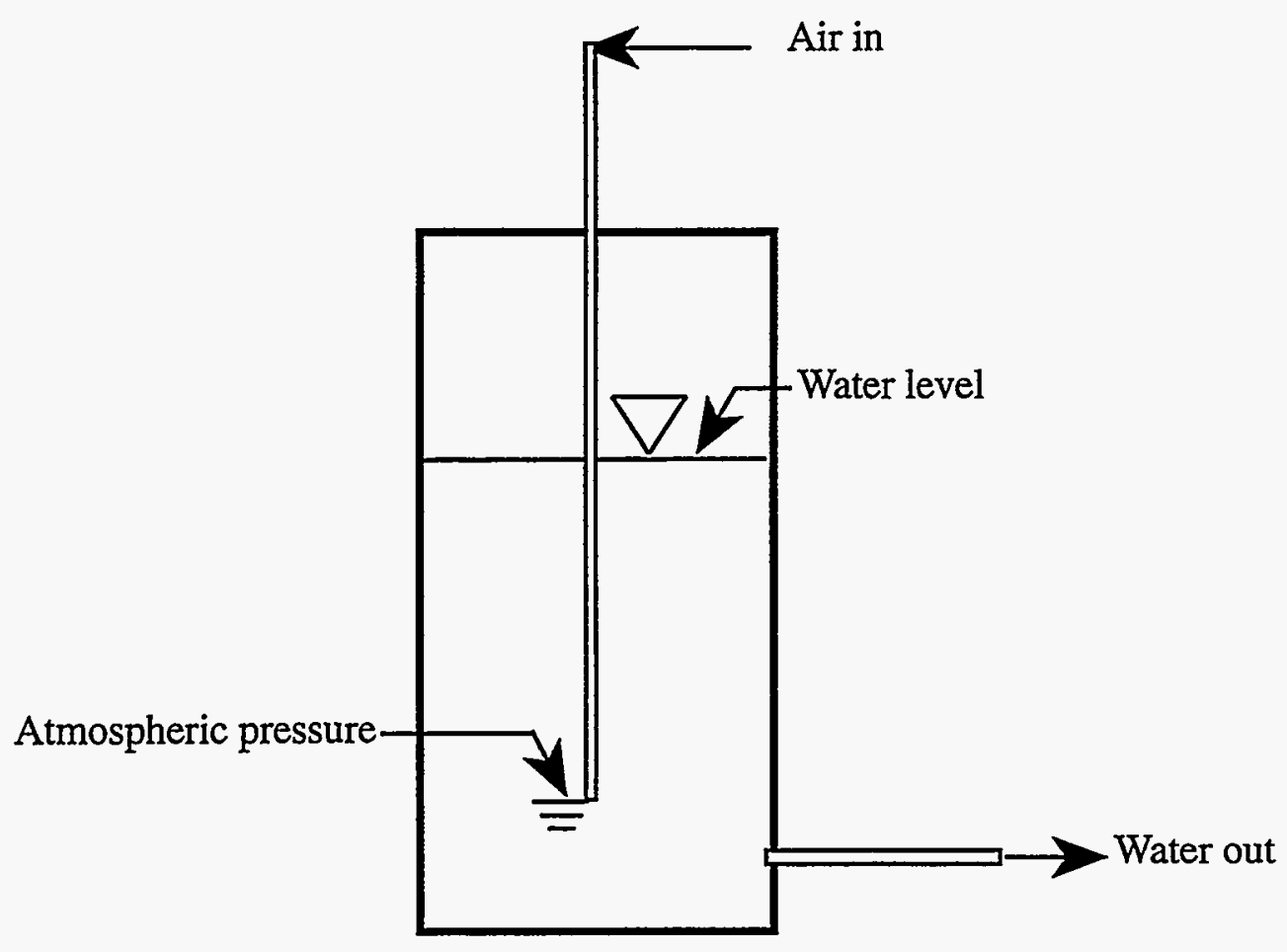

Figure 12. Mariotte bottle for constant head with gravitational flow 


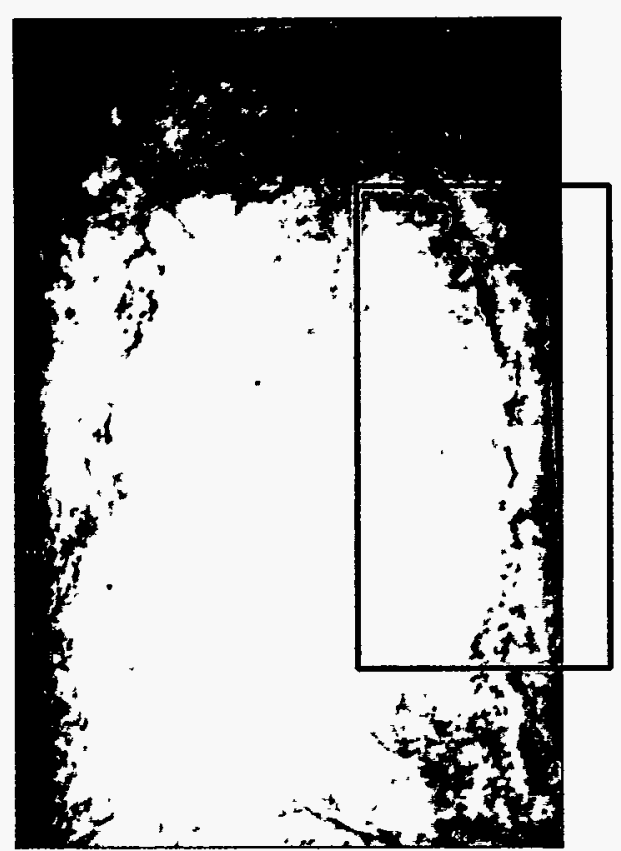

(a) $t=12: 39-1$

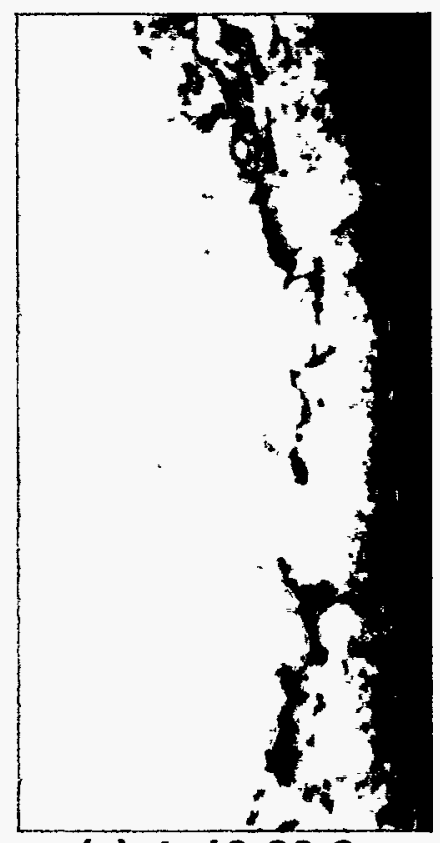

(c) $t=12: 39-3$

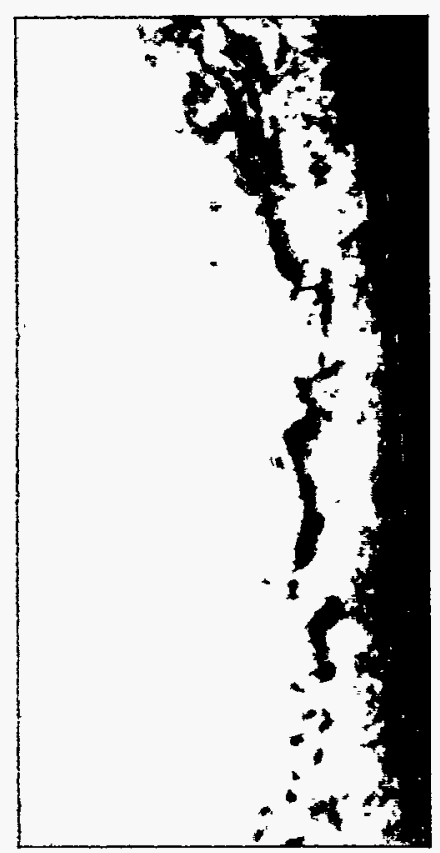

(b) $\mathrm{t}=12: 39-2$

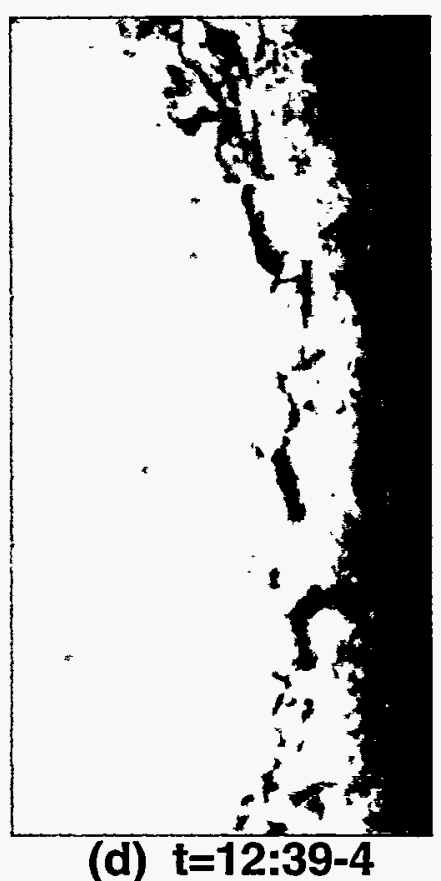

(d) $t=12: 39-4$

Figure 13. Liquid distribution during percolation, Series $2 \mathrm{C}, \theta=70^{\circ}, \mathrm{P}_{\mathrm{w}}=-3.5 \mathrm{~cm}$. The fracture orientation is the same as in series $2 \mathrm{~B}$. Liquid channels appear disconnected, but water is flowing through the right channel as indicated by the change in distribution with time. Photographs are within seconds of one another. (b)-(d) are enlargements of boxed area in (a). 


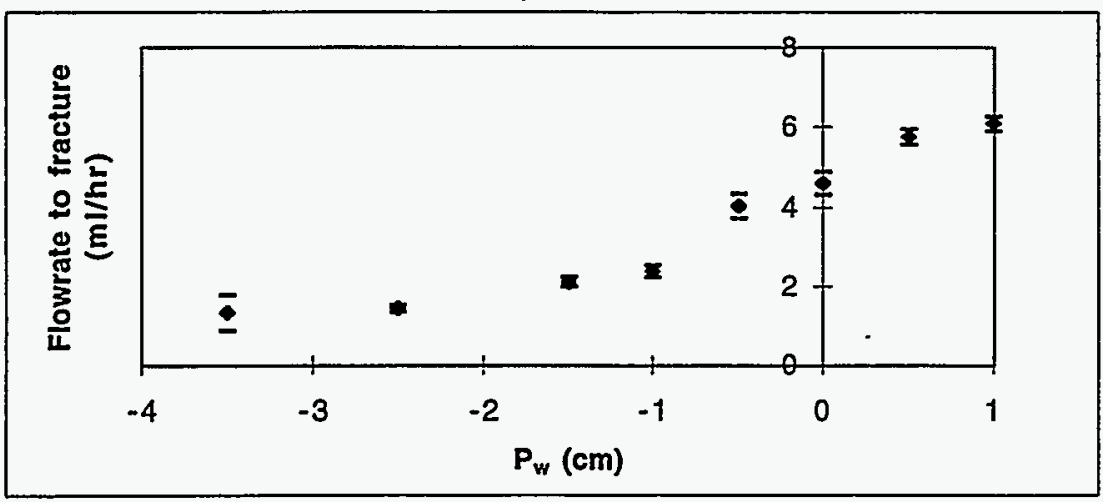

(a) Flowrate into fracture (bars are plus and minus one standard deviation)

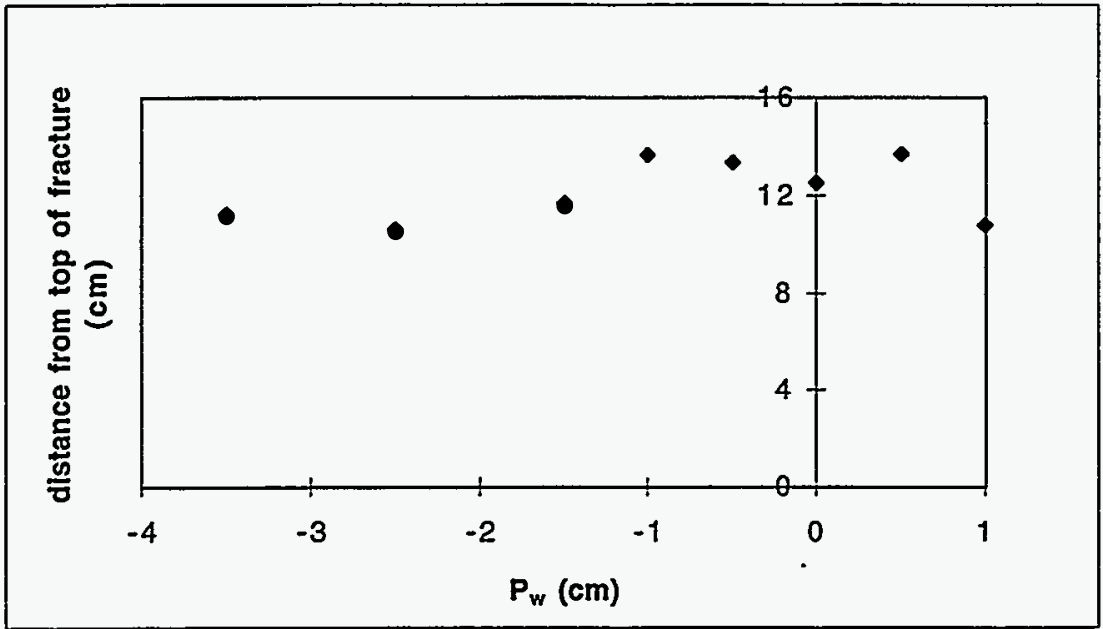

(b) Location of thread-snapping in right channel

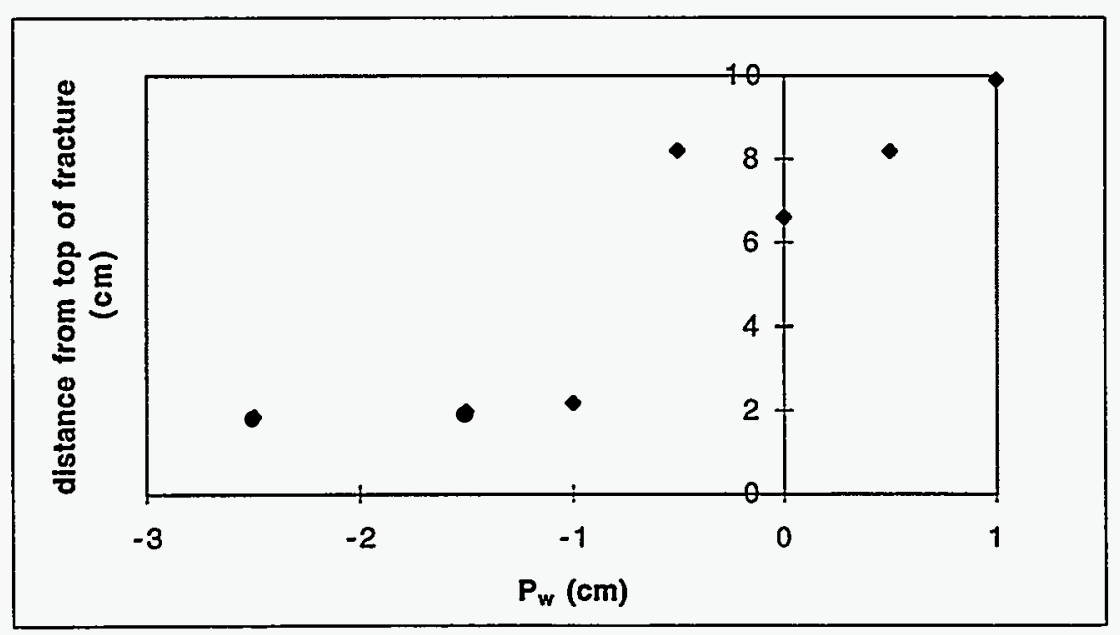

(c) Location of thread-snapping in left channel

Figure 14. Flow behavior as a function of inlet pressure head $\left(\mathrm{P}_{\mathrm{w}}\right)$ for series $2 \mathrm{C}, \theta=70^{\circ}$ 


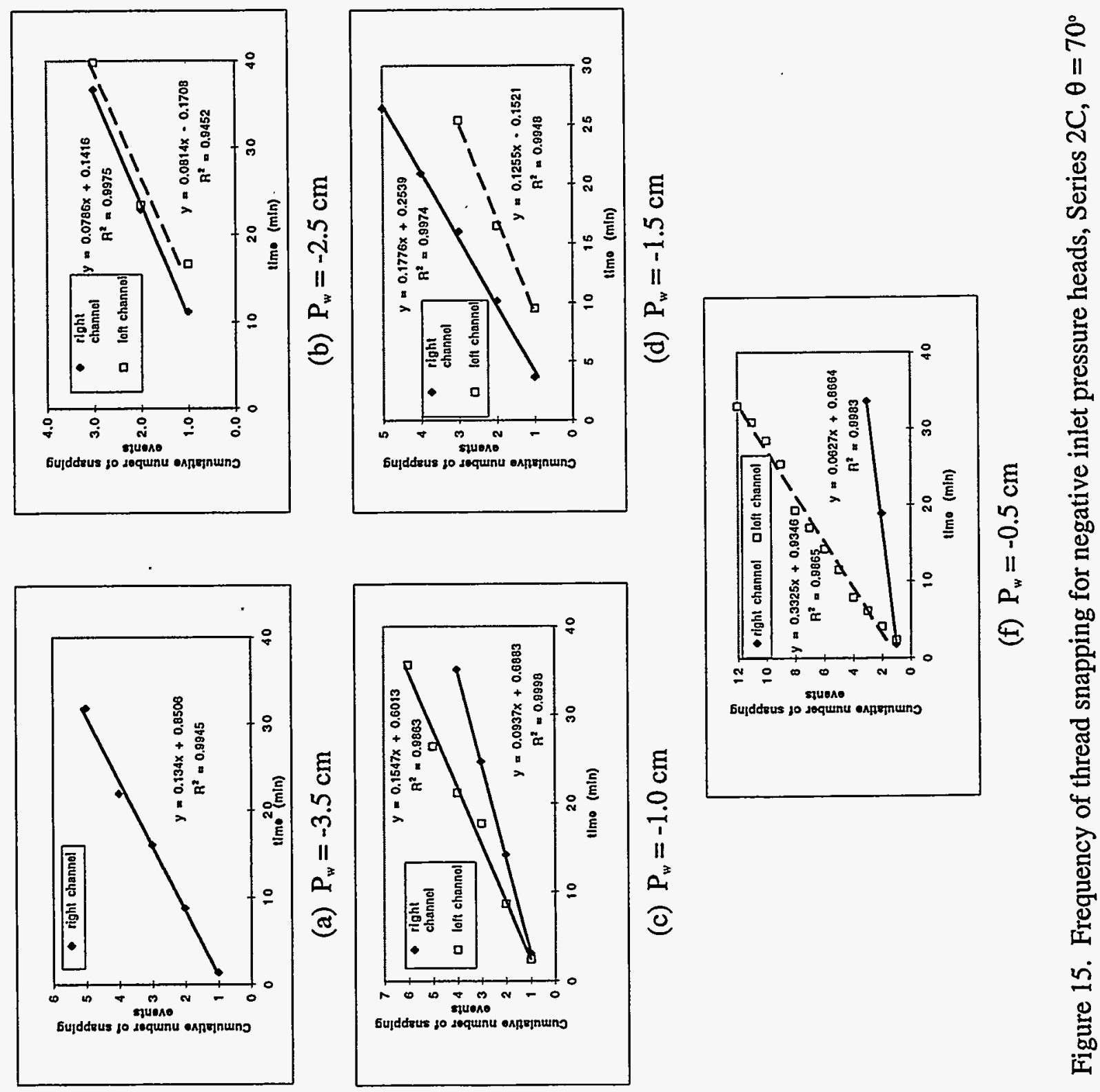



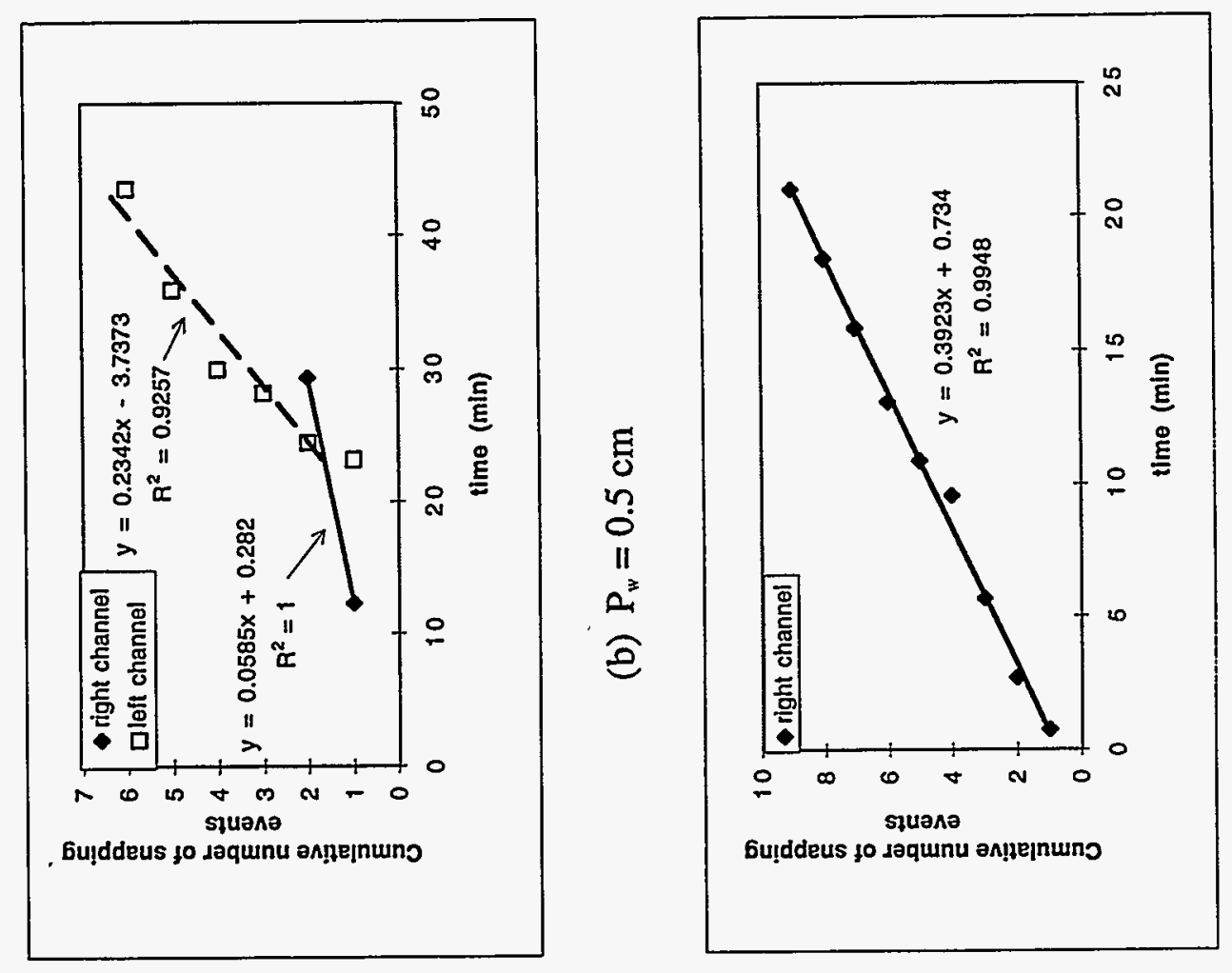

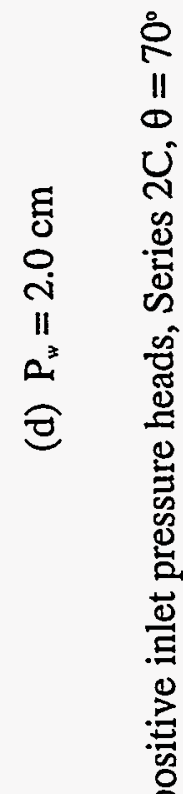
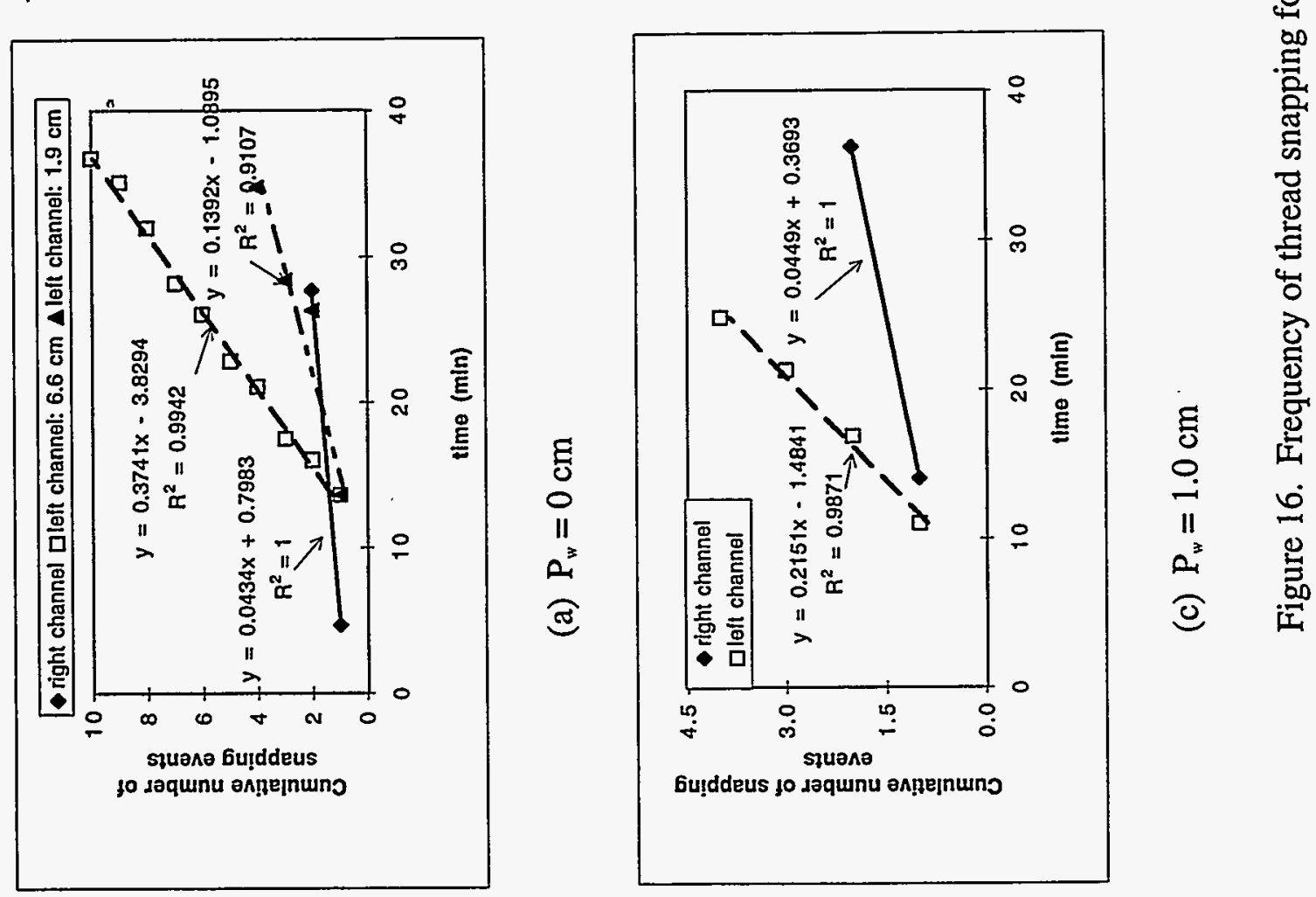


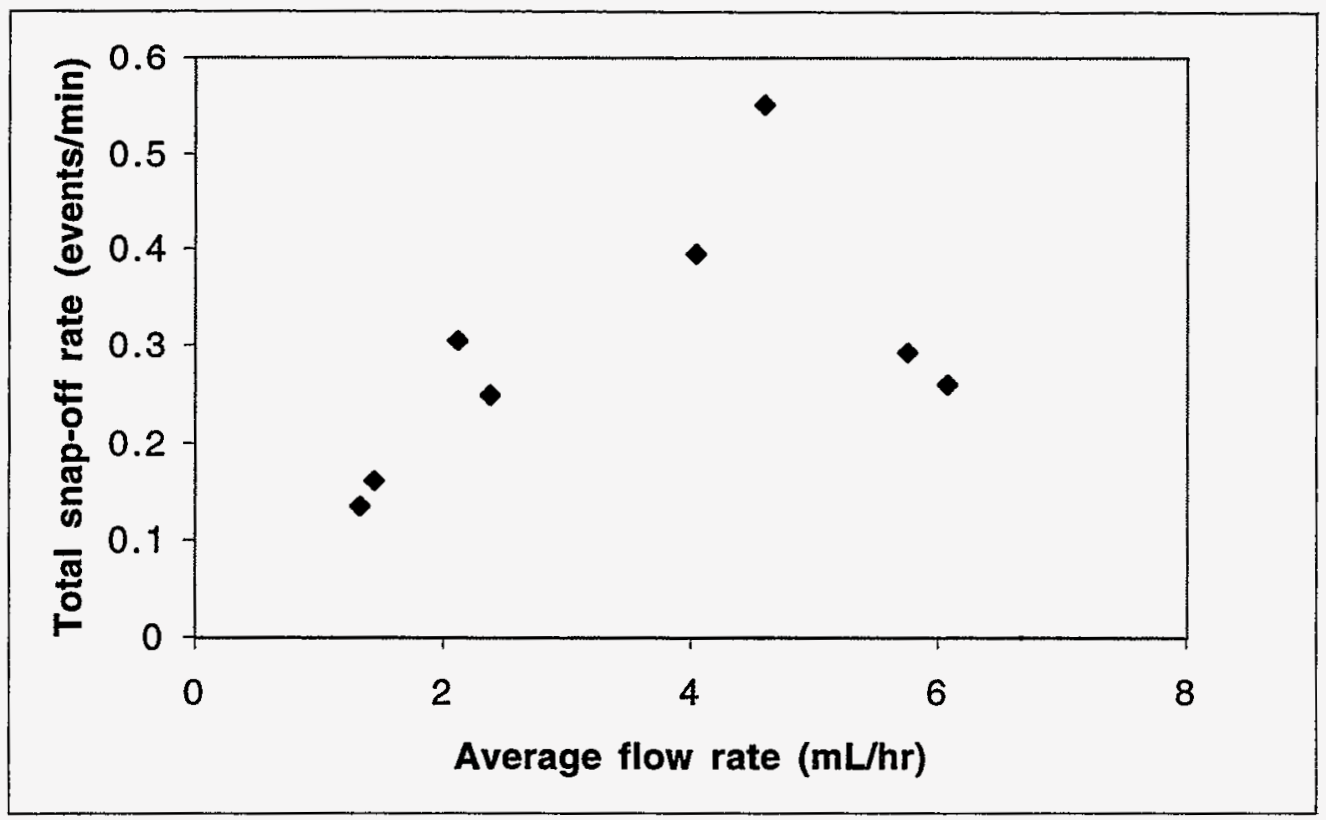

(a) Total snap-off rate

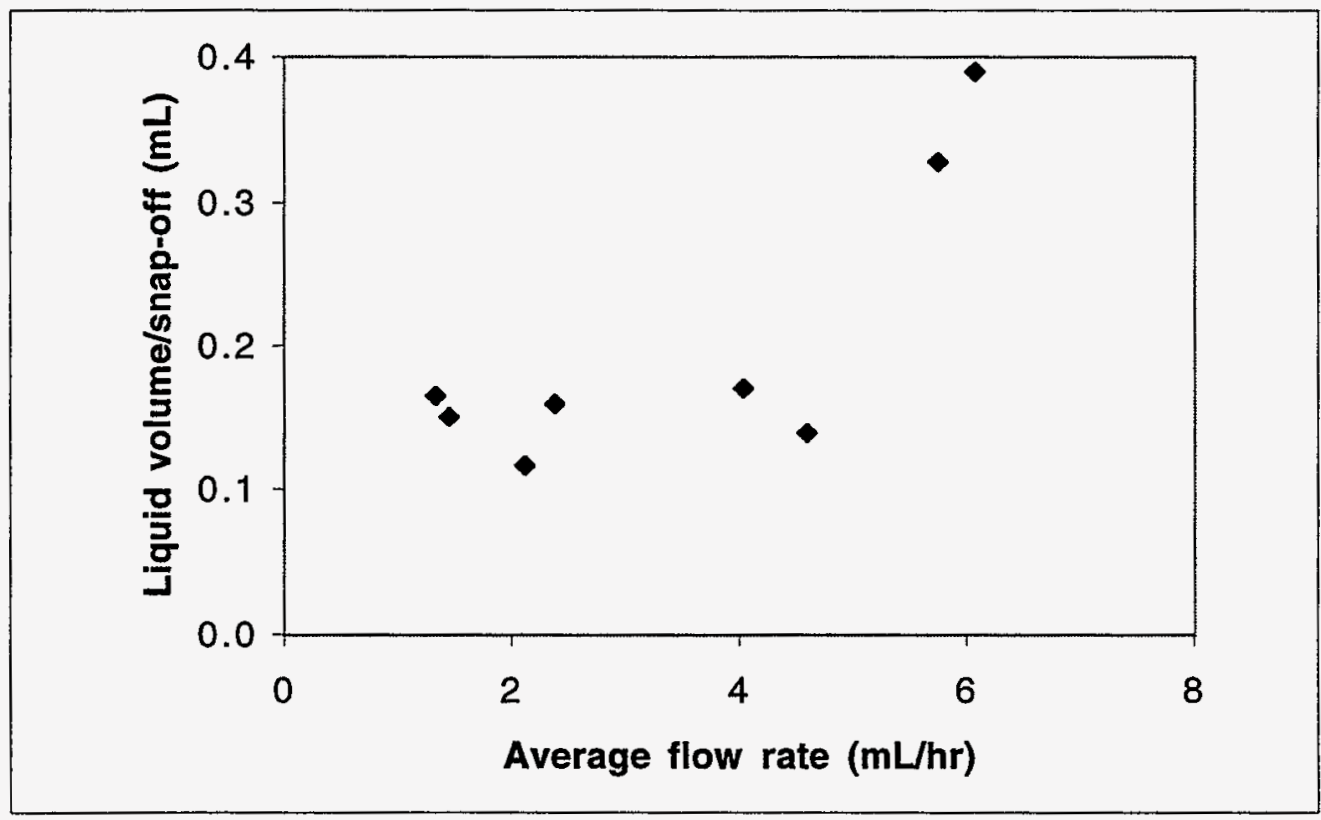

(b) Liquid volume/snap-off

Figure 17. Snap-off rates and liquid volume/snap-off in Series $2 \mathrm{C}$ experiments. 


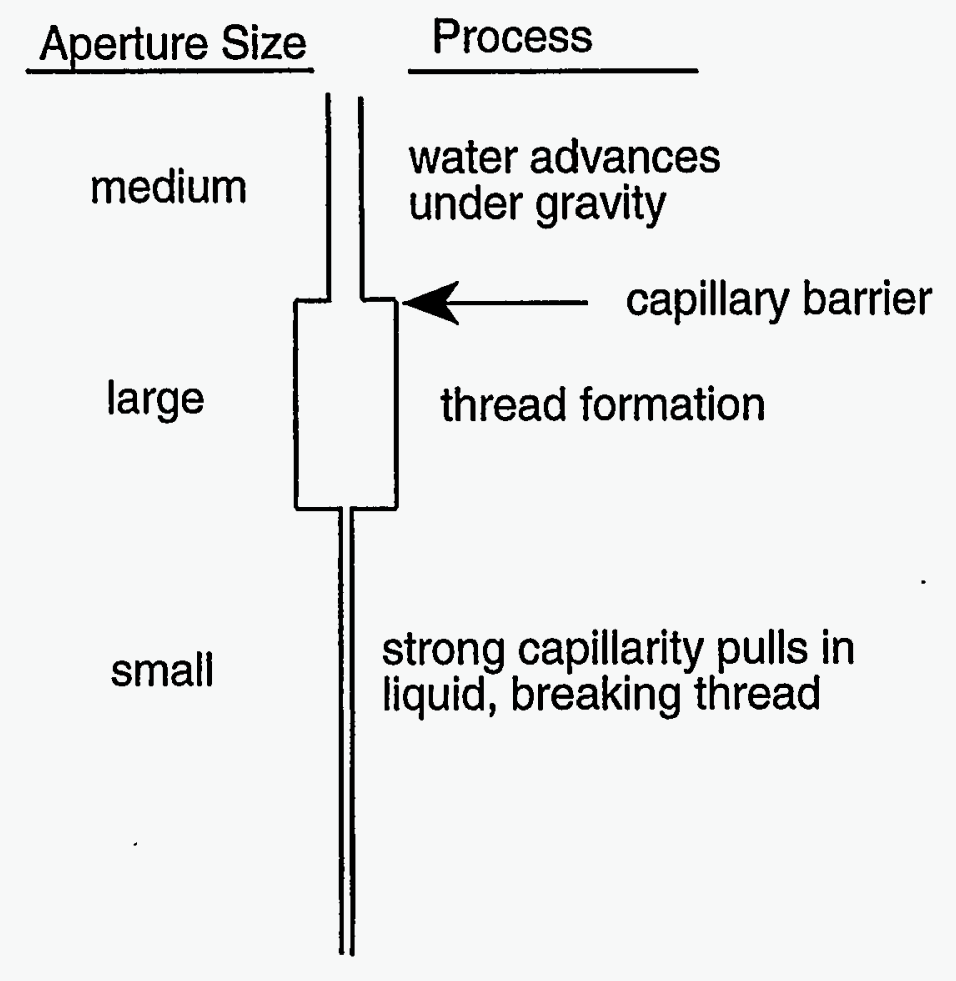

(a) Aperture sequence hypothesized as giving rise to flow intermittency.
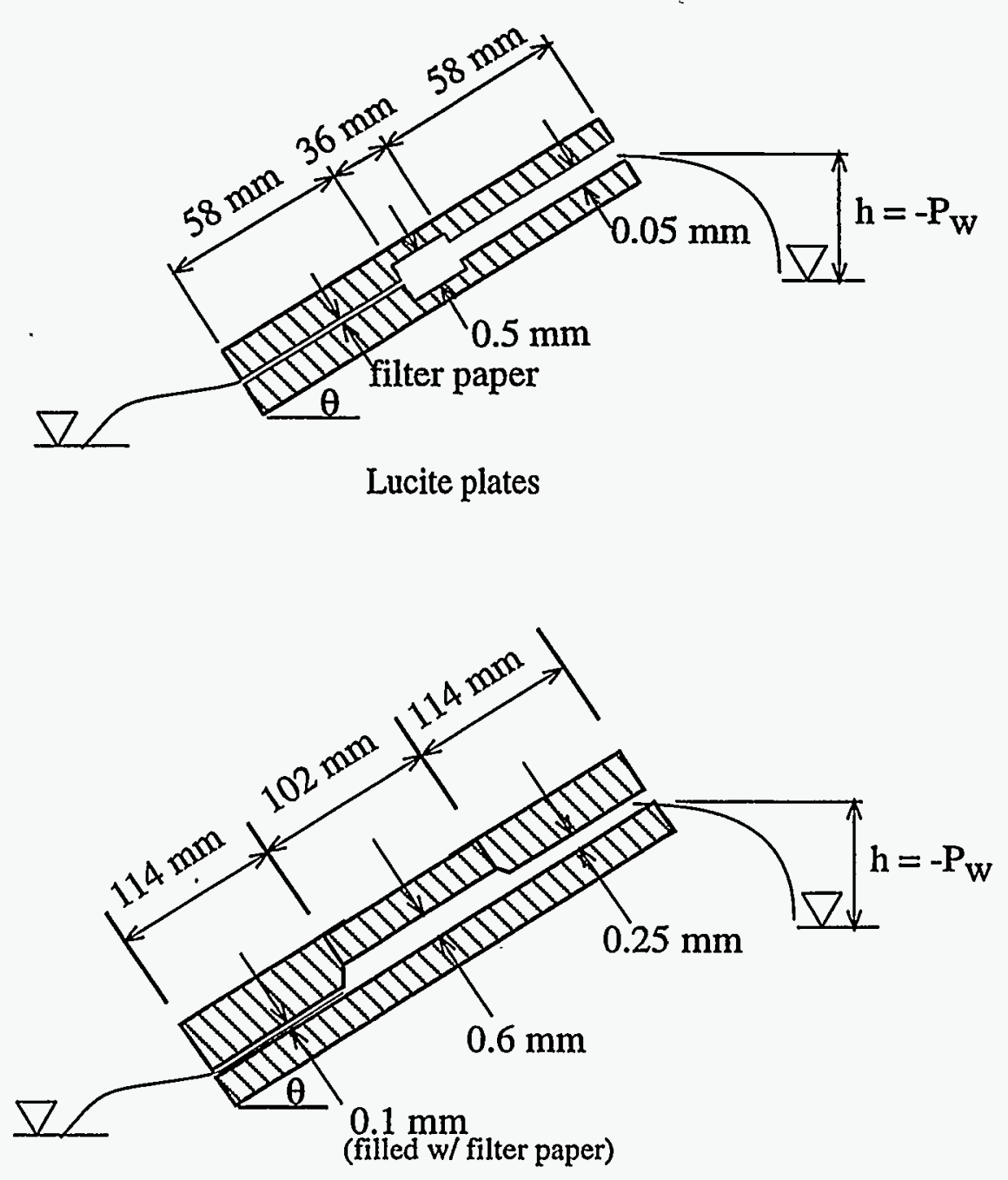

Glass plates

(b) Cross sections of lucite and glass plate cells used in Series 3 experiments

Figure 18. Schematic of parallel plate flow cells 

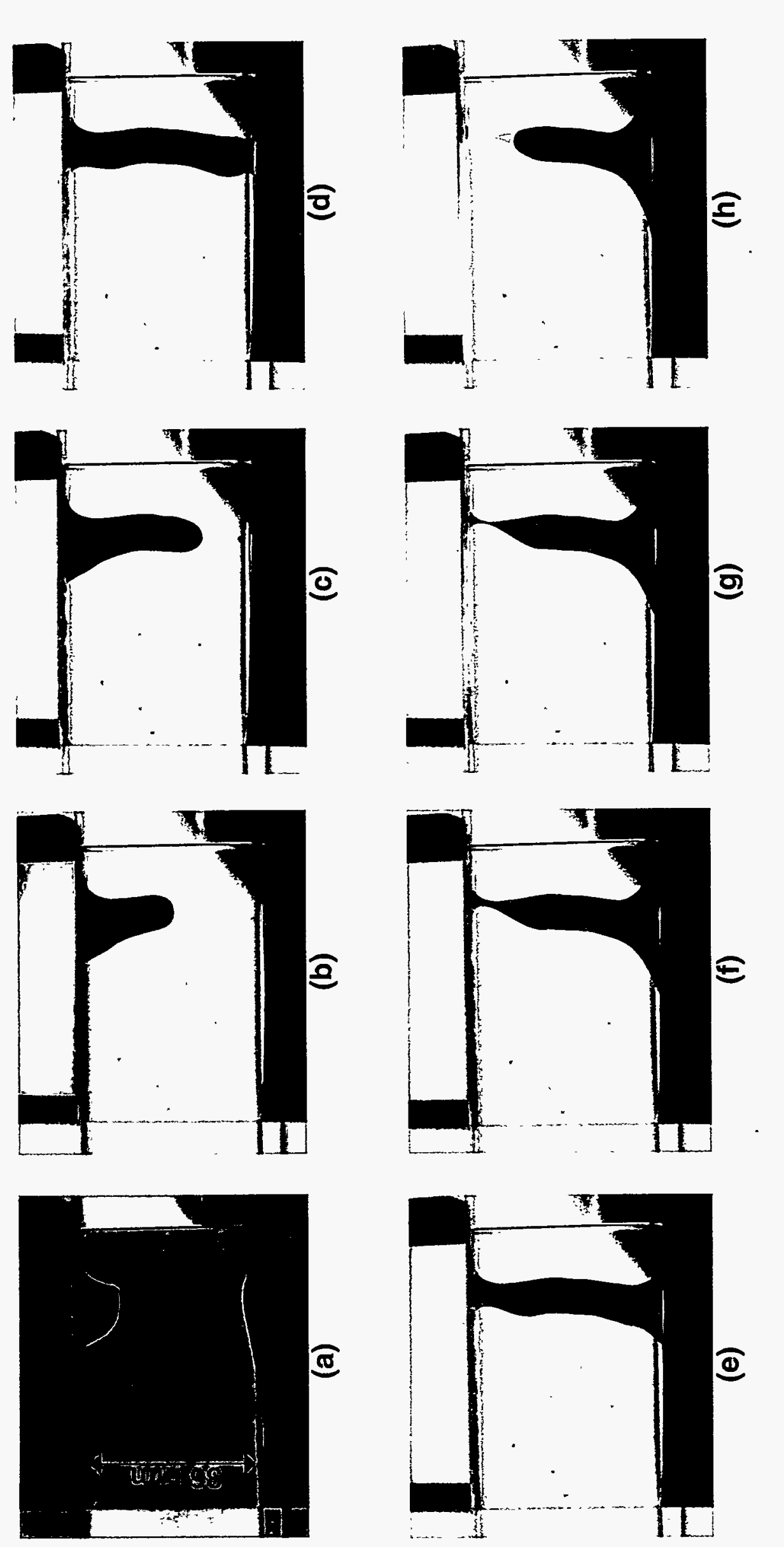

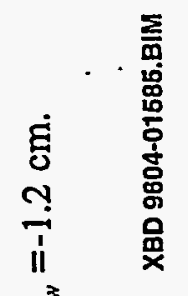

吕

혼

옹

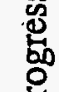

음

छี

궁

売

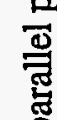

莺

.

$\Theta$

.

善

몽

으묘묘

点

导

至

ญ्.

总

gi

瓷 


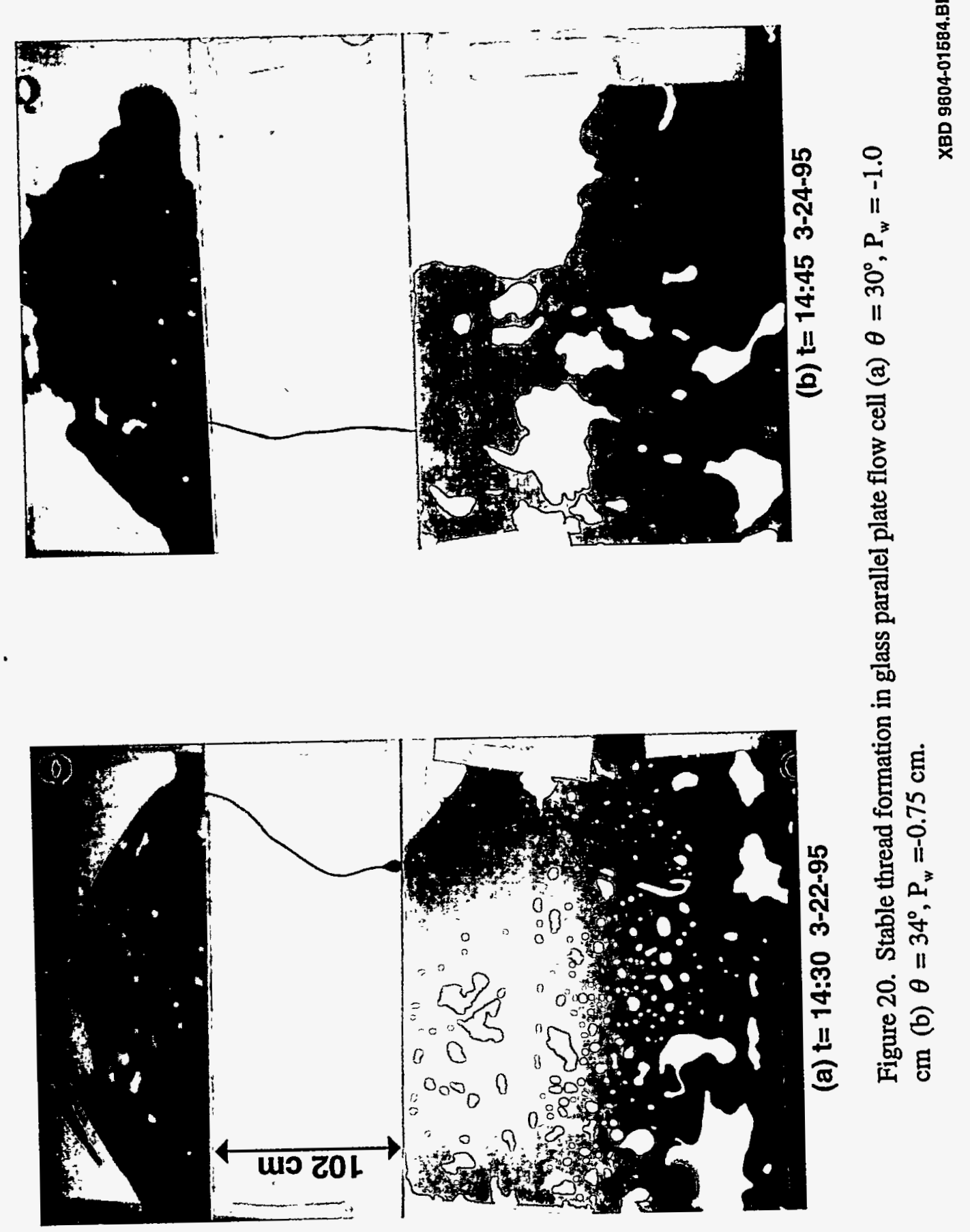




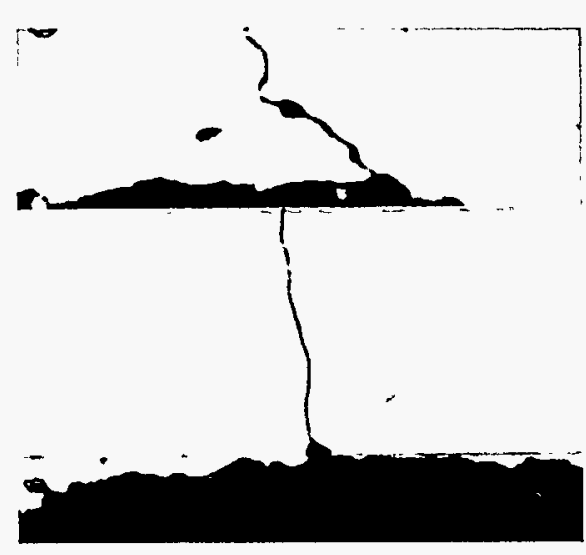

(a) 12:04-2

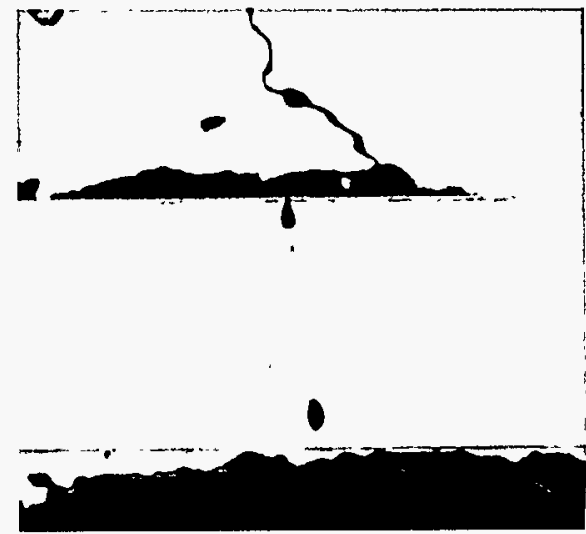

(e) 12:11-1

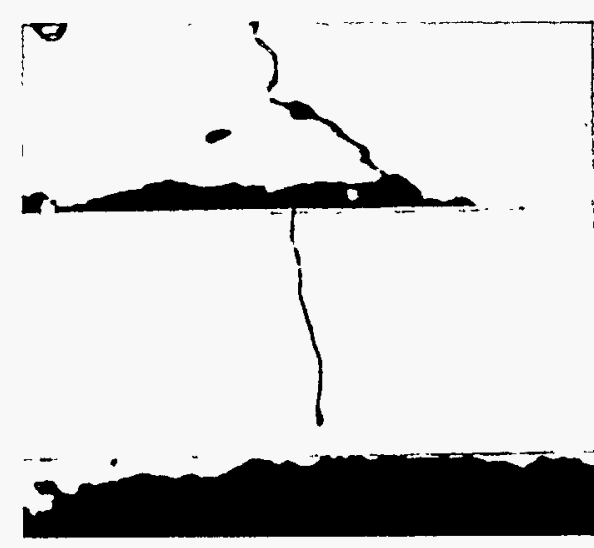

(b) 12:04-3
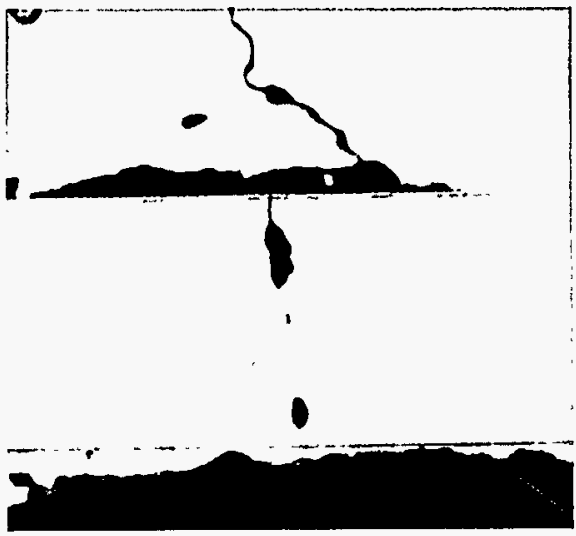

(f) 12:11-2

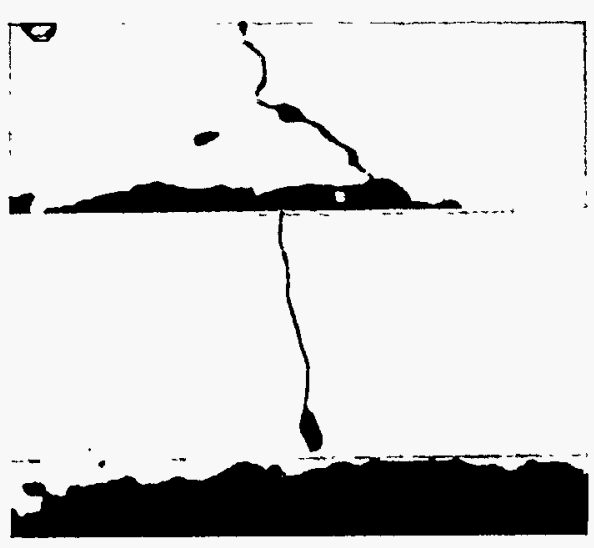

(c) $12: 04-5$

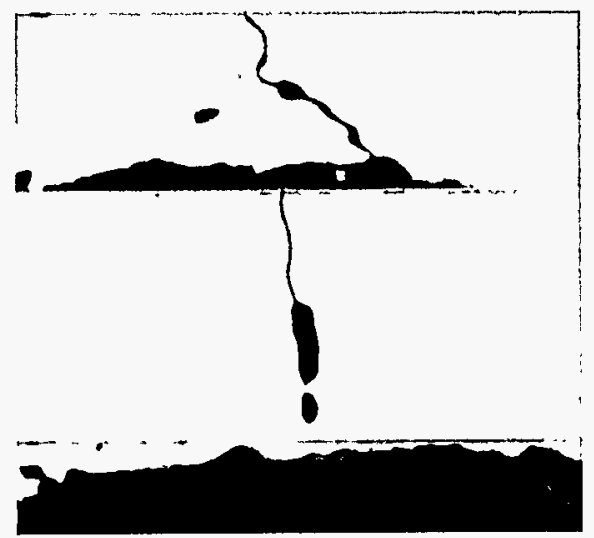

(g) 12:11-3

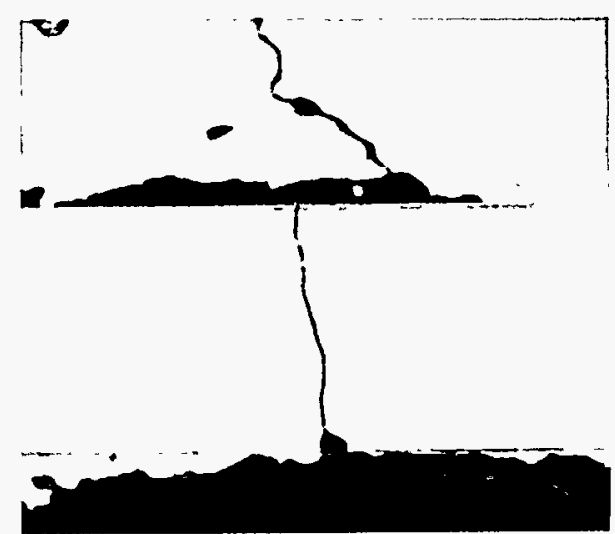

(d) $\quad 12: 04-6$

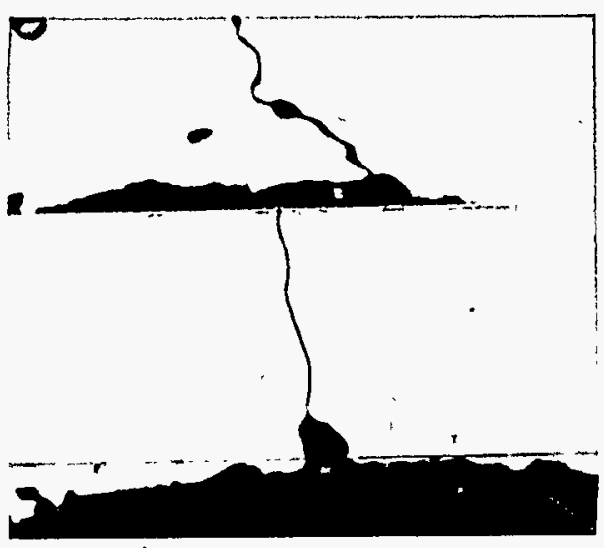

(h) $\quad 12: 11-4$

Figure 21. Sequence of thread formation and snapping in glass parallel plate flow cell, with filter paper in bottom section, $\theta=48^{\circ}, P_{w}=-$ $1.2 \mathrm{~cm}$. (a)-(d) Thread snaps near bottom section. (e)-(h) Thread snaps near top section, leaving residual drop of liquid near bottom section. Frames were photographed within seconds of one another. 


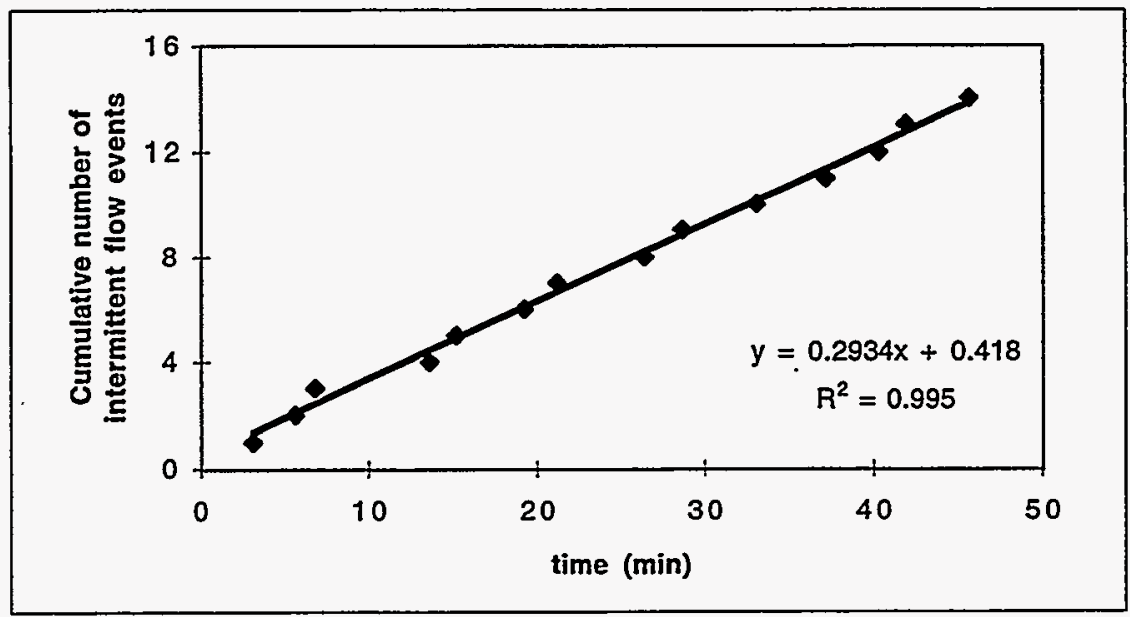

(a) $\theta=74^{\circ}$

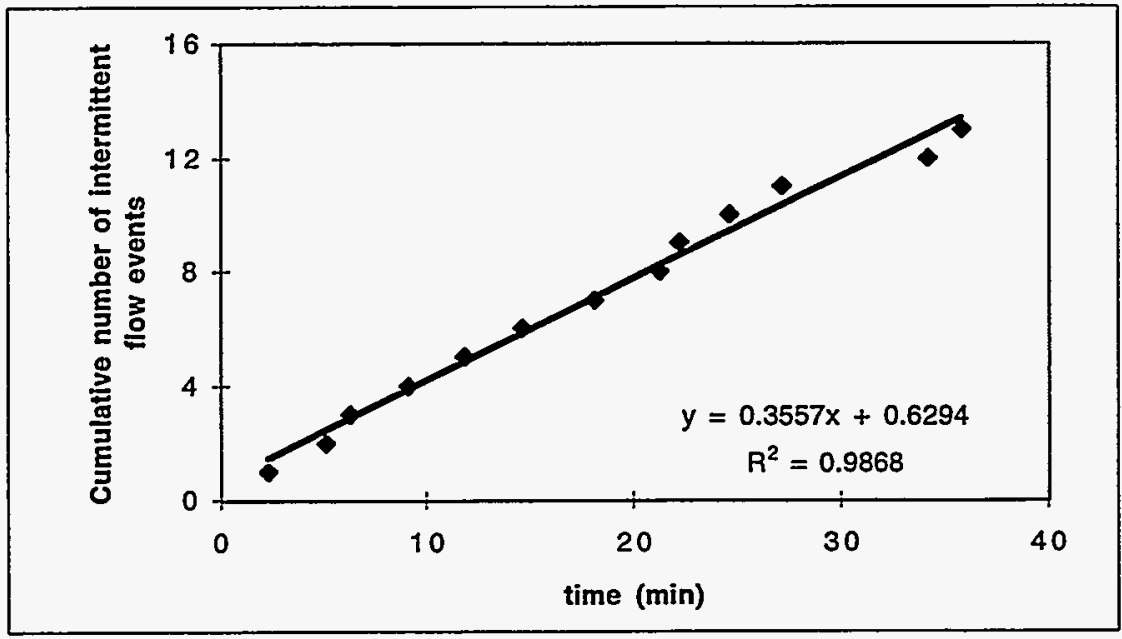

(b) $\theta=70^{\circ}$

Figure 22. Frequency of thread-snapping in series $3 C$ (parallel glass plates), $P_{w}=-1.2 \mathrm{~cm}$ 

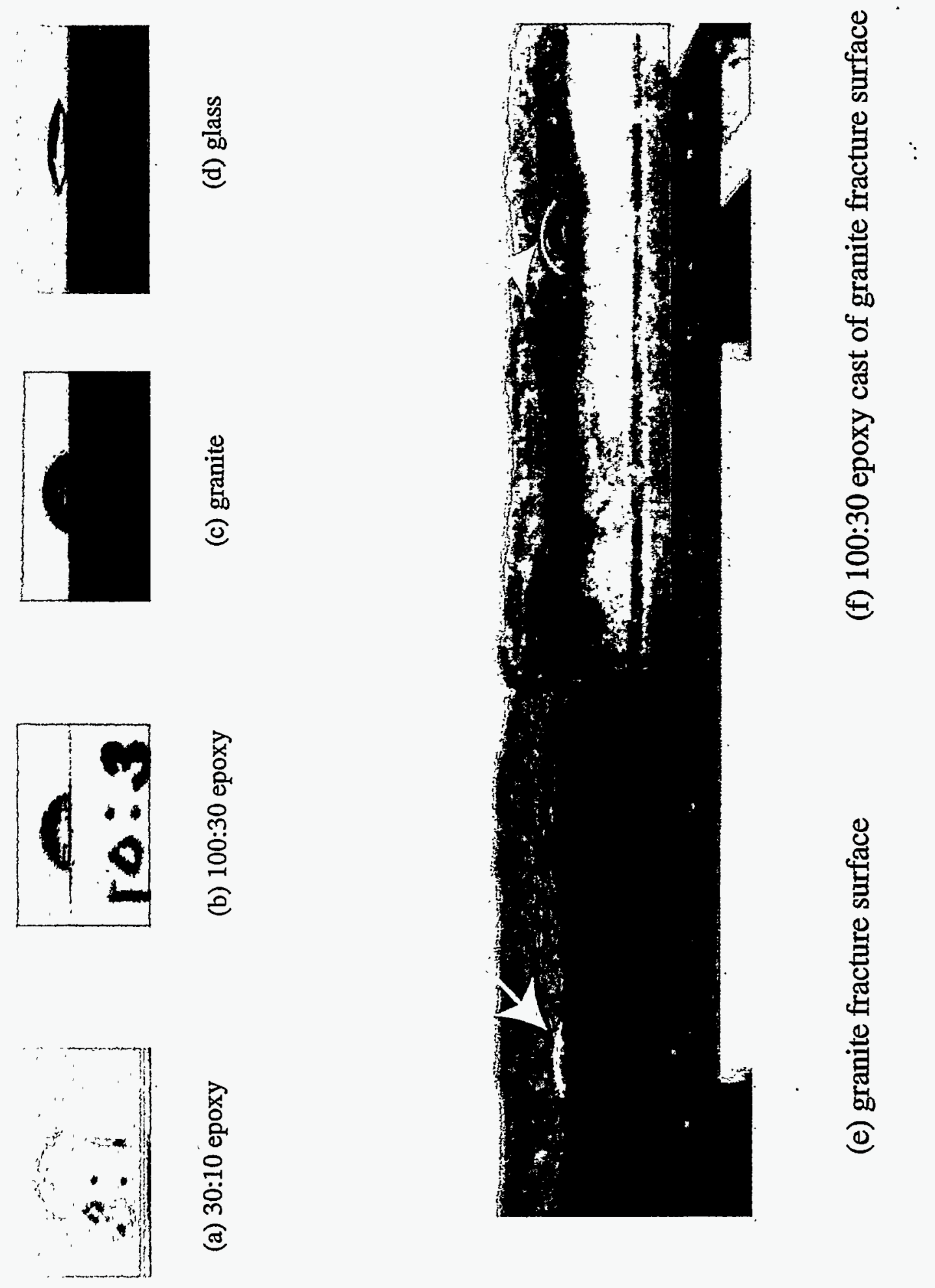

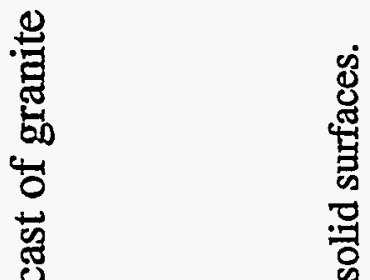

言

용

ळ

$\Theta$

兽害害

岂

晃

(1) 


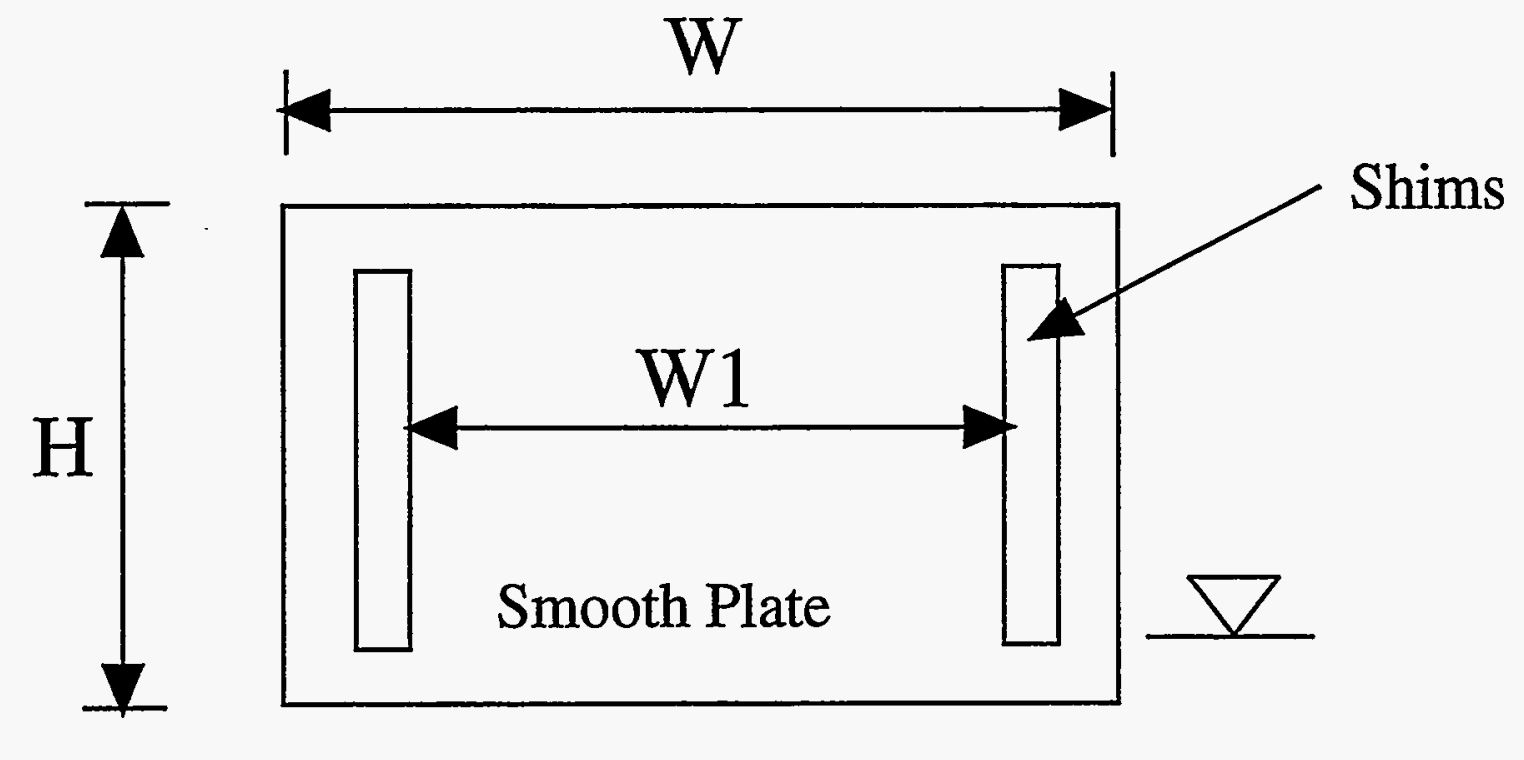

(a) Face view of parallel plates

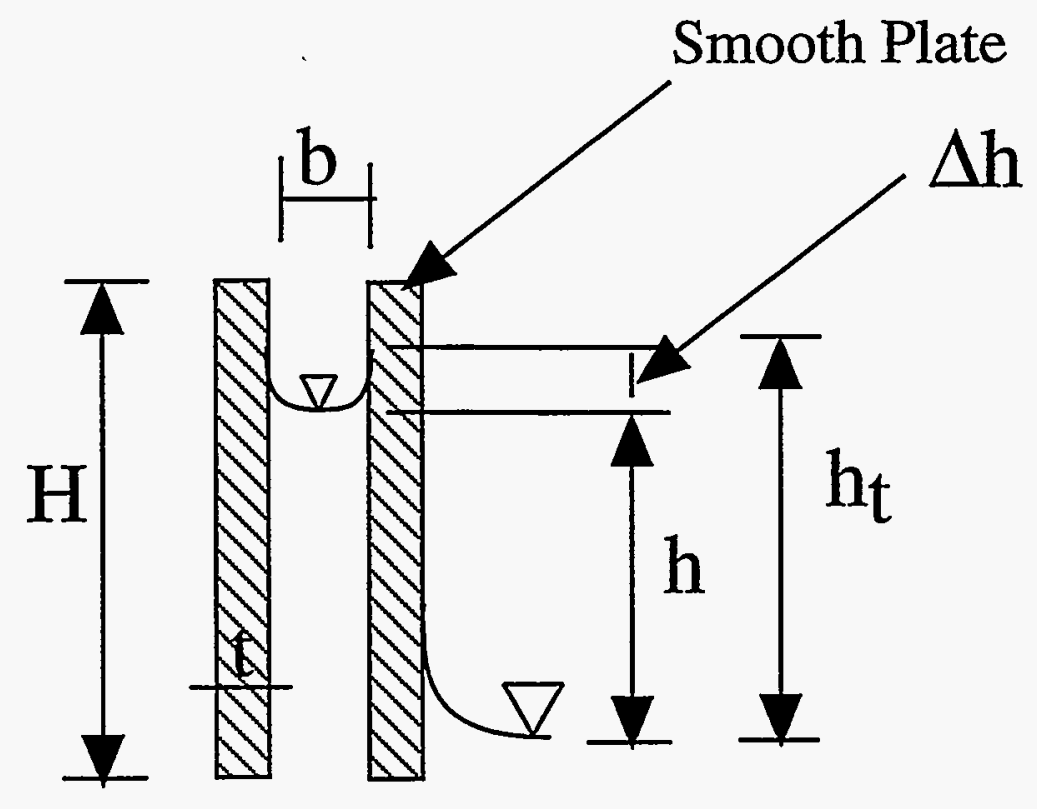

(b) Cross-section of parallel plates

Figure A2. Plate arrangement for Capillary Rise Experiments 


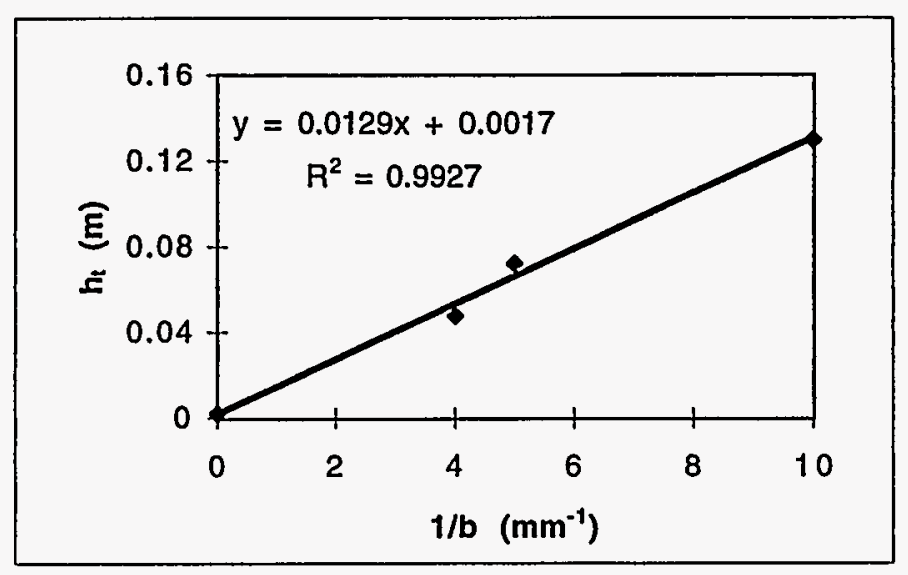

(a) Glass plates

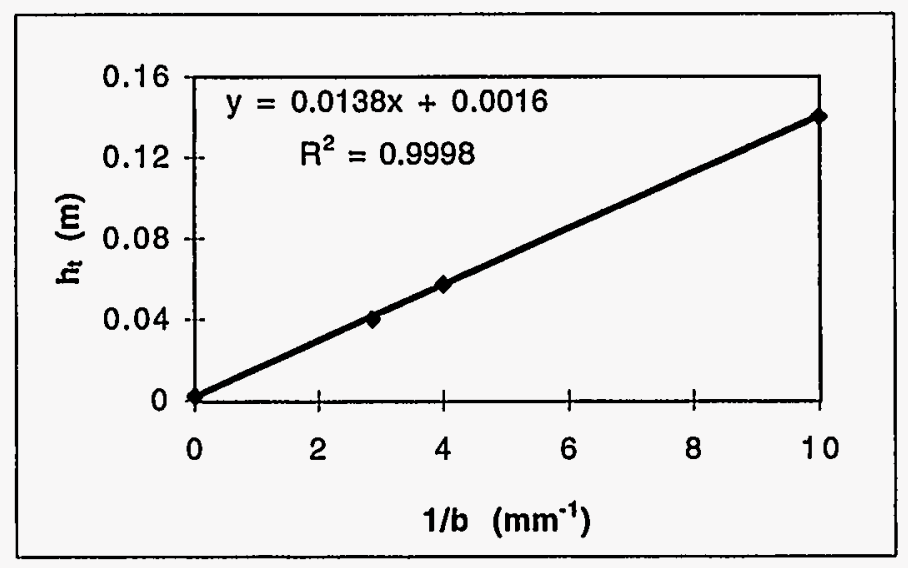

(c) Rigorously cleaned glass plates

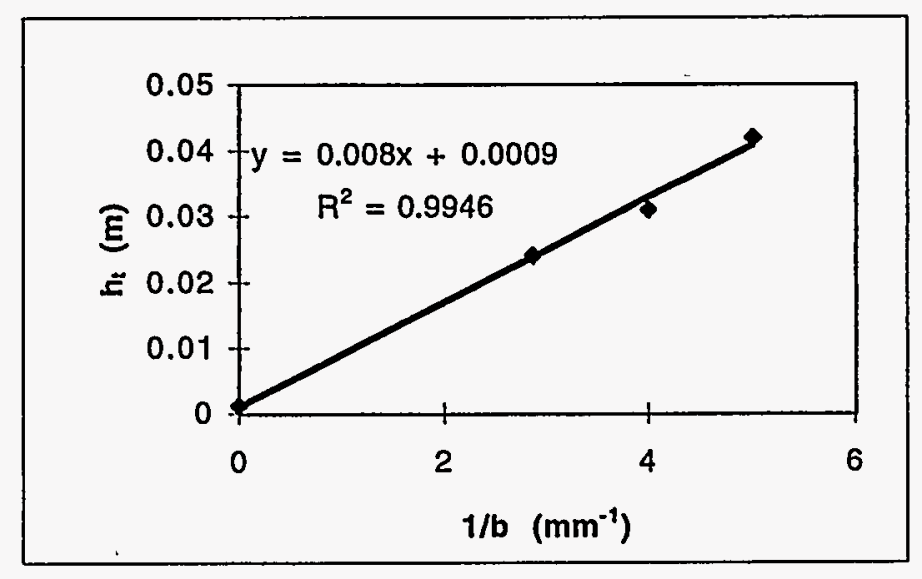

(b) Polished epoxy 30:10, shim spacing $=10 \mathrm{~cm}$

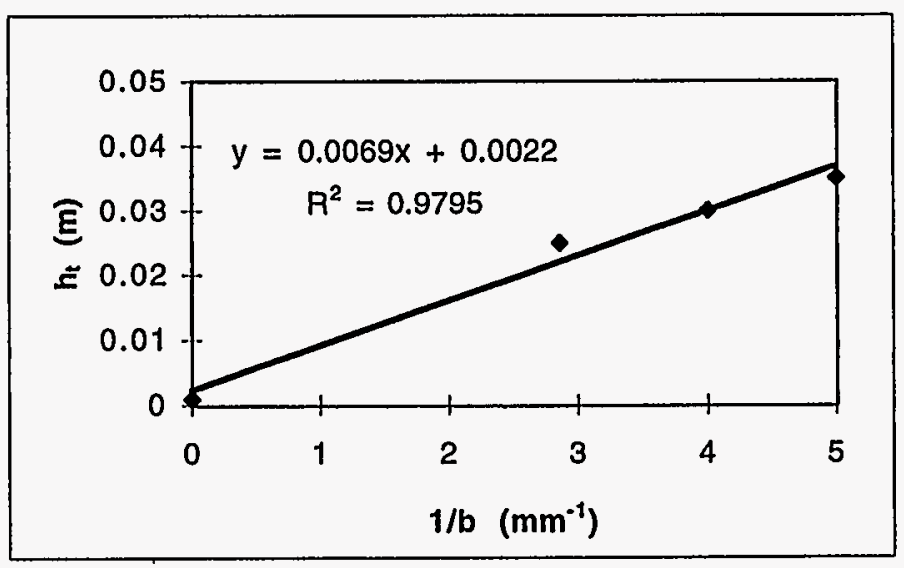

(d) Cast epoxy 100:30, shim spacing $=6 \mathrm{~cm}$

Figure A3. Capillary rise $\left(h_{1}\right)$ as a function of inverse plate separation (1/b) (figures (a)-(d)) 


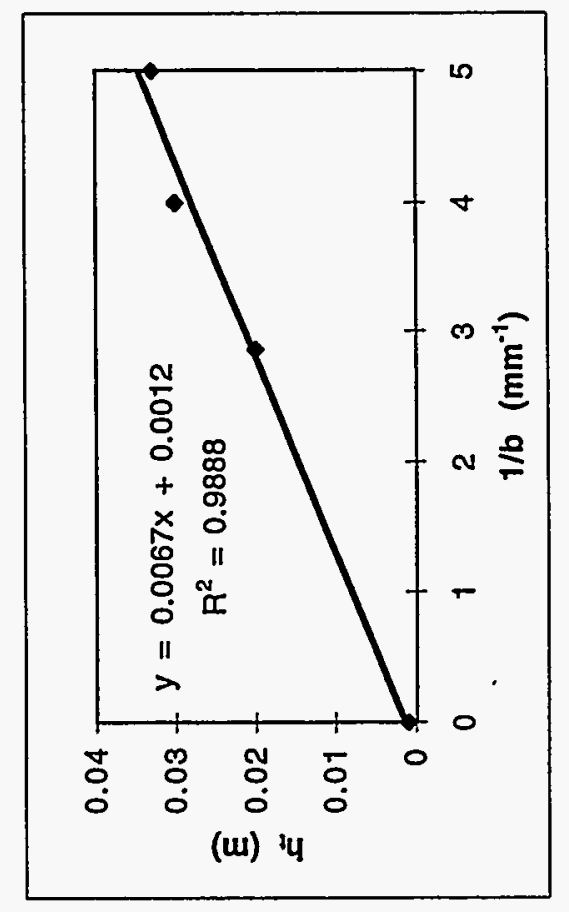

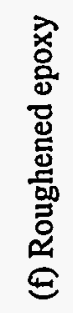
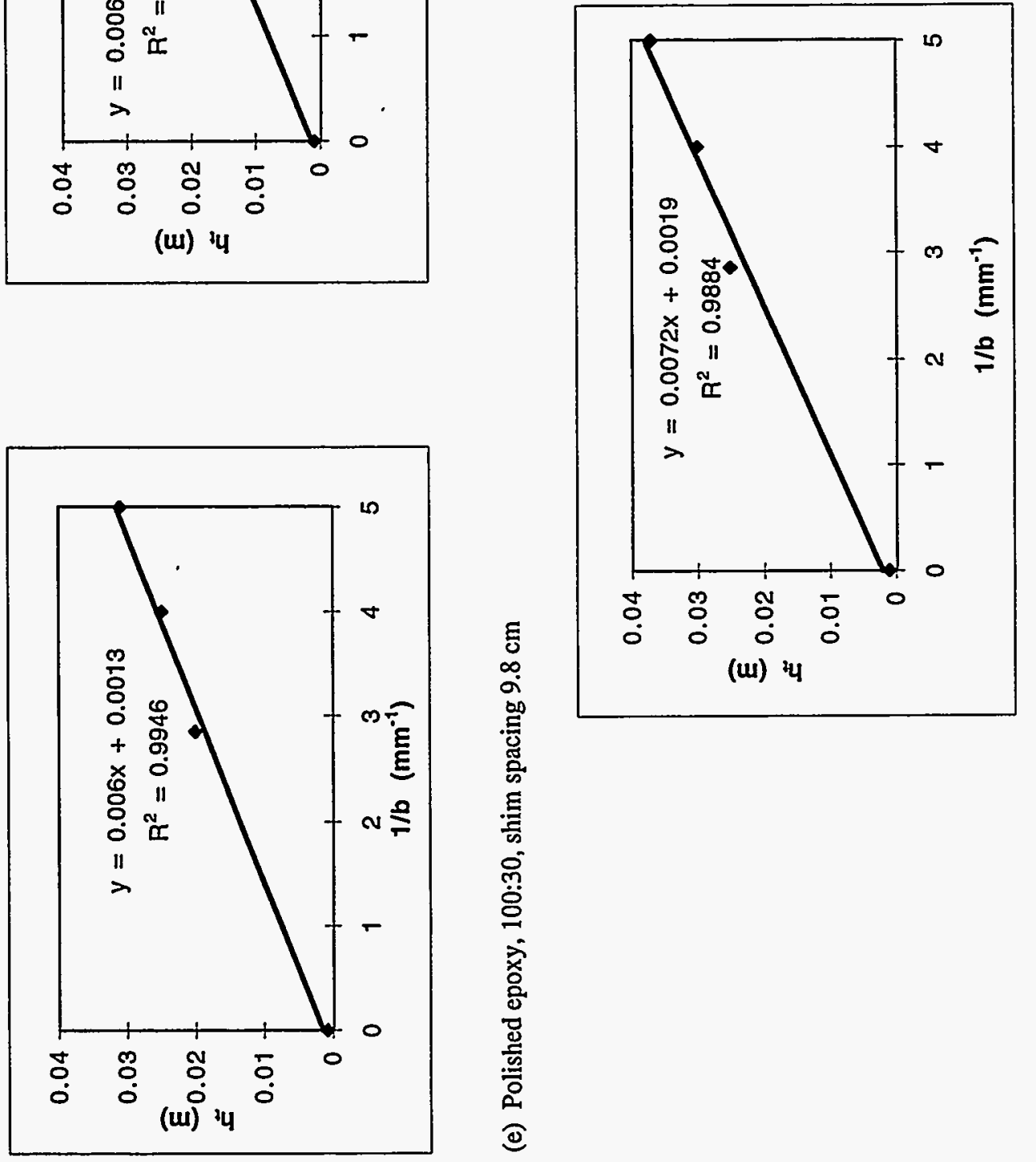

每 

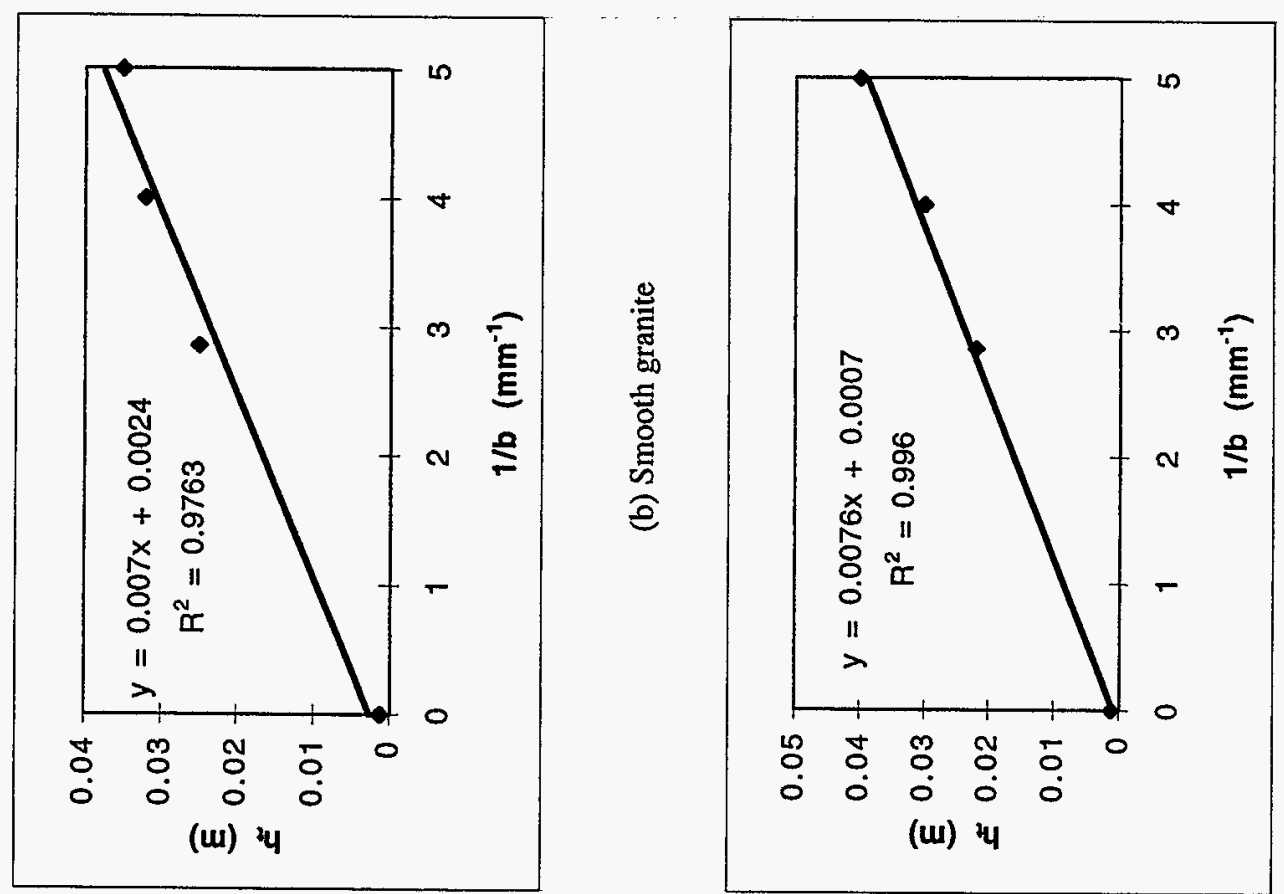

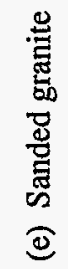

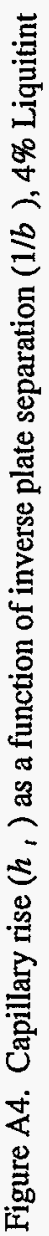
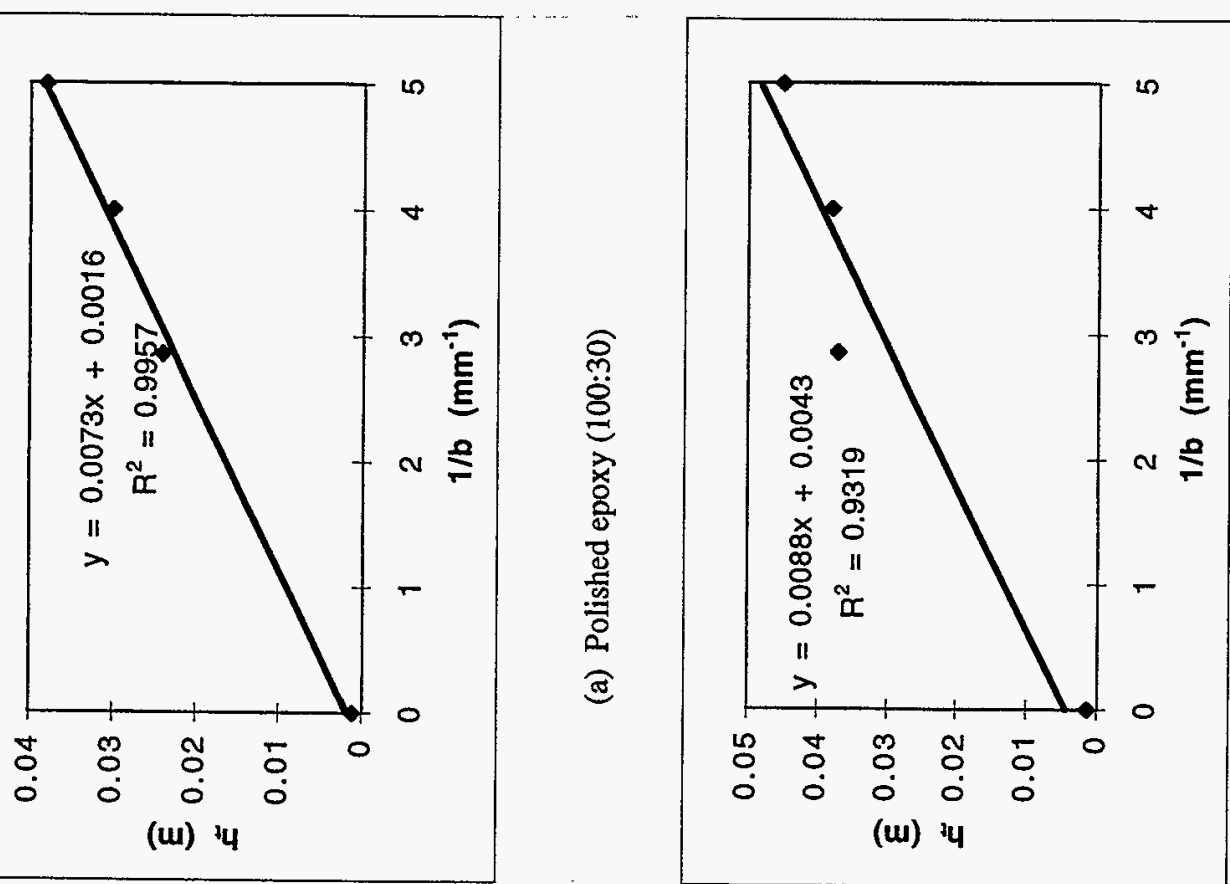

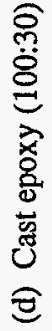

